\title{
FUGITIVE DUST EMISSIONS FROM OFF-ROAD VEHICLE MANEUVERS ON MILITARY TRAINING LANDS
}

by

JEREMY C. MEEKS

B.S., Kansas State University, 2011

\begin{abstract}
A THESIS
submitted in partial fulfillment of the requirements for the degree
\end{abstract}

\section{MASTER OF SCIENCE}

Department of Biological and Agricultural Engineering

College of Engineering

\section{KANSAS STATE UNIVERSITY \\ Manhattan, Kansas}

2013

Approved by:

Major Professor

Dr. Ronaldo G. Maghirang 


\section{Copyright}

JEREMY C. MEEKS

2013 


\begin{abstract}
Military installations in the United States may be large sources of fugitive dust emissions. Off-road vehicle training can contribute to air quality degradation resulting from increased wind erosion events as a result of soil disruption; however, limited information exists regarding the impacts of off-road vehicle maneuvering. This study was conducted to determine the effects of soil texture and intensity of training with off-road vehicles on fugitive dust emission potential due to wind erosion at military training installations.

Multi-pass trafficking experiments, involving wheeled and tracked military vehicles (i.e., M1A1 Abrams tank, M925A1 water tanker and various HMMWV models), were conducted at three military training facilities with different climate and soil texture (i.e., Fort Riley, KS; Fort Benning, GA; and Yakima Training Center, WA). Dust emissions were measured on site using a Portable In-Situ Wind Erosion Laboratory (PI-SWERL) coupled with a DustTrak ${ }^{\mathrm{TM}}$ dust monitor. In addition, a top layer of soil was collected in trays and tested in a laboratory wind tunnel for dust emission potential. In wind tunnel testing, the amount of emitted dust was measured using glass-fiber filters through high-volume samplers. Also, the particle size distribution and concentration of the emitted dust were measured using a GRIMM aerosol spectrometer.

Comparison of the PI-SWERL (with DustTrak ${ }^{\mathrm{TM}}$ dust monitor) and wind tunnel test (with GRIMM aerosol spectrometer) results showed significant difference and little correlation. Also, comparison of the filter and GRIMM aerosol spectrometer data showed significant difference but high correlation. The dust emission potential (as measured with the GRIMM spectrometer) was significantly influenced by soil texture, vehicle type and number of passes. For the light-wheeled vehicle, total dust emissions increased from $66 \mathrm{mg} \mathrm{m}^{-2}$ for undisturbed soil to $304 \mathrm{mg} \mathrm{m}^{-2}$ (357\%) and $643 \mathrm{mg} \mathrm{m}^{-2}$ (868\%) for 10 and 50 passes, respectively. For the tracked vehicle, an average increase in total dust emission of $569 \%$ was observed between undisturbed conditions and 1 pass, with no significant increase in emissions potential beyond 1 pass. For the heavy-wheeled vehicle, emissions increased from $75 \mathrm{mg} \mathrm{m}^{-2}$ for undisturbed soil to $1,652 \mathrm{mg} \mathrm{m}^{-2}$ $(1,369 \%)$ and 4,023 $\mathrm{mg} \mathrm{m}^{-2}(5,276 \%)$ for 10 and 20 passes, respectively. Soil texture also played an important role in dust emission potential. For all treatment effects, there was a 1,369\% difference in emissions between silty clay loam soil and loamy sand soil.
\end{abstract}




\section{Table of Contents}

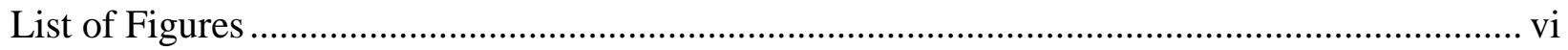

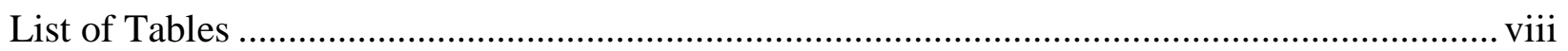

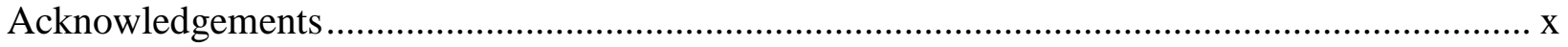

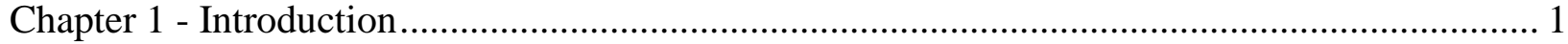

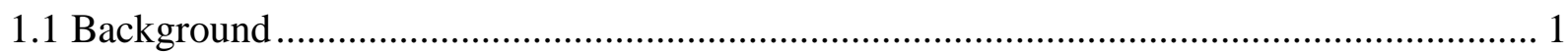

1.1.1 Off-Road Military Training ….................................................................... 1

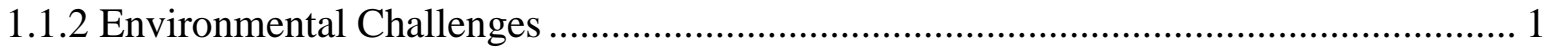

1.1.3 Emission Susceptibility of Soils ................................................................. 3

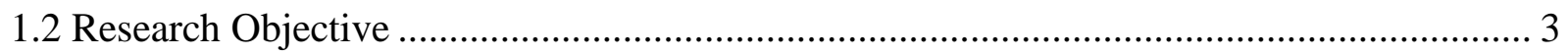

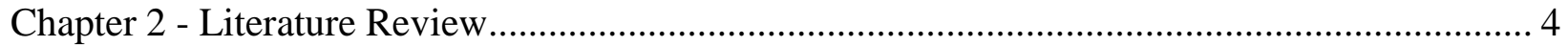

2.1 Particulate Emissions from Military Installations ..................................................... 4

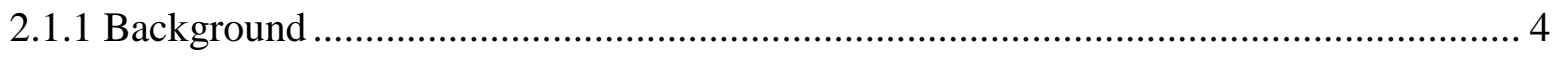

2.1.2 Air Quality Regulations Affecting DoD Installations.......................................... 5

2.2 Health Effects of Particulate Matter ................................................................................ 7

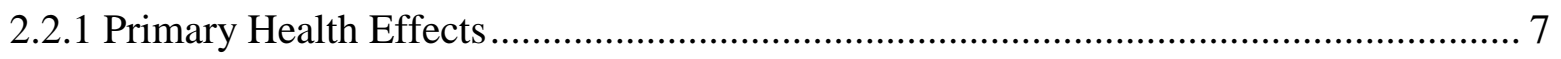

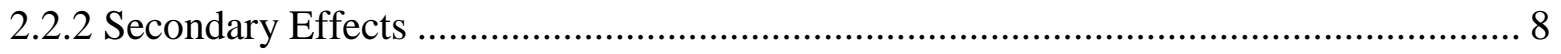

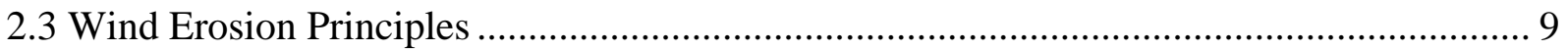

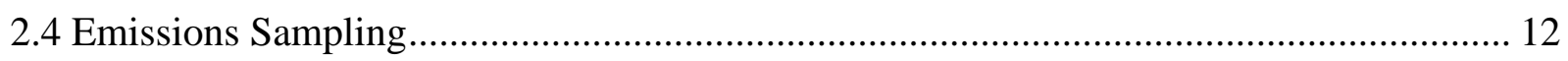

2.4.1 Portable In-Situ Wind Erosion Laboratory (PI-SWERL) ..................................... 12

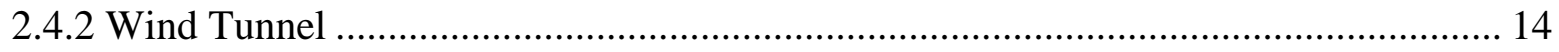

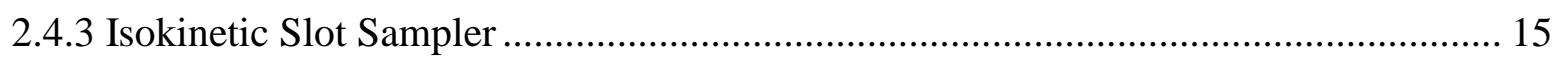

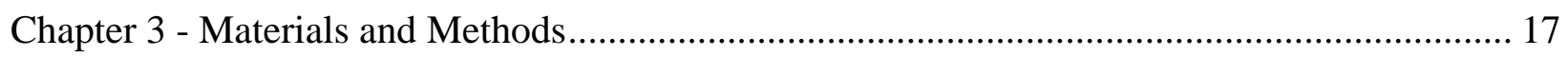

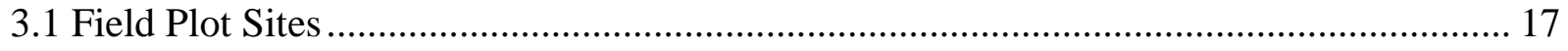

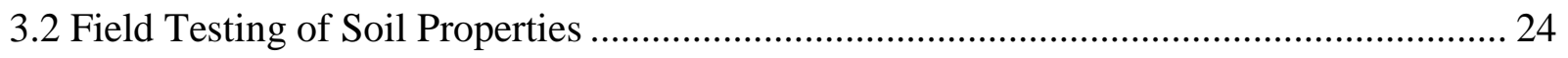

3.2.1 PI-SWERL Field Sampling ........................................................................... 25

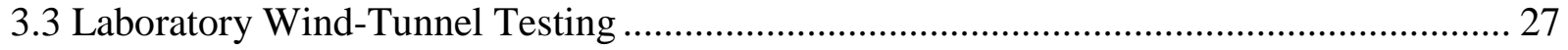

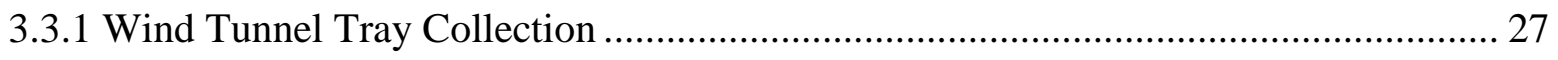

3.3.2 Wind Tunnel Testing Instrumentation ......................................................... 28

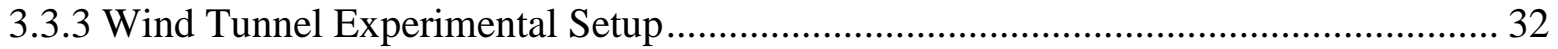


3.3.3.1 Wind Tunnel Tray Preparation ....................................................................... 36

3.3.3.2 Wind Tunnel Tray Testing Procedure................................................................. 37

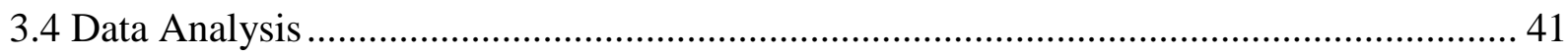

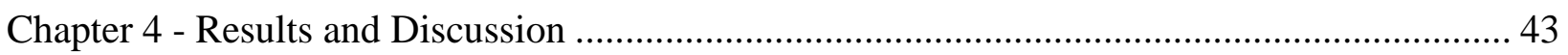

4.1 Comparison of Measurement Techniques ....................................................................... 43

4.1.1 Comparison of PI-SWERL and Wind Tunnel (GRIMM Spectrometer) Tests ............ 43

4.1.2 Comparison of Wind Tunnel Emissions Measurements ................................................ 49

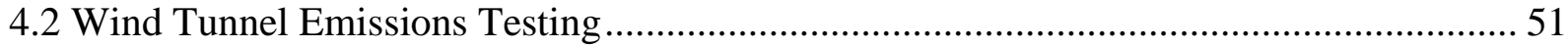

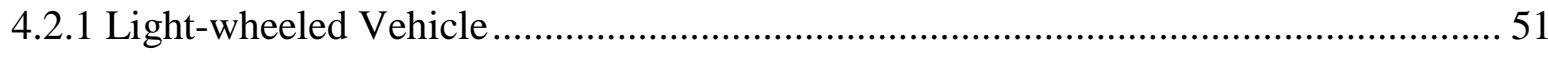

4.2.2 Tracked Vehicle ………………………………................................................... 57

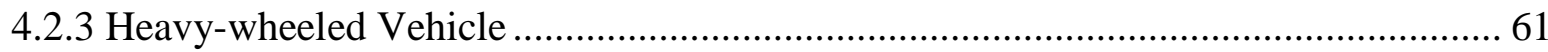

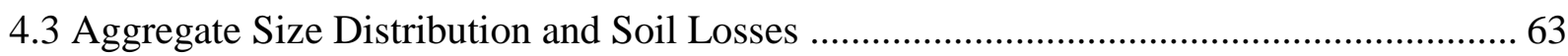

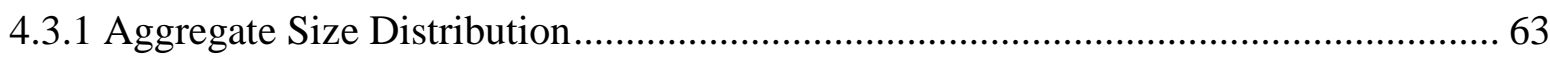

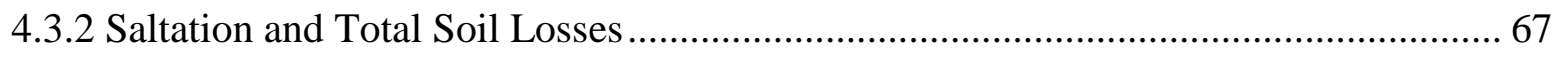

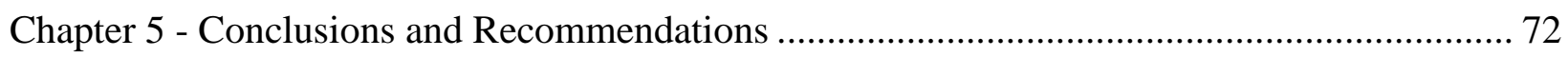

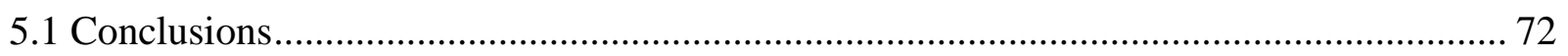

5.2 Recommendations for Future Research ...................................................................... 73

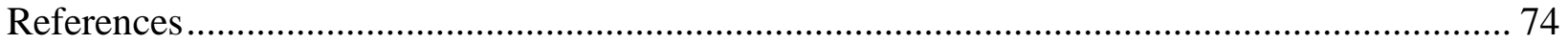




\section{List of Figures}

Figure 2.1 Direct emissions from military vehicle training ............................................... 5

Figure 2.2 Size components of wind erosion (Presley and Tatarko, 2009)............................. 10

Figure 2.3 Illustration of vegetative barrier (Presley and Tatarko, 2009). ............................... 12

Figure 2.4 Portable In-Situ Wind Erosion Laboratory (PI-SWERL). .................................... 13

Figure 2.5 Example of test data from PI-SWERL......................................................... 14

Figure 3.1 Fort Riley, KS sampling location (Google Earth)................................................ 19

Figure 3.2 Fort Benning, GA sampling location (Google Earth). ........................................... 20

Figure 3.3 Yakima Training Center sampling location (Google Earth). ................................. 21

Figure 3.4 Layout of Fort Riley figure-8 plots. ................................................................ 23

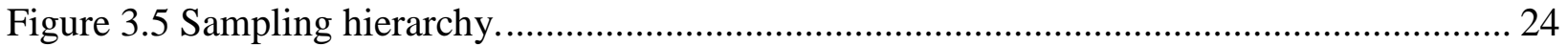

Figure 3.6 Sample figure-8 plot showing sample locations................................................. 25

Figure 3.7 Portable In-Situ Wind Erosion Laboratory (PI-SWERL). .................................... 26

Figure 3.8 DustTrak ${ }^{\mathrm{TM}}$ II 8531 portable aerosol photometer (DustTrak ${ }^{\mathrm{TM}}$ monitor)................. 26

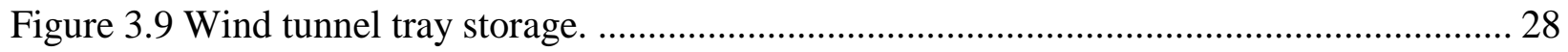

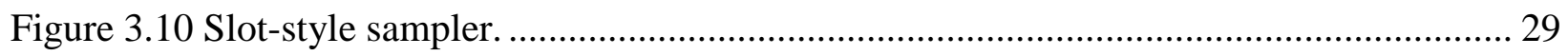

Figure 3.11 GRIMM model 1.108 aerosol spectrometer (GRIMM spectrometer).................... 29

Figure 3.12 Vaisala HMP 110 temperature and humidity sensor........................................... 30

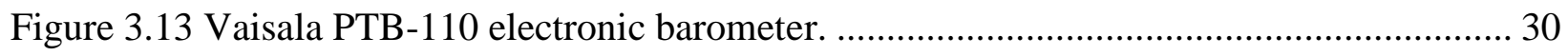

Figure 3.14 Setra model 264 differential pressure transducer. ............................................ 31

Figure 3.15 Schematic of the wind tunnel showing upstream flow conditioning elements. ........ 32

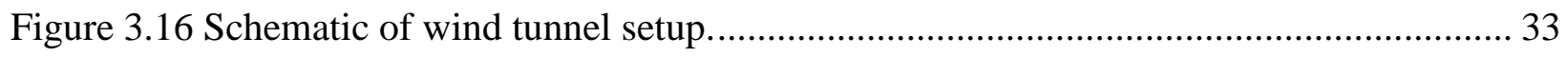

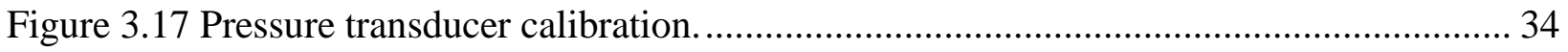

Figure 3.18 Fort Riley tray sample after filling procedure .............................................. 37

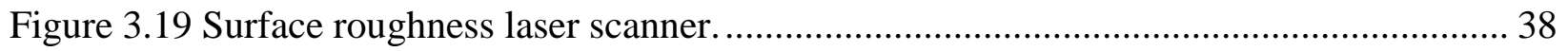

Figure 3.20 Sampling train configuration for wind tunnel testing......................................... 39

Figure 3.21 Subsample expansion outside (a) and inside (b) views. .................................... 41

Figure 4.1 Comparison of sample dataset from (a) PI-SWERL and (b) wind tunnel (GRIMM

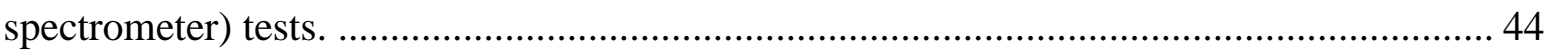


Figure 4.2 Correlation of wind tunnel (with GRIMM spectrometer) and PI-SWERL (with DustTrak $^{\mathrm{TM}}$ monitor) tests - all sites. The solid line represents the least-squares regression line, while dashed line represents 1:1 correspondence.

Figure 4.3 Correlation of wind tunnel (with GRIMM spectrometer) and PI-SWERL (with

DustTrak $^{\mathrm{TM}}$ monitor) tests - Fort Riley. The solid line represents the least-squares regression line, while dashed line represents 1:1 correspondence.

Figure 4.4 Correlation of wind tunnel (with GRIMM spectrometer) and PI-SWERL (with

DustTrak $^{\mathrm{TM}}$ monitor) tests - Fort Benning. The solid line represents the least-squares regression line, while dashed line represents 1:1 correspondence. 48

Figure 4.5 Sample PI-SWERL dataset - Fort Benning 48

Figure 4.6 Correlation of wind tunnel measurements - all sites. The solid line represents the least-squares regression line, while dashed line represents 1:1 correspondence.

Figure 4.7 Correlation of wind tunnel measurements - Fort Riley. The solid line represents the least-squares regression line, while dashed line represents 1:1 correspondence. 50

Figure 4.8 Correlation of wind tunnel measurements - Yakima Training Center. The solid line represents the least-squares regression line, while dashed line represents 1:1 correspondence. 51

Figure 4.9 Soil-pass interaction plot for total dust emissions from wind tunnel tests (GRIMM spectrometer) - light-wheeled vehicle.

Figure 4.10 Emissions of dust $<10 \mu \mathrm{m}$ from wind tunnel tests (GRIMM spectrometer) - lightwheeled vehicle. Error bars represent $95 \%$ confidence limits. 56

Figure 4.11 Emissions of dust $<2.5 \mu \mathrm{m}$ from wind tunnel tests (GRIMM spectrometer) - lightwheeled vehicle. Error bars represent $95 \%$ confidence limits.

Figure 4.12 Soil-pass interaction plot of dust $<2.5 \mu \mathrm{m}$ from wind tunnel tests (GRIMM spectrometer) - tracked vehicle.

Figure 4.13 Emissions of dust $<2.5 \mu \mathrm{m}$ from wind tunnel tests (GRIMM spectrometer) - tracked vehicle. Error bars represent $95 \%$ confidence limits. 60

Figure 4.14 Total dust emissions by pass from wind tunnel tests (GRIMM spectrometer) heavy-wheeled vehicle 62

Figure 4.15 Saltation loss by soil type for light-wheeled vehicle. 70 


\section{List of Tables}

Table 2.1 National ambient air quality standards (EPA, 2011) .......................................... 6

Table 3.1 Approximate coordinates and elevations of sampling sites.................................... 17

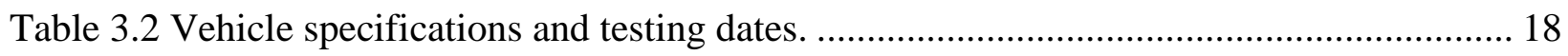

Table 3.3 Initial temporal soil properties for experiment locations....................................... 22

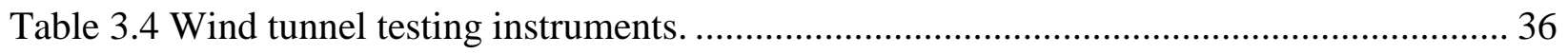

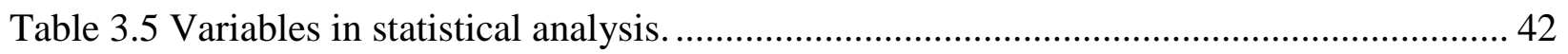

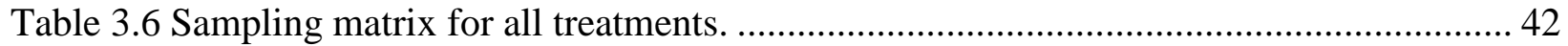

Table 4.1 Light-wheeled vehicle sampling matrix ........................................................ 51

Table 4.2 Type III tests of fixed effects - light-wheeled vehicle. ....................................... 52

Table 4.3 Pairwise comparisons of total dust emissions from wind tunnel tests (GRIMM

spectrometer) - light-wheeled vehicle. ............................................................ 53

Table 4.4 Least squares means of dust emissions from wind tunnel tests (GRIMM spectrometer)

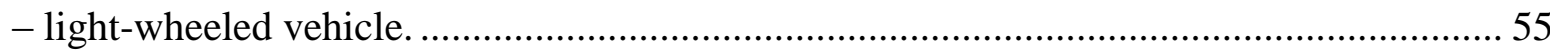

Table 4.5 Tracked vehicle sampling matrix...................................................................... 57

Table 4.6 Type III tests of fixed effects for dust emissions $<2.5 \mu \mathrm{m}$ - tracked vehicle............. 58

Table 4.7 Pairwise comparisons of total dust emissions from wind tunnel tests (GRIMM spectrometer) - tracked vehicle. ..................................................................... 58

Table 4.8 Least squares means of dust emissions from wind tunnel tests (GRIMM spectrometer)

- tracked vehicle.

Table 4.9 Pairwise comparisons of total dust emissions from wind tunnel tests (GRIMM spectrometer) - heavy-wheeled vehicle.

Table 4.10 Least squares means of dust emissions from wind tunnel tests (GRIMM spectrometer) - heavy-wheeled vehicle. 63

Table 4.11 Type III tests of fixed effects for aggregate size distribution - light-wheeled vehicle.

Table 4.12 Pairwise comparisons of soil fraction $<0.84 \mathrm{~mm}$ - light-wheeled vehicle............... 64

Table 4.13 Pairwise comparisons of soil aggregates $<0.84 \mathrm{~mm}$ - tracked vehicle. .................. 65

Table 4.14 Least squares means for soil aggregates $<0.84 \mathrm{~mm}$ - light-wheeled vehicle............. 66

Table 4.15 Least squares means for soil aggregates $<0.84 \mathrm{~mm}$ - tracked vehicle..................... 67 
Table 4.16 Pairwise comparisons of saltation and total soil losses - light-wheeled vehicle. ....... 68

Table 4.17 Pairwise comparisons of saltation and total soil losses - tracked vehicle................. 68

Table 4.18 Least squares means for saltation and total soil losses - light-wheeled vehicle. ........ 69

Table 4.19 Least squares means for saltation and total soil losses - tracked vehicle. ................. 71 


\section{Acknowledgements}

I want to extend a heartfelt thanks to my major professor, Dr. Ronaldo G. Maghirang, for supporting me in both my undergraduate and graduate studies. A special thanks to both Dr. John Tatarko and Dr. Larry Wagner with the Engineering and Wind Erosion Research Unit at USDAARS for taking time to support me as well. These three individuals have taken time to become personal mentors, as well as friends, throughout my journey to complete this thesis. Additionally, I would like to extend thanks to Nicholas Bloedow and Dr. Leigh Murray of the Statistical Consulting Lab at Kansas State University for assisting during the data analysis. Most of all I would like to thank my wife, Angela, and son, Jared, for their steadfast love and support. I want them both to know that they have been my sole inspiration for continuing along this journey in life. Thanks to Michael Berggren, Matt Kucharski and the rest of the wind erosion group at USDA-ARS for helping during the testing and setup phases. Finally, I would like to thank the Department of Defense Strategic Environmental Research and Development Program (SERDP) for providing the funding for this project. 


\section{Chapter 1 - Introduction}

\subsection{Background}

Soil erosion by wind has the potential to remove the fertile top layer of soil resulting in decreased agricultural productivity and cause severe air quality degradation. Activity at military installations in the United States can have a significant impact on air quality concerns.

Increasing environmental regulatory standards require military installations to focus on reducing air quality degradation, including that resulting from wind erosion of soil and military vehicle dust emissions from trafficking.

\subsubsection{Off-Road Military Training}

The United States Department of Defense (U.S. DoD) occupies and conducts training on over 12.1 million hectares of land. This land is used for various purposes, including residential and commercial activities and intensive combat training operations. Additionally, U.S. DoDmanaged land encompasses a wide diversity of climates and ecosystems across many different environmental regions.

Many combat training activities require navigating large, heavy off-road vehicles across potentially sensitive and undisturbed off-road locations. The vehicles can range from the more common vehicles such as the 2.4 metric ton High Mobility Multipurpose Wheeled Vehicle (HMMWV; commonly known as Humvee), to the very large, heavily armored 63 metric ton M1A2 Abrams tracked tank vehicle (U.S. Army, 2012). These activities can create significant disturbance to the soil surface and adversely affect the local ecosystem. The most prevalent impacts include loss of vegetation, soil compaction and soil loss due to erosion by water and wind (Althoff et al., 2010).

With continued concern for national security interests, U.S. DoD will continue to maintain operations and training activities well into the future. As such, the U.S. DoD must approach these operations with best management practices to help ensure that training lands are available for future military use as well as being habitable for native wildlife.

\subsubsection{Environmental Challenges}

Off-road military training has the potential to severely disturb the soil surface and ultimately degrade the training land. Retta et al. (2013) reported that soil bulk density 
significantly $(\mathrm{P}<0.05)$ increased while vegetation cover significantly $(\mathrm{P}<0.05)$ decreased with increasing passes of an M1A1 tank. Vehicle training activities can result in loss of vegetation, soil compaction and loss of soil through wind and water erosion. Soil loss through wind erosion can severely degrade the air quality locally as well as downwind of the source. Particulate matter (PM) emitted from military installations can be carried long distances from the training land and well beyond property boundaries. Soil transport by wind movement can cause nearby areas to exceed the National Ambient Air Quality Standards (NAAQS) (Ashbaugh et al., 2003).

The NAAQS-regulated PM is categorized for two distinct size classes: (a) $\mathrm{PM}_{10}-\mathrm{PM}$ with equivalent aerodynamic diameter of $10 \mu \mathrm{m}$ or less, and (b) $\mathrm{PM}_{2.5}-\mathrm{PM}$ with equivalent aerodynamic diameter of $2.5 \mu \mathrm{m}$ or less. The current NAAQS for $\mathrm{PM}_{10}$ and $\mathrm{PM}_{2.5}$ are $150 \mu \mathrm{g}$ $\mathrm{m}^{-3}$ and $35 \mu \mathrm{g} \mathrm{m}^{-3}$, respectively. Additionally, $15.0 \mu \mathrm{g} \mathrm{m}^{-3}$ is set as an annual average for $\mathrm{PM}_{2.5}$ (EPA, 2011). Although these are federally mandated standards, state and local government may also impose additional, more stringent, limits. Because of the current NAAQS regulation, some military installations may be considered "non-attainment" areas. This is a negative designation signifying that an area does not meet NAAQS standards. This can result in not only losing federal funding but also being viewed negatively by the surrounding communities and by the public as a whole. Determining, and subsequently counteracting, the primary factors contributing to air quality degradation is critical in attempting to prevent or reverse this designation.

Many activities on military training lands may contribute to fugitive dust emissions such as rotary-winged aircraft maneuvering, artillery fire testing and tracked vehicle travel. Du et al. (2011) quantified several sources of fugitive dust emissions at U.S. DoD installations including tracked vehicle and flying helicopters. Researchers in this study utilized an optical remote sensing technique to quantify emissions in terms of $\mathrm{PM}_{10}$ and $\mathrm{PM}_{2.5}$. They found that the M1A1 tracked vehicle produced an average emission factor of $4.74 \mathrm{~kg} \mathrm{PM} 10 / \mathrm{km}$ travelled on unimproved roads. This study did not, however, consider soil texture or wind speed effects of the resulting disturbed soil and only considered vehicle dust emissions resulting at the time of testing. Another study (van Donk et al., 2003) reported that military training activities overall can reduce vegetation cover, disturb soil conditions and make training land more susceptible to wind erosion events. 


\subsubsection{Emission Susceptibility of Soils}

In arid and semiarid climates, soil loss from wind erosion is more significant than from water erosion (Gomes et al., 2003a). Factors that can influence susceptibility to wind erosion include climatic conditions, topography, soil texture, moisture content and vegetation cover. Typically dry, barren and arid lands and soils with low clay content and aggregation are more susceptible to wind erosion. Clay content is especially important as it acts as a cohesion agent holding particles together as larger aggregates to reduce the chance of emissions by wind forces. However, Chepil and Woodruff (1963) described how erodibility of soils with respect to clay content can be highly variable. Although soils with high clay content were found to have generally good aggregation after fall tillage, their shrink-swell capacity in conjunction with exposure to freezing over winter can result in poorer aggregate stability and high erodible fraction in the spring. Additionally, good vegetation cover acts to elevate the boundary layer conditions of the wind forces above the soil surface so the wind does not create the shearing stress that would be present on a smooth, relatively flat surface.

In addition to climatic and natural conditions, wind erosion can be heavily impacted by anthropogenic activities and land-use changes (Gomes et al., 2003a; van Donk et al., 2003; Rajot et al., 2003). Degradation of land can come from a wide variety of sources including conversion to agricultural land, deforestation and military training disturbances. The primary effects of these activities are reducing vegetation cover resulting in the soil surface being less protected from and more exposed to natural factors such as impaction by precipitation and saltating particles and increased shear stress from wind. Tegen (1995) found through modeling that roughly $50 \%$ of total atmospheric dust loading is due to anthropogenic disturbances such as vegetation removal and deforestation.

\subsection{Research Objective}

This research was conducted to determine the effects of off-road trafficking on fugitive dust emissions from military training lands. Specific objectives were to (1) compare methods for measuring dust emission potential and (2) determine effects of soil texture, vehicle type and number of passes on dust emission potential. 


\section{Chapter 2 - Literature Review}

\subsection{Particulate Emissions from Military Installations}

Military installations take up vast land areas encompassing a wide diversity of landscapes within almost all major climatic zones. Many activities take place on these sites, including industrial, commercial and residential activity. This is in addition to heavy munitions and vehicle training; including ground and air combat readiness training. Military installations in the U.S. may be located in or around "non-attainment" areas due to the surrounding areas being unable to meet standards for criteria pollutants in the National Ambient Air Quality Standards (NAAQS). There can be many sources of criteria pollutants from these installations; however, the subject of this study focuses on particulate matter (PM) emissions resulting from wind erosion of soils subject to current and future off-road military vehicle activity.

\subsubsection{Background}

Military training locations cover a wide diversity of landscapes and terrain both in the U.S. and abroad. Many of these locations are used for off-road training activities and require the use of large tracts of uninhabited, and potentially undisturbed, land that may contain sensitive species or ecosystems. Off-road training in these areas can disturb the soil surface, potentially resulting in loss of vegetation cover and higher susceptibility to large wind erosion events and increased vehicle dust emissions. This disruption can contribute to significant air quality degradation and soil loss due to wind erosion.

U.S. DoD training lands can often be found in arid or semi-arid environments due to the availability of large open field spaces necessary for military activity. Desert ecosystems typically experience relatively little rainfall and have sparse vegetation which can be ideal for large vehicle maneuvering. However, vehicle traffic can significantly degrade this type of landscape, producing effects similar to large amounts of overgrazing and animal trampling (van Donk et al., 2003). Additionally, van Donk et al. (2003) found that, in general, military installations having soils with higher sand fraction produced the most significant wind erosion events. The said study investigated military installations that had previously been disrupted and studied in-situ wind erosion events using on-site slot-style BSNE sampling stations. The study did not consider vehicle type or extent of trafficking events. 
Training from both wheeled and tracked vehicles can have significant impacts on the soil surface, depending on type, amount and duration of training. Continuous vehicle trafficking may affect many soil properties, including aggregation, increased compaction and biological crust removal. Significant deterioration can result from these types of changes, resulting in higher susceptibility to wind erosion events and greater vehicle dust emissions. Eroding soil can severely degrade the local air quality, creating a health hazard possibly extending far from the training location. Figure 2.1 shows an example of direct dust emissions resulting from both a tracked and wheeled off-road military vehicle at the Fort Riley sampling site.

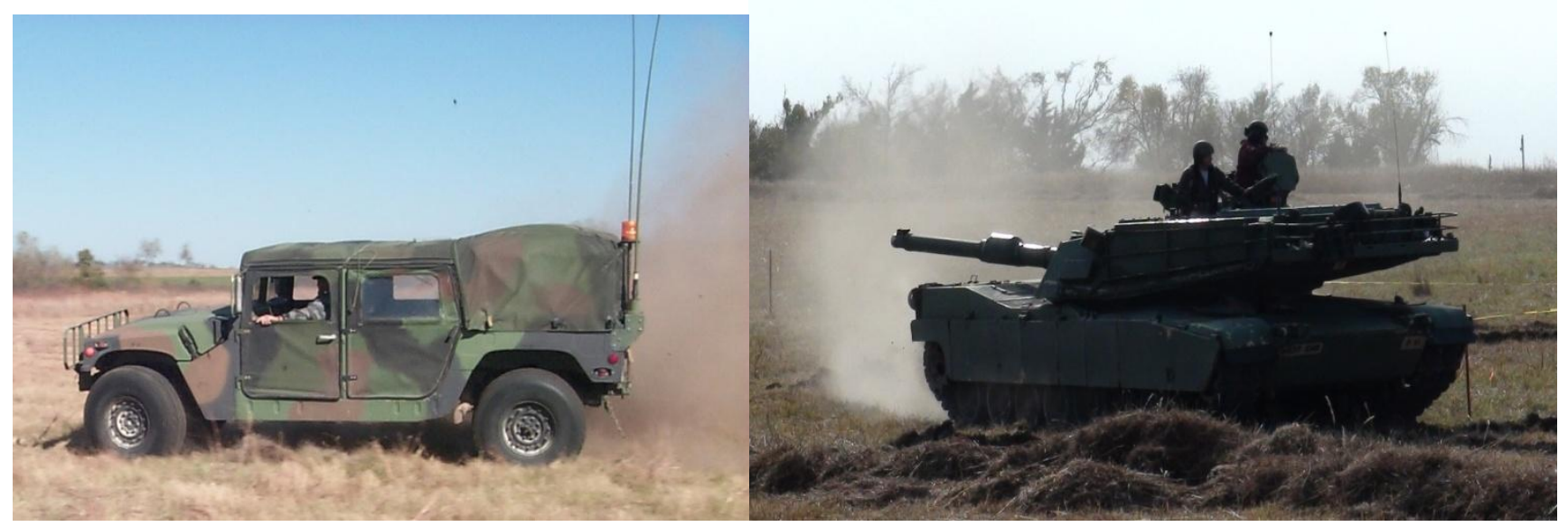

Figure 2.1 Direct emissions from military vehicle training.

Vehicle trafficking can lead to direct as well as subsequent emissions of fugitive dust. As seen in Figure 2.1, dust can be emitted directly as the vehicle training is occurring. However, of more significant importance to this study is the effect of future wind erosion susceptibility resulting from the disruption of the soil surface. The resulting compaction, vegetation removal and aggregate destruction can lead to large future emissions events resulting from wind erosion.

\subsubsection{Air Quality Regulations Affecting DoD Installations}

Fugitive dust generated by wind erosion can contribute a significant amount of suspended particles less than $10 \mu \mathrm{m}$ in aerodynamic diameter $\left(\mathrm{PM}_{10}\right)$ as well as particles less than $2.5 \mu \mathrm{m}$ in aerodynamic diameter $\left(\mathrm{PM}_{2.5}\right)$, which have been shown to have negative health effects ( $\mathrm{Li}$ et al., 2013; Sawyer et al., 2010). The negative health effects may come about directly when inhaled as well as indirectly through events such as deposition and reduced visibility. Military installations 
and nearby communities may not be able to meet National Ambient Air Quality Standards (NAAQS) set forth by the U.S. Environmental Protection Agency (EPA) due to fugitive particulate emissions from both point and non-point sources such as wind erosion of soil (Hagen et al., 1996). Air emissions can travel beyond the property boundary of military installations and negatively impact local and regional air quality far beyond the original source. The NAAQS cover six criteria pollutants (Table 2.1), one of which is suspended PM consisting of two distinct size classes, $\mathrm{PM}_{10}$ and $\mathrm{PM}_{2.5}$.

Table 2.1 National ambient air quality standards (EPA, 2011).

\begin{tabular}{|c|c|c|c|c|c|}
\hline \multicolumn{2}{|l|}{ Pollutant } & $\begin{array}{l}\text { Primary/ } \\
\text { Secondary }\end{array}$ & $\begin{array}{c}\text { Averaging } \\
\text { Time }\end{array}$ & Level & Form \\
\hline \multirow{2}{*}{\multicolumn{2}{|c|}{ Carbon Monoxide }} & \multirow{2}{*}{ primary } & 8-hour & $9 \mathrm{ppm}$ & \multirow{2}{*}{$\begin{array}{l}\text { Not to be exceeded more than } \\
\text { once per year }\end{array}$} \\
\hline & & & 1-hour & $35 \mathrm{ppm}$ & \\
\hline \multicolumn{2}{|l|}{ Lead } & $\begin{array}{l}\text { primary and } \\
\text { secondary }\end{array}$ & $\begin{array}{l}\text { Rolling } 3 \\
\text { month } \\
\text { average }\end{array}$ & $0.15 \mathrm{\mu g} \mathrm{m}^{-3}$ & Not to be exceeded \\
\hline \multirow{2}{*}{\multicolumn{2}{|c|}{ Nitrogen Dioxide }} & primary & 1-hour & 100 ppb & $\begin{array}{l}\text { 98th percentile, averaged over } \\
3 \text { years }\end{array}$ \\
\hline & & $\begin{array}{l}\text { primary and } \\
\text { secondary }\end{array}$ & Annual & $53 \mathrm{ppb}$ & Annual Mean \\
\hline \multicolumn{2}{|l|}{ Ozone } & $\begin{array}{l}\text { primary and } \\
\text { secondary }\end{array}$ & 8-hour & 0.075 ppm & $\begin{array}{l}\text { Annual fourth-highest daily } \\
\text { maximum } 8 \text {-hr concentration, } \\
\text { averaged over } 3 \text { years }\end{array}$ \\
\hline \multirow[t]{2}{*}{ Particle Pollution* } & \multirow{3}{*}{$\mathrm{PM}_{2.5}$} & primary & Annual & $12 \mu \mathrm{g} \mathrm{m}^{-3}$ & $\begin{array}{l}\text { annual mean, averaged over } 3 \\
\text { years }\end{array}$ \\
\hline & & secondary & Annual & $15 \mu \mathrm{g} \mathrm{m}^{-3}$ & $\begin{array}{l}\text { annual mean, averaged over } 3 \\
\text { years }\end{array}$ \\
\hline \multirow[t]{2}{*}{$\begin{array}{l}{ }^{*} \text { As of Dec 14, } \\
2012\end{array}$} & & $\begin{array}{l}\text { primary and } \\
\text { secondary }\end{array}$ & 24-hour & $35 \mu \mathrm{g} \mathrm{m}^{-3}$ & $\begin{array}{l}98 \text { th percentile, averaged over } \\
3 \text { years }\end{array}$ \\
\hline & $\mathrm{PM}_{10}$ & $\begin{array}{l}\text { primary and } \\
\text { secondary }\end{array}$ & 24-hour & $150 \mu \mathrm{g} \mathrm{m}^{-3}$ & $\begin{array}{l}\text { Not to be exceeded more than } \\
\text { once per year on average over } \\
3 \text { years }\end{array}$ \\
\hline \multirow{2}{*}{\multicolumn{2}{|c|}{ Sulfur Dioxide }} & primary & 1-hour & $75 \mathrm{ppb}$ & $\begin{array}{l}\text { 99th percentile of } 1 \text {-hour daily } \\
\text { maximum concentrations, } \\
\text { averaged over } 3 \text { years }\end{array}$ \\
\hline & & secondary & 3-hour & 0.5 ppm & $\begin{array}{l}\text { Not to be exceeded more than } \\
\text { once per year }\end{array}$ \\
\hline
\end{tabular}




\subsection{Health Effects of Particulate Matter}

$\mathrm{PM}_{10}$ can be easily inhaled and can cause significant negative health effects. Although the human body has many control mechanisms for keeping harmful substances from entering the body, $\mathrm{PM}_{10}$ can still have many serious health implications when inhaled. Because of the recognized health effects, $\mathrm{PM}_{10}$ is classified as a regulated health hazard.

In 1997, it was acknowledged that $\mathrm{PM}_{2.5}$ may have more significant health effects, which resulted in the EPA implementing $\mathrm{PM}_{2.5}$ NAAQS for the first time (EPA, 2012). Since the first standard in 1997, $\mathrm{PM}_{2.5}$ has been considered under a distinct separate category from $\mathrm{PM}_{10}$ in updated NAAQS limits. Municipalities and other local areas are required to meet specified, health-based standards for both $\mathrm{PM}_{10}$ and $\mathrm{PM}_{2.5}$ under the NAAQS.

In addition to having primary health effects when inhaled, suspended PM can also result in several secondary effects. This can include reduced visibility caused by blowing dust and machinery fouling due to deposition. Property damage can also result from mechanical abrasion of blowing PM and from deposition.

\subsubsection{Primary Health Effects}

Suspended PM, especially $\mathrm{PM}_{10}$, has been confirmed through epidemiological studies to be associated with increased mortality and morbidity (Rabl et al., 2011). Sawyer et al. (2010) stated that exposure to ambient PM is associated with adverse cardiopulmonary health effects, exacerbation of inflammatory diseases and increased hospitalization for lung disease. The adverse health effects especially impact more vulnerable populations such as very young, elderly and those with respiratory illnesses.

The respiratory system is a major pathway for air pollutants such as suspended PM to enter into the body. Many larger particles may be trapped by natural human defense mechanisms, such as by hairs in the nasal passageway, while others may eventually enter into the deep areas of the lungs such as the alveoli before becoming lodged. Larger particles that are not filtered initially by the nasal passageway may be deposited within the upper respiratory system such as in the trachea or bronchi. When particles are deposited in these upper areas, the hair-like cilia cells within the lungs will work to expunge the foreign particles from the body. However, smaller particles such as $\mathrm{PM}_{2.5}$ may not be filtered by the preliminary defense mechanisms and can reach the inner areas of the respiratory system. Once particles reach inner depths of the 
lungs, such as in the alveoli or bronchioles, they may not easily be exhaled and may become trapped. The alveoli are the smallest portion of the inner lungs and are where the exchange of oxygen to the bloodstream takes place (Ricketts, 2011).

Although regulations and many literature sources consider PM holistically as a single pollutant, this type of pollution can contain a wide variety of constituents and chemical composition. Particulate matter can range from relatively low toxicity substances such as mineral matter to highly toxic and radioactive particles such as from manufacturing activities and munitions training. Because regulations surrounding particulate pollution are often nondiscretionary of the individual species of particles, the health effects may be highly variable depending on the source and composition of the material. Because of the complexity of epidemiological studies, the long term effects of many specific compositions of PM may be unknown.

\subsubsection{Secondary Effects}

Several negative secondary effects can also result from suspended PM in the ambient environment. One major secondary effect is the reduction of visibility due to high PM concentrations (Presley and Tatarko, 2009). Sunlight interacts with the small particles in the air and causes scattering of light which distorts the color and clarity that reaches the eyes. This can be a serious concern as reduced visibility can cause accidents on highways and roads. This is primarily a concern in very large metropolitan areas with high traffic density, during natural dust storms and near large fires. This can also be a direct concern for military vehicles travelling on unimproved roads in large convoys as reduced visibility can lead to collisions.

PM pollution can also result in detrimental soil removal and deposition effects. When PM is emitted from a source, it may travel a long distance before being deposited (Tsoar and Pye, 1987). During large wind erosion events, topsoil is stripped from productive agricultural lands and can be carried to a new location. This results in decreased agricultural productivity as well as machinery fouling due to dust deposition.

Soil may be deposited in areas such as water bodies where it can result in contamination of water supplies (Presley and Tatarko, 2009). High concentrations of toxic particulate deposition can have a negative effect on fish and other aquatic populations. Particles can also be deposited onto surfaces during a precipitation event. High concentrations of PM during 
precipitation results in the cleansing of the air as well as the subsequent contamination of the rain water with PM. This water may become acidic and/or toxic which can ultimately lead to contamination of water bodies (González and Aristizábal, 2012).

Finally, particulate pollution can result in severe degradation of property and structures. PM may be directly deposited on surfaces near the source of emission. The other manner in which structures can be affected is through acidification of precipitation. When PM pollution is high during precipitation events, an area may be covered in water that is slightly acidic. Over time, the acidity of water begins to erode away substances such as marble and limestone which may make up buildings and monuments (Charola, 1987).

\subsection{Wind Erosion Principles}

Soil erosion by wind is a dynamic, non-linear process that often results in loss of the fertile top layer of soil which can reduce agricultural production as well as degrade local air quality (Hagen et al., 1996). Wind erosion was first determined to be a major environmental and public health problem in the U.S. during the "dust bowl" era of the 1930's. During this time period, a combination of intensive tillage and prolonged drought brought about some of the worst cases of soil erosion by wind in modern history. Although the days of the dust bowl are in the past, the effects of wind erosion still threaten societies today. Wind can remove the most productive layer of top soil and deposit the soil in places where it may cause fouling of machinery, aggravation of respiratory problems and contamination of water bodies. Suspension of soil may also result in serious degradation of the local air quality thus creating a significant health hazard.

Wind erosion of soil is a natural process that has been shown to be exacerbated by anthropogenic activities (Gomes et al., 2003a). Intensive tillage, and other agricultural practices, on arid and semi-arid land can contribute to an increase in soil loss due to erosion by wind. Many other factors such as unpaved roads, animal feeding operations and intensive use of military training lands may also contribute to dust emissions due to wind erosion (Gillies et al., 2005). Gomes et al. (2003a) suggested that emission of dust from wind erosion can cause significant changes in climate as well as increase arid desert landscapes. Soil erosion can ultimately transform a fertile food-producing area into a barren desert land in extreme cases. 
Wind erosion is a physical process by which a mass of air moving across a landscape creates a force on soil particles. This force applied to the soil particles can result in movement of soil particles. The extent and duration of the particle transport is dependent on many factors. The mechanics of soil movement are often thought of in three distinct movement patterns: surface creep, saltation and suspension (Figure 2.2). Surface creep involves the largest soil particles of approximately $0.5 \mathrm{~mm}$ or larger in diameter that roll or hop along the ground surface as the wind blows. The saltation component includes the mid-size range of erodible particles of about 0.5 to $0.1 \mathrm{~mm}$ in diameter.

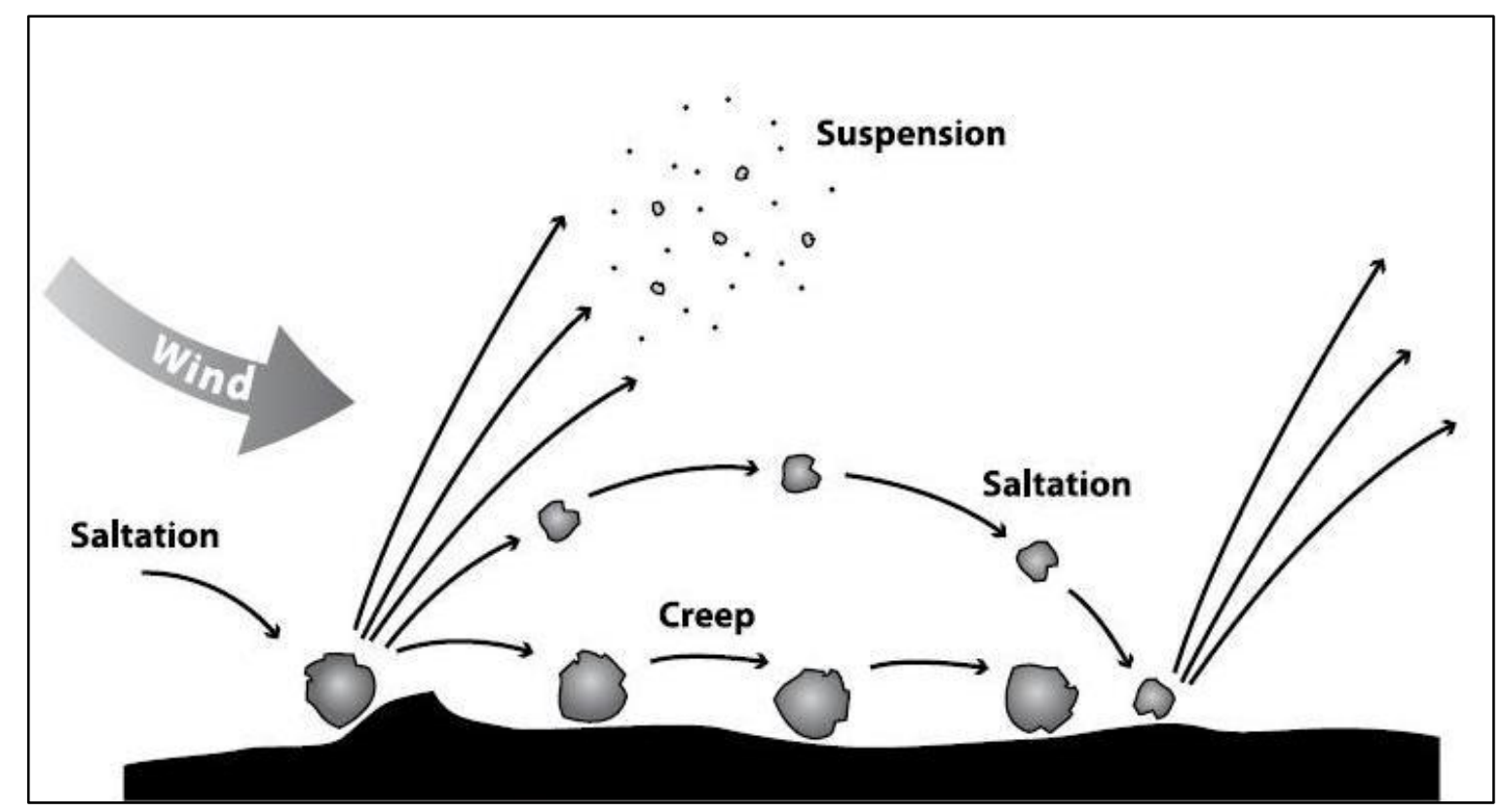

Figure 2.2 Size components of wind erosion (Presley and Tatarko, 2009).

The saltation component may become temporarily suspended in air before dropping back down to the surface and striking other soil particles. This action can cause mechanical abrasion of the soil surface which can generate significant amounts of suspended material (Hagen et al. 1996; Alfaro et al., 2004). Saltation is also responsible for the mechanical abrasion of other surfaces such as agronomic plants and machinery.

The suspension component of wind erosion consists of particles less than $0.1 \mathrm{~mm}$ in diameter that become suspended above the surface for a significant period of time. Suspension can result in soil being carried long distances. The suspension component of wind erosion 
contributes to air quality degradation as well as significant soil loss. Tsoar and Pye (1987) observed that particles $<20 \mu \mathrm{m}$ could stay suspended in air on the timescale up to multiple years given favorable atmospheric conditions. Suspension material can result directly from loose soil material on a surface as well as indirectly from saltation-sized material breaking down due to abrasion (Hagen et al., 1996).

In addition to wind speed and direction, transport also depends highly on soil composition, aggregation, vegetation cover and surface roughness, as well as topography of the surrounding landscape. Soil erosion is initiated by the act of shear stress caused by a moving air mass. The amount of shear stress a soil can withstand before beginning to erode is different for each soil surface and location. It is necessary to determine the minimum amount of shear stress needed to initiate movement when attempting to study wind erosion. Two factors that have been found important in understanding this shear stress are the threshold friction velocity and aerodynamic roughness (Li et al., 2010).

The ability of a landscape to be eroded by wind can depend on many other factors including direction of prevailing wind, orientation of the field, vegetative cover and wind barriers. Wind barriers are often planted in the form of hedge rows and shelterbelts perpendicular to the prevailing wind direction. Presley and Tatarko (2009) noted that this practice can reduce the amount of wind erosion on a field. Vegetative barriers physically reduce the energy from the wind directly downwind of a distance of approximately 10 times the height of the barrier. Additionally, Zobeck et al. (2003) demonstrated that standing residue cover acts to elevate the boundary layer of the moving wind above the soil surface which can significantly reduce wind erosion. Figure 2.3 shows an example of how vegetative barriers can be used to prevent soil erosion by wind. 


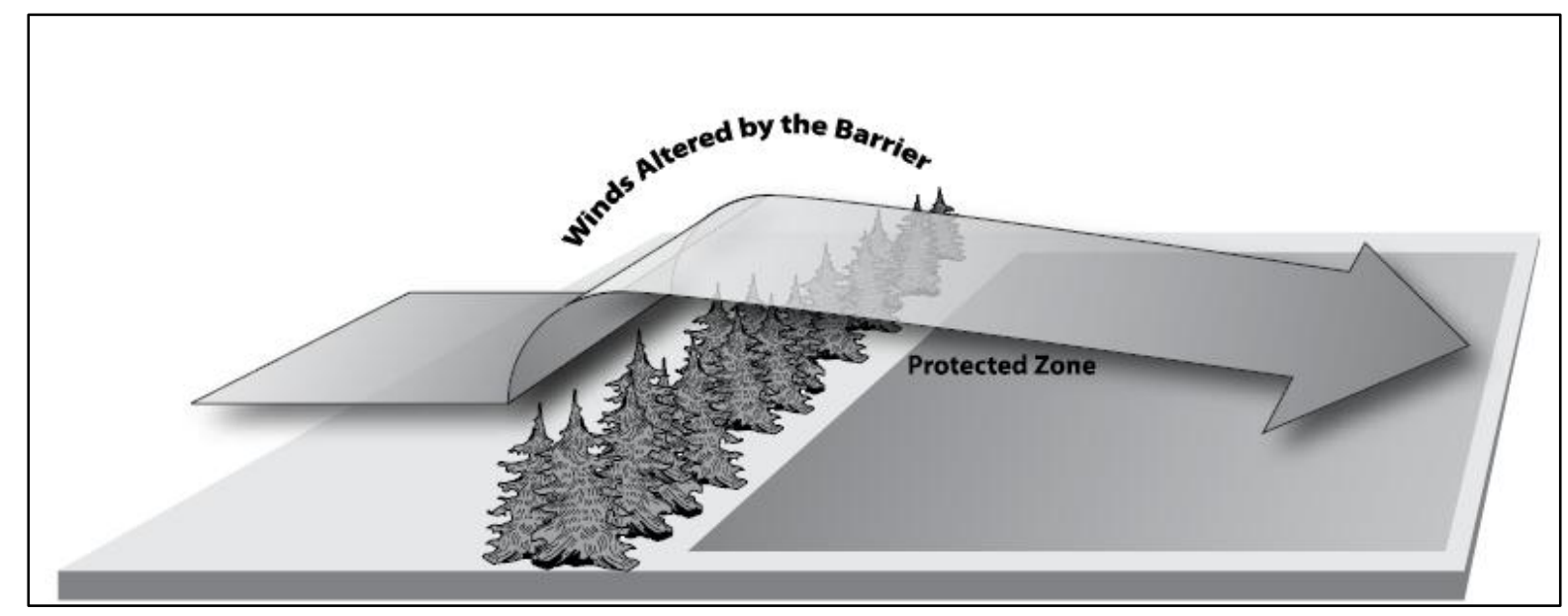

Figure 2.3 Illustration of vegetative barrier (Presley and Tatarko, 2009).

\subsection{Emissions Sampling}

In order to determine the wind erosion potential of a particular landscape, it is necessary to collect surface soil and air emission samples from the site. Wind erosion is a dynamic process that can be highly unpredictable; as such, it is often necessary to carry out laboratory scale experiments. These experiments can be designed to initiate favorable conditions for soil erosion by wind and subsequently capture meaningful data. Several experimental designs were utilized during this study and are identified in the following sections.

\subsubsection{Portable In-Situ Wind Erosion Laboratory (PI-SWERL)}

The Portable In-Situ Wind Erosion Laboratory (PI-SWERL) is a device developed and patented by researchers at the Desert Research Institute (DRI). It is a potential alternative to the traditional straight-line field wind tunnel used for wind erosion research. This method provides a more portable and economical means of collecting wind erosion data without the cumbersome task of setting up a large, full-scale wind tunnel.

The PI-SWERL uses a spinning annular ring to generate a shear stress over a small surface area of soil (Etyemezian et al., 2007). This type of shear stress is designed to simulate the physical action of blowing wind. The shear stress results in any erodible PM being suspended within the device. The suspended dust is then measured with the attached lightscattering laser photometer (DustTrak ${ }^{\mathrm{TM}}$ II Model 8531, TSI, Inc.), herein referred to as DustTrak $^{\mathrm{TM}}$ monitor, which gives real-time aerosol concentration readings. Figure 2.4 shows an image of the annular ring and a full view of the PI-SWERL instrument. 


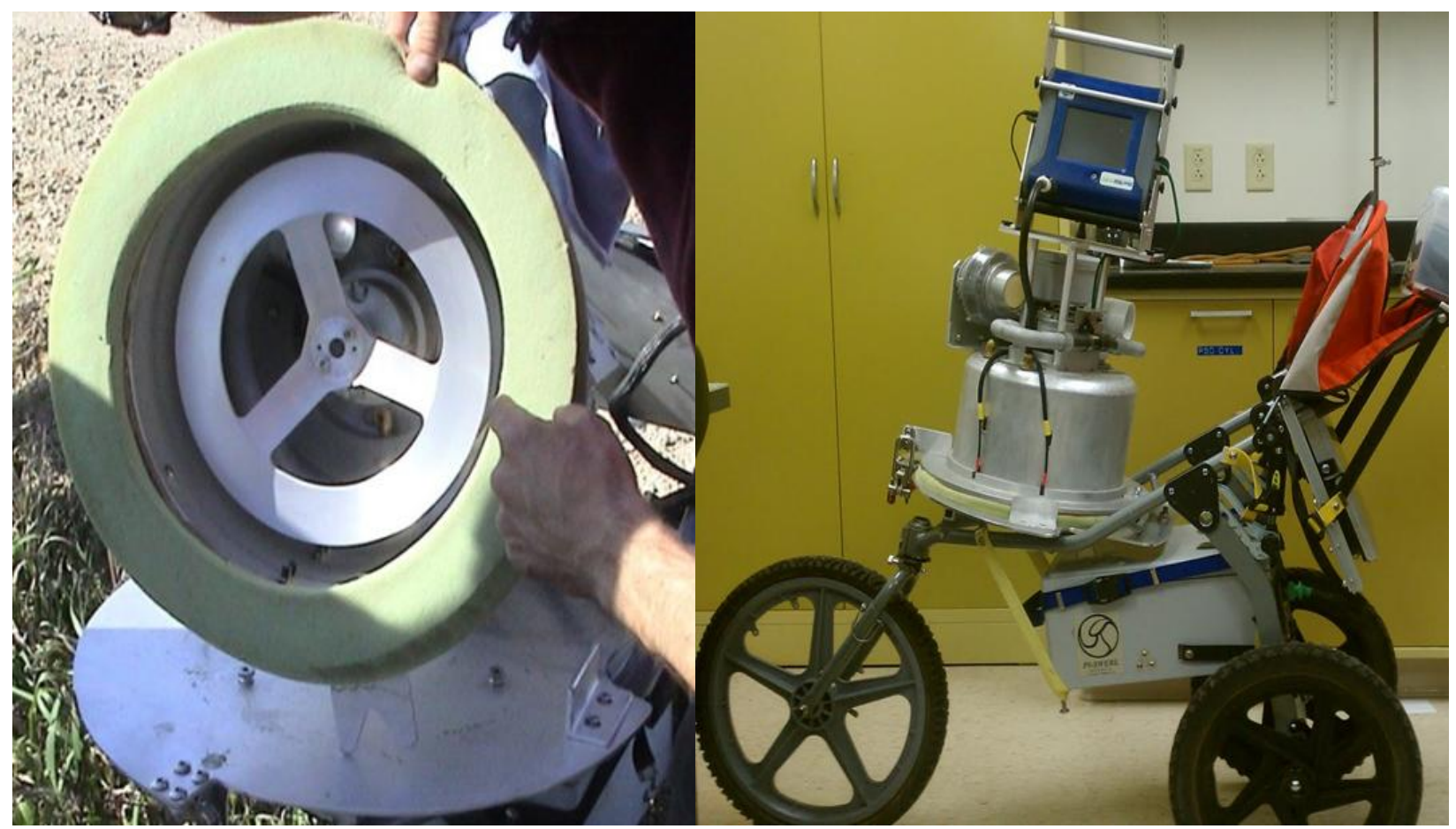

Figure 2.4 Portable In-Situ Wind Erosion Laboratory (PI-SWERL).

Although a correlation has been shown between the PI-SWERL and straight-line field wind tunnels, several limitations have been identified with this instrument. The most prevalent error comes about with use on very rough surfaces such as a gravel-packed bed. Because the instrument uses the principle of Coulette flow, which is the shearing force developed between two infinitely flat plates, the calculated friction likely underestimates the actual friction developed on a rough surface (Sweeney et al., 2008). Another limitation of this system is that it does not generate a velocity profile and boundary layer condition as observed in nature. This will affect the way that saltation-sized particles are suspended and measured.

Because of these limitations, this system is not ideal for a detailed investigation of the principal mechanics of wind erosion. Despite the mentioned limitations, the PI-SWERL has been shown to be sufficient for measurement of relative dust emission potential over a wide range of surface conditions and is useful for evaluating smaller areas in-situ than a portable wind tunnel. Figure 2.5 shows a representative diagram of the RPM profile of spinning annular blade, as well as a sample of data collected with the PI-SWERL, from the current study. 


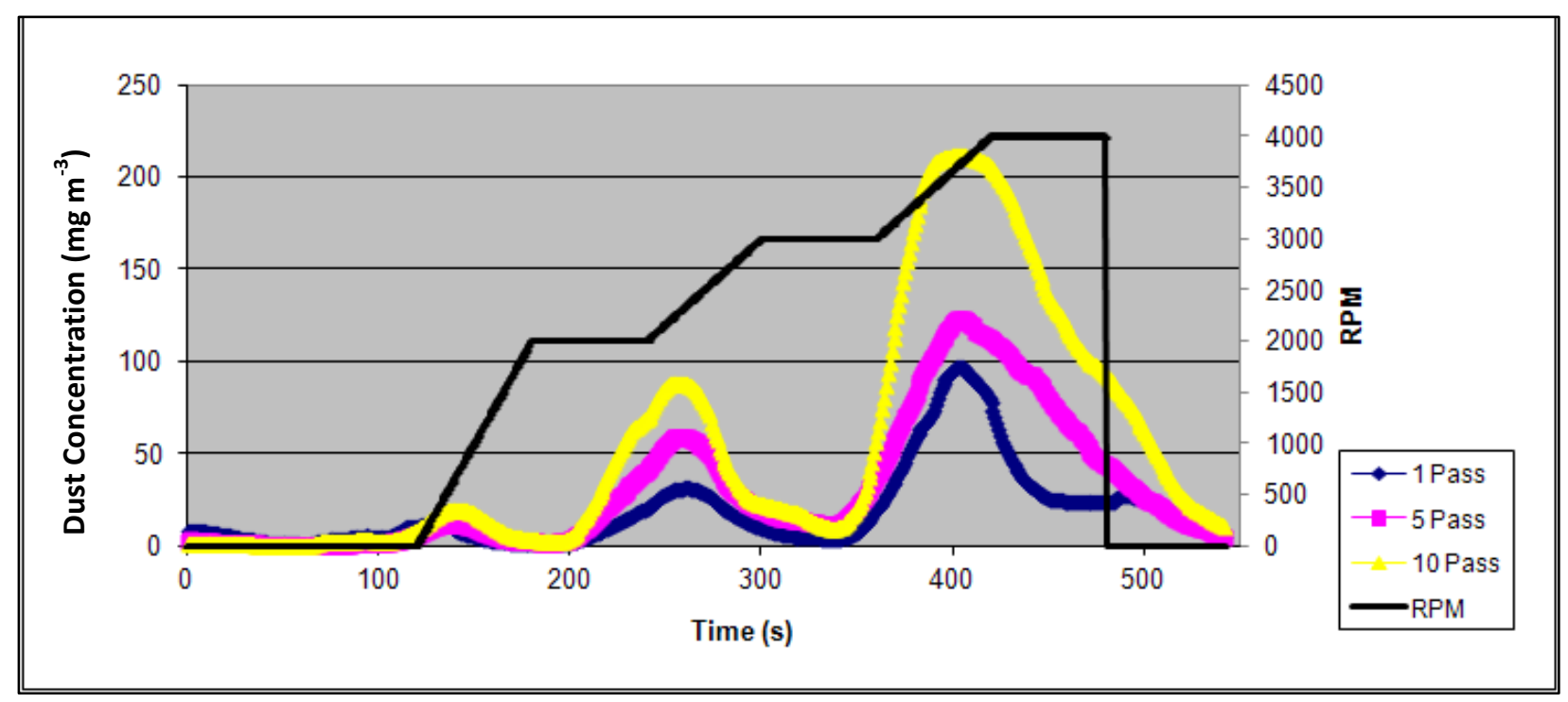

Figure 2.5 Example of test data from PI-SWERL.

The PI-SWERL instrument has been evaluated as a method for measuring dust emissions potential from wind erosion events and results have been published in several refereed journal publications (Kavouras et al., 2009; Etyemezian et al., 2007; Sweeney et al., 2008). These studies have demonstrated that this instrument provides data comparable with a portable straightline wind tunnel on a wide range of surface conditions.

\subsubsection{Wind Tunnel}

Wind erosion is driven by dynamic weather conditions and an erosion event is often difficult to accurately predict. Because of the difficulty in determining exactly when a large wind erosion event will occur, in-situ wind erosion studies are often carried out over long periods of time in order to obtain meaningful results (van Donk et al., 2003; Gomes et al., 2003b; van Donk and Skidmore, 2003). Additionally, isokinetic dust sampling is critical to ensuring accurate measurements. When attempting to measure fugitive emissions in the field, ensuring isokinetic sampling conditions is difficult given the unpredictability of the weather (Vrins, 1996)

One method to overcome this problem is to utilize a wind tunnel to initiate high wind speeds over a given land area. Several studies have utilized in-situ semi-portable wind tunnels that are set up directly in the field on the surface of interest (Sweeney et al., 2008; Marticorena and Bergametti, 1997). Other studies have utilized large laboratory wind tunnels to control both wind and soil surface conditions to some degree (Hagen, 1999; Guoliang et al., 2003; Kohake et 
al., 2010). These studies have shown that wind tunnels can be successfully utilized to study the underlying principles of wind erosion while simulating optimal conditions that contribute to initiating large wind erosion events.

Previous studies have shown that laboratory wind tunnels can be used to assess wind erosion parameters if several key parameters are considered (Hagen, 1999; Mirzamostafa et al., 1998). A wind tunnel can provide researchers with invaluable options for a controlled environment; however, several conditions must be met to ensure the air mass flow within the wind tunnel represents actual field conditions. One of the most important factors is proper establishment of upwind boundary layer conditions (Hagen, 1999).

Kohake et al. (2010), using the USDA-ARS Engineering and Wind Erosion Research Unit (EWERU) laboratory wind tunnel, showed that all loose erodible material was successfully removed from a soil surface when subjected to $13 \mathrm{~m} / \mathrm{s}$ wind for 5 minutes. Additionally, this study found the use of silica sand as an abrasion agent across soil trays to have significant value in representing saltation effects of wind erosion while allowing control over conditions such as particle diameter.

\subsubsection{Isokinetic Slot Sampler}

Sampling solid particles in a moving fluid stream requires that certain physical conditions be met to ensure an accurate representation of actual aerosol concentration. One primary requirement is that sampling must be conducted under isokinetic conditions. Stetler (1997) stated that for a sampler to be isokinetic it should not interfere with the passing air stream or particle motion. This is especially true for the case of sampling the suspension component of wind erosion emissions. If sampling is not isokinetic, suspended particles may not be correctly captured and large measurement errors can occur. Wanjura et al. (2009) suggested that nonisokinetic sampling conditions contributed to inaccurate emission factors being used in regulatory compliance actions.

When air velocity is higher in the wind stream than inside the sampler, small particles will tend to flow around the sampler and measurement values can underestimate actual conditions. The opposite is true when the velocity within the sampler is higher than that of the moving air stream. Because of this phenomenon, passive sampling techniques are not usually considered adequate for accurately measuring suspended particle concentration in a moving air 
stream (Zobeck et al., 2003). Goossens and Offer (2000) suggested that efficiency loss due to non-isokinetic sampling conditions is the most important factor to consider when attempting to measure sediment flux. In order to obtain isokinetic sampling conditions, it is necessary to incorporate an active technique that will equalize the pressure inside the sampler to match that of the moving air stream. This can be successfully obtained by developing a negative pressure using a blower or pump. 


\section{Chapter 3 - Materials and Methods}

Three military installations were chosen for off-road military vehicle testing to determine susceptibility of the soil to wind erosion events and subsequent dust emissions from vehicle trafficking. Soil samples were collected in the field for emission testing in a laboratory wind tunnel. The top layer of soil was collected for each treatment and was used to conduct laboratory emission testing in a wind tunnel. The soil sample trays were subjected to wind alone at approximately $14 \mathrm{~m} / \mathrm{s}$ for 5 minutes each. Kohake et al. (2010) noted that this setting ensured all loose erodible material was fully removed.

\subsection{Field Plot Sites}

The three sites were Fort Riley, KS, Fort Benning, GA, and Yakima Training Center, WA. These sites represent diverse climatic conditions, soil types and off-road trafficking activities. Table 3.1 lists the approximate geographic coordinates of the sample testing locations.

Table 3.1 Approximate coordinates and elevations of sampling sites.

\begin{tabular}{|l|c|c|}
\hline \multicolumn{1}{|c|}{ Site } & Approximate Location & Elevation (m) \\
\hline Fort Riley, KS & $39^{\circ} 18^{\prime} 0^{\prime \prime} \mathrm{N} ; 96^{\circ} 55^{\prime} 18^{\prime \prime} \mathrm{W}$ & 410 \\
\hline Fort Benning, GA & $32^{\circ} 24^{\prime} 14^{\prime \prime} \mathrm{N} ; 84^{\circ} 45^{\prime} 21^{\prime \prime} \mathrm{W}$ & 145 \\
\hline Yakima Training Center, WA & $46^{\circ} 41^{\prime} 36^{\prime \prime} \mathrm{N} ; 120^{\circ} 26^{\prime} 15^{\prime \prime} \mathrm{W}$ & 480 \\
\hline
\end{tabular}

Two off-road military training vehicles were used at each location representing a range of relatively lightweight to very heavy, fully armored military off-road vehicles as shown in Table 3.2. Two soil textures were identified for testing at Fort Riley, with one texture class from each of the other two sites. 
Table 3.2 Vehicle specifications and testing dates.

\begin{tabular}{|l|c|c|c|c|c|c|}
\hline \multicolumn{1}{|c|}{ Vehicle } & $\begin{array}{c}\text { Traction } \\
\text { Type }\end{array}$ & $\begin{array}{c}\text { Mass } \\
\mathbf{( k g})\end{array}$ & $\begin{array}{c}\text { Speed } \\
\mathbf{( k m / h )}\end{array}$ & $\begin{array}{c}\text { Fort } \\
\text { Riley }\end{array}$ & $\begin{array}{c}\text { Fort } \\
\text { Benning }\end{array}$ & $\begin{array}{c}\text { Yakima } \\
\text { Training } \\
\text { Center }\end{array}$ \\
\hline M1025A2 HMMWV & Wheeled & 3,075 & $25-30$ & Nov. 2010 & & Aug. 2012 \\
\hline $\begin{array}{l}\text { M1A1 } \\
\text { Abrams tank }\end{array}$ & Tracked & 61,325 & 8 & Oct. 2010 & Jul. 2012 & \\
\hline $\begin{array}{l}\text { M1151A } \\
\text { Up-armored } \\
\text { HMMWV }\end{array}$ & Wheeled & 3,697 & $25-30$ & & Jul. 2012 & \\
\hline $\begin{array}{l}\text { M925A1 } \\
\text { Fire Truck }\end{array}$ & Wheeled & 15,100 & 12 & & & Aug. 2012 \\
\hline
\end{tabular}

Fort Riley was the first installation chosen for testing. This installation is located in the Flint Hills region of north central Kansas in both Geary and Riley counties (Figure 3.1) and covers $407 \mathrm{~km}^{2}$, with $287 \mathrm{~km}^{2}$ being utilized for maneuver training (EPA, 2010). Over the past 64 years, Fort Riley has received an annual precipitation of about $889 \mathrm{~mm}$ with an average temperature of $12.6^{\circ} \mathrm{C}$. Fort Riley is a historic military site that has been an active installation since the mid-1800s. Testing at Fort Riley was conducted on silty clay loam and silt loam soil types. Both an M1A1 Abrams heavily armored tracked vehicle $(61,325 \mathrm{~kg})$ and an M1025A2 HMMWV light armored wheeled vehicle $(3,075 \mathrm{~kg})$ were used for testing. 


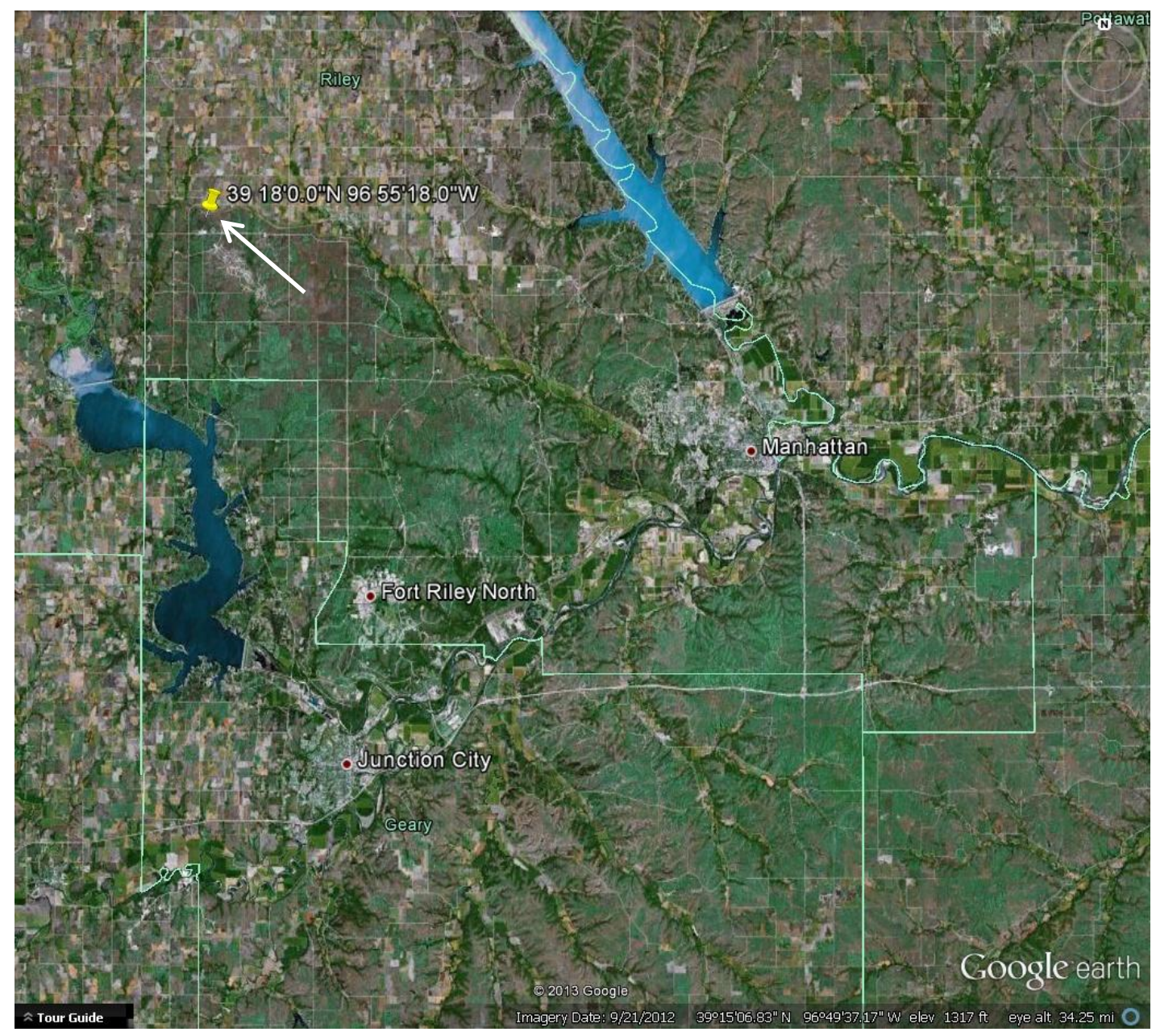

Figure 3.1 Fort Riley, KS sampling location (Google Earth).

The second installation was Fort Benning, GA. Fort Benning is located on $765 \mathrm{~km}^{2}$ in west central Georgia (Figure 3.2). Fort Benning has received an average of $1245 \mathrm{~mm}$ of precipitation annually over the past 64 years. The Fort Benning site has an annual mean temperature of $18.3^{\circ} \mathrm{C}$ for the same time period. This site is located in the humid Southeastern region of the United States with relatively high precipitation and is affected by tropical maritime events including frequent thunderstorms and inland moving hurricanes (NOAA, 2011). Testing at Fort Benning was done on a loamy sand soil type. The two vehicles used were a HMMWV heavily up-armored vehicle (Model M1151A1) having a curb weight of 3,697 kg and an M1A1 heavily armored tracked tank vehicle weighing $61,325 \mathrm{~kg}$. 


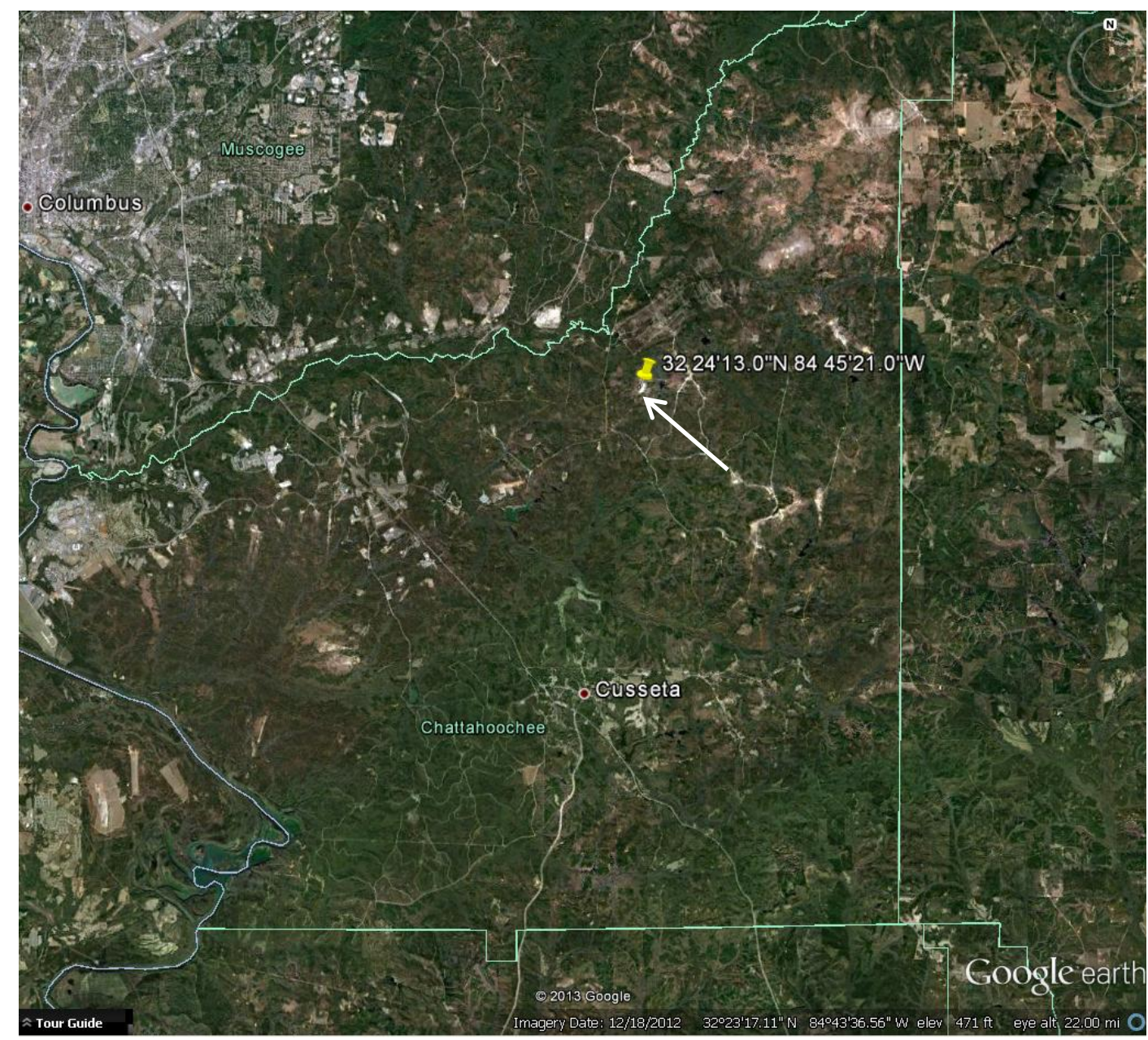

Figure 3.2 Fort Benning, GA sampling location (Google Earth).

Yakima Training Center, WA was selected as the third site. This site is situated on 1323 $\mathrm{km}^{2}$ of shrub-steppe land in south central Washington (Figure 3.3). Yakima training center has relatively low precipitation, receiving an average of $207 \mathrm{~mm}$ over the past 65 years. This site is located in the Yakima Valley region which is mild in temperature and very dry. The local topography is highly varied with a large variety of local ridges and valleys (NOAA, 2011). Testing at Yakima Training Center was conducted on a loam soil type. A tracked vehicle was not available for use; therefore a fully loaded M925A1 fire water tanker vehicle weighing 15,100 $\mathrm{kg}$ was used in addition to the light armored HMMWV (Model M1025A2). 


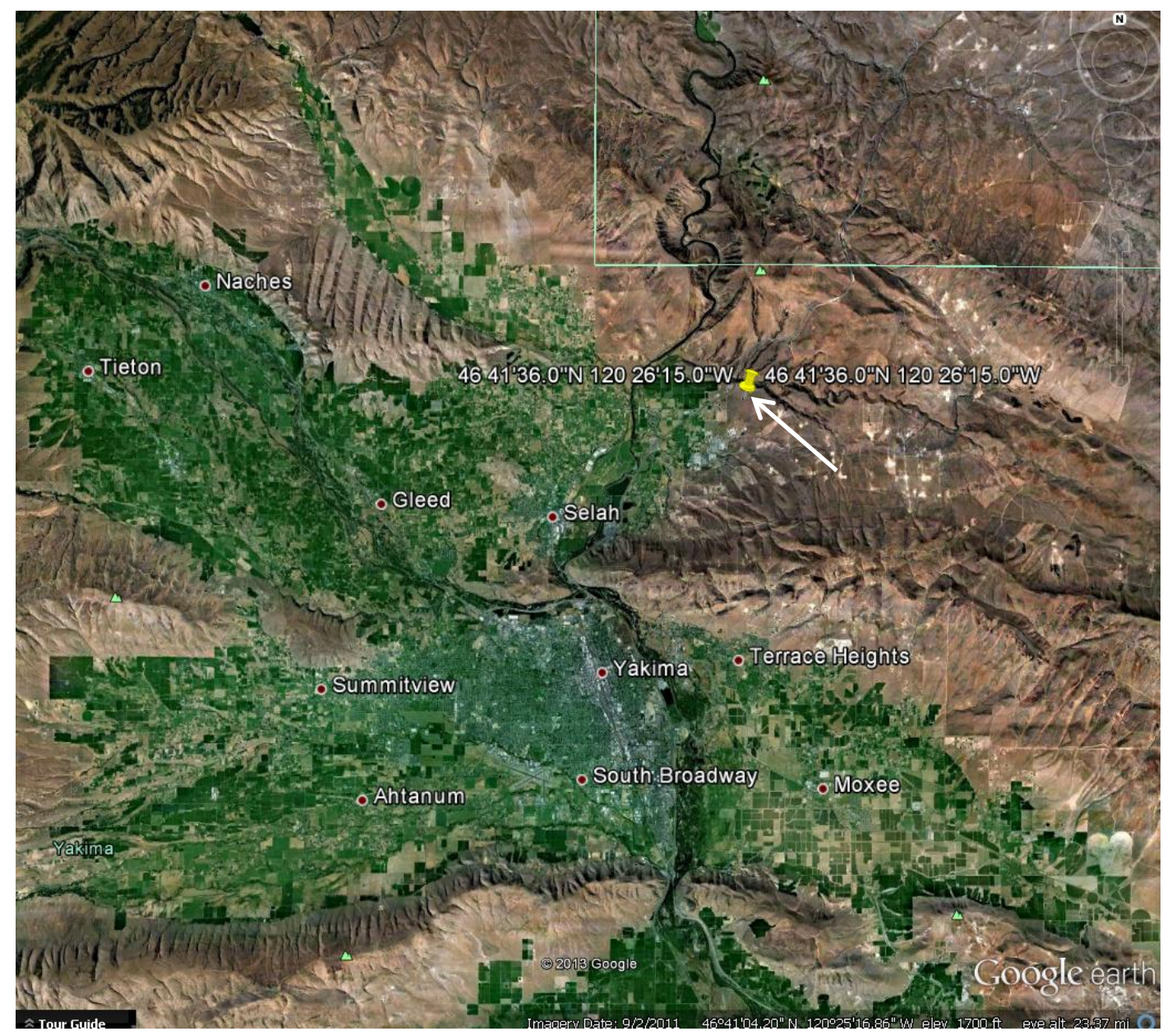

Figure 3.3 Yakima Training Center sampling location (Google Earth).

At each of the installations, sites were selected with as little prior disturbance as possible. The sites may have been utilized for training activities in the past, but all site locations had been undisturbed for an extended period of time, with plentiful natural vegetation regrowth for the climatic conditions at the site. Figure-8 patterns were staked out for each replication at each of the installations. Three replications were staked out for each vehicle/soil combination at each site. Three levels of trafficking intensity were conducted on each replication with samples being taken after each pass intensity level as well before any testing to determine initial conditions. Before testing, soil core samples were taken from each plot location to determine soil texture. Table 3.3 shows the initial temporal soil properties from the sampling locations. 
Table 3.3 Initial temporal soil properties for experiment locations.

\begin{tabular}{|c|c|c|c|c|c|c|c|c|c|c|c|}
\hline Site & Soil Texture & $\begin{array}{l}\text { Sand } \\
(\%)\end{array}$ & $\begin{array}{l}\text { Silt } \\
(\%)\end{array}$ & $\begin{array}{l}\text { Clay } \\
(\%)\end{array}$ & $\begin{array}{l}\text { OM } \\
(\%)\end{array}$ & $\begin{array}{c}\mathrm{CaCO}_{3} \\
(\%)\end{array}$ & $\begin{array}{c}\text { CEC } \\
(\mathrm{meq} / \mathbf{1 0 0 g})\end{array}$ & $\begin{array}{r}\text { IWC } \\
(\%)\end{array}$ & $\begin{array}{c}\text { IBD } \\
\left(\mathrm{g} \mathrm{cm}^{-2}\right)\end{array}$ & $\begin{array}{c}\text { OWC } \\
(\%)\end{array}$ & $\begin{array}{c}\text { PD } \\
\left(\mathrm{g} \mathrm{cm}^{-2}\right)\end{array}$ \\
\hline \multirow{2}{*}{ Fort Riley } & silt loam & 10.2 & 75.5 & 14.3 & 4.0 & 3.2 & 2.26 & 16.2 & 1.27 & 20.5 & 1.60 \\
\hline & $\begin{array}{l}\text { silty clay } \\
\text { loam }\end{array}$ & 7.9 & 67.9 & 24.3 & 4.1 & 5.0 & 2.90 & 19.4 & 1.22 & 23.5 & 1.51 \\
\hline Fort Benning & loamy sand & 87.7 & 9.5 & 2.8 & 0.9 & 5.2 & 0.25 & 2.2 & 1.47 & 8.6 & 1.82 \\
\hline $\begin{array}{l}\text { Yakima } \\
\text { Training } \\
\text { Center }\end{array}$ & loam & 51.3 & 43.8 & 4.9 & 2.1 & 5.0 & 1.37 & 1.3 & 1.30 & 17.0 & 1.65 \\
\hline
\end{tabular}

$\mathrm{OM}$ is Organic Matter, $\mathrm{CaCO}_{3}$ is Calcium Carbonate, CEC is Cation Exchange Capacity, IWC is Initial Water Content at time of sampling, IBD is Initial Bulk Density, OWC is Optimum Water Content at Proctor Density and PD is Proctor Density.

At the Fort Riley location, two soil texture classes, along with two distinct vehicle types, were used for testing. With three replications for each combination, 12 total "figure- 8 " patterns were traversed (Figure 3.4). On each figure-8 pattern, samples were collected on the outside curve, inside curve and the straight section of the track pattern after three increasing levels of trafficking passes (Figure 3.4). For tracked vehicle testing, 1, 5 and 10 passes were used for the trafficking intensity levels. Because the wheeled vehicle caused significantly less disturbance to the soil surface, 10, 25 and 50 passes were used with this vehicle. Figure 3.5 summarizes the sampling scheme at the three sampling locations. Note that the numbers highlighted in red indicate the randomization of the sampling locations within the curved and straight sections of the figure- 8 plots. 


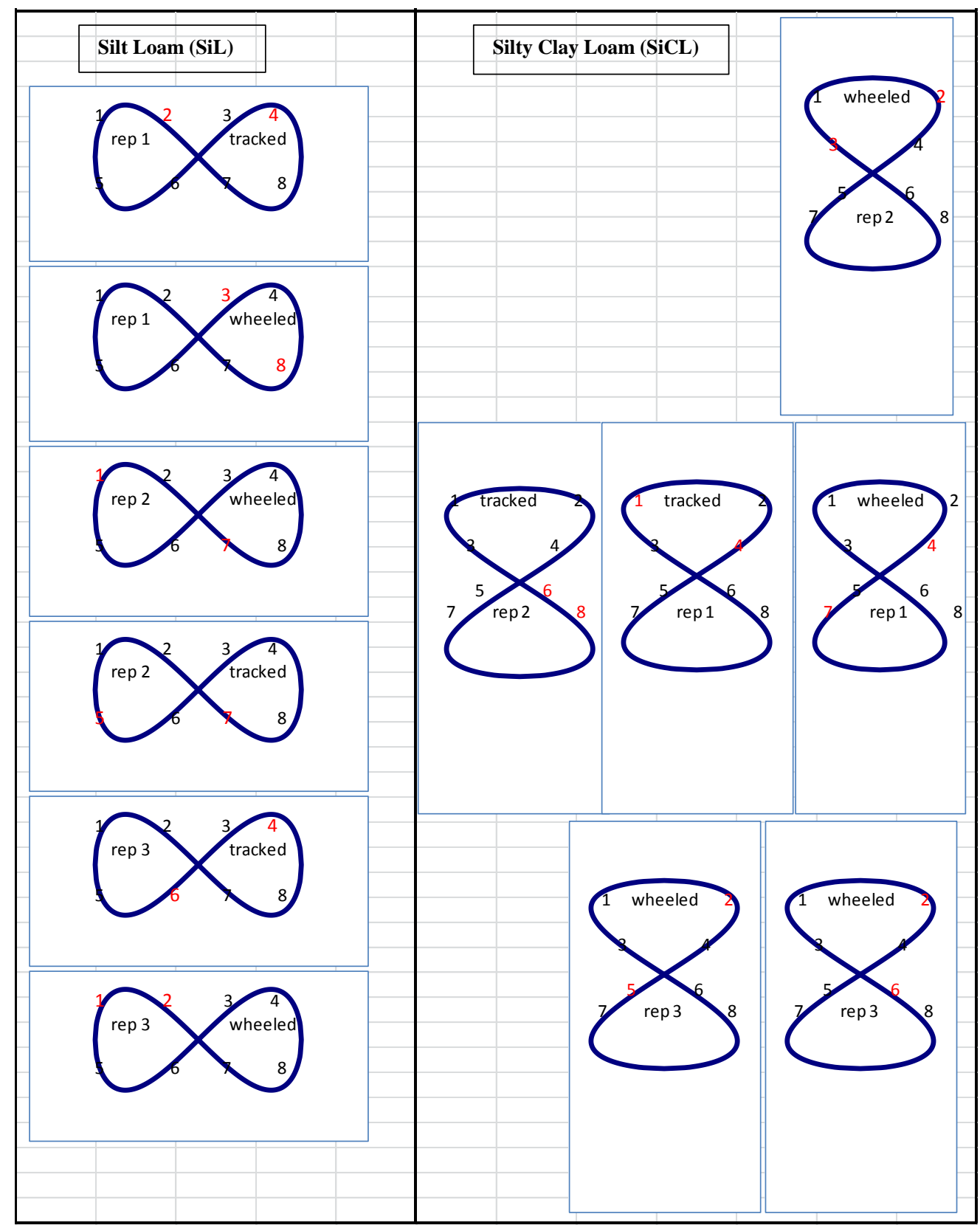

Figure 3.4 Layout of Fort Riley figure-8 plots.

A similar figure-8 pattern technique was used at the Fort Benning and Yakima Training Center locations. Due to vehicle and personnel availability, slightly different testing was conducted at the three sites (Figure 3.5). At Fort Benning, a loamy sand soil was identified on all replication sites. A tracked vehicle (M1A1 tank) was used that was nearly identical to the vehicle at Fort Riley with 1, 5 and 10 passes being used. The wheeled vehicle available at Fort Benning was similar to the HMMWV at Fort Riley but had extensive modifications to add armor 
and additional capabilities to the vehicle. Because of the modifications, this vehicle was about $600 \mathrm{~kg}$ heavier than the one used at Fort Riley. Pass levels of 10, 25 and 50 were used for this vehicle. Three replications were used for each vehicle/pass treatment.

At Yakima Training Center, a loam soil texture was identified on all replication plots (Figure 3.5). At this site, a tracked vehicle was not available, so a large wheeled fire water vehicle (filled to capacity with water) was used with pass levels of 2, 10 and 20 passes. The wheeled vehicle was a HMMWV similar to that used at Fort Riley with pass levels of 10, 25 and 50 passes. Figure 3.5 shows a hierarchy indicating the sampling parameters used during the collection phase of the experiment.

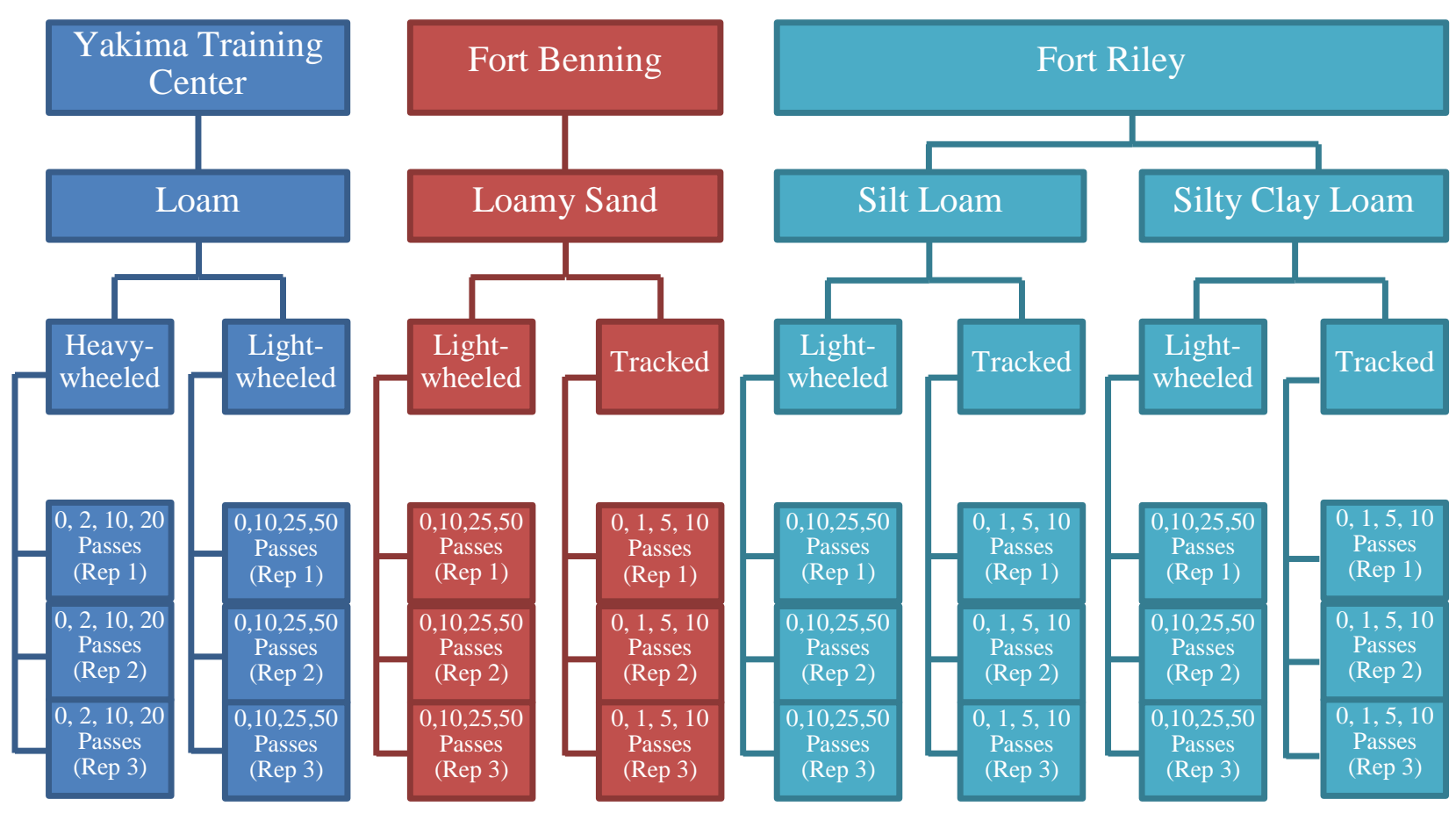

Figure 3.5 Sampling hierarchy.

\subsection{Field Testing of Soil Properties}

At the three military installations, soil samples were collected initially prior to testing, as well as after a series of treatments by off-road military vehicle maneuvering. The soil samples were collected on the outside curve, inside curve and straight sections on a figure- 8 pattern traversed by all vehicles as shown in Figure 3.6. Similar samples were collected after a series of increasing numbers of passes with three replications for each treatment. 


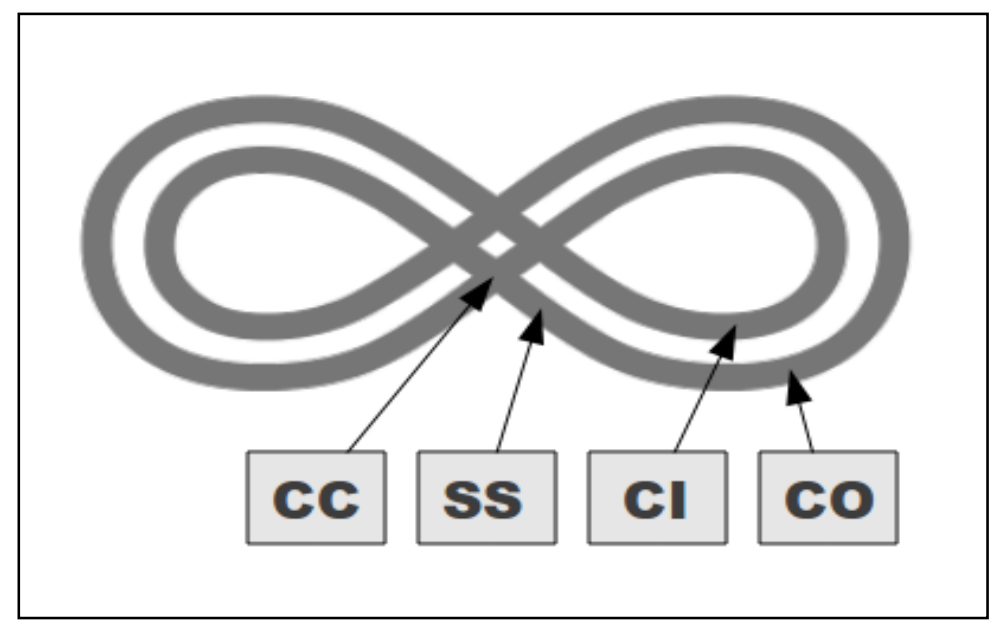

Figure 3.6 Sample figure-8 plot showing sample locations.

*CC is Center Cross, SS is Straight Section, CI is Curve Inside and CO is Curve Outside

At each sample location, the top layer of soil was collected in a specially built tray for later testing in a laboratory wind tunnel. Additionally, soil moisture cores were taken for the top 5,10 and $15 \mathrm{~cm}$ of soil. A sample was also taken from each treatment site for laboratory analysis of aggregate size distribution. This included taking approximately $5 \mathrm{~kg}$ of soil from the surface and running it through a series of sieve screen sizes in a rotary sieve explained by Lyles et al. (1970). This technique was used to determine the size distribution of aggregates. The fraction of soil aggregates $<0.84 \mathrm{~mm}$ is typically considered the wind erodible fraction (Chepil, 1958; Kohake et al., 2010). Samples were also collected for determination of bulk density after each replication.

\subsubsection{PI-SWERL Field Sampling}

At each sampling location (SS, CI and CO) where a wind tunnel tray sample was collected, a measurement was also taken with the PI-SWERL (Figure 3.7). The measurement was taken in close proximity to the tray locations to allow for possible correlation between the two different methods for determining dust emissions. The PI-SWERL instrument is explained in detail in Section 2.4.1. This instrument was used for field testing to determine loose PM emissions in the field at the time of testing. The PI-SWERL uses a rotating high-speed annular ring and a DustTrak ${ }^{\mathrm{TM}}$ monitor to determine emissions as a result of the shear stress caused by the spinning ring. 


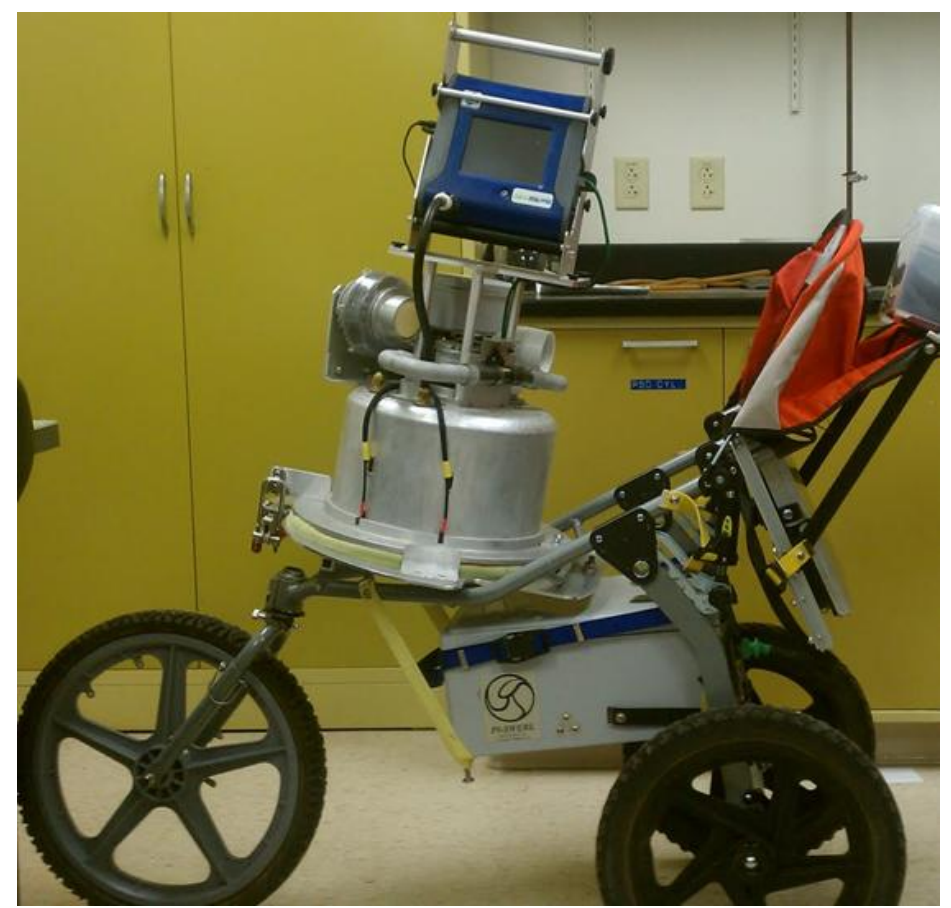

Figure 3.7 Portable In-Situ Wind Erosion Laboratory (PI-SWERL).

The PI-SWERL is instrumented with a DustTrak ${ }^{\mathrm{TM}}$ monitor that uses $90^{\circ}$ light scattering technology to determine particle concentration (Figure 3.8). During field testing, a size-selective inlet $(<10 \mu \mathrm{m})$ was used to ensure only particles smaller than $10 \mu \mathrm{m}$ in diameter were included in the sampling analysis.

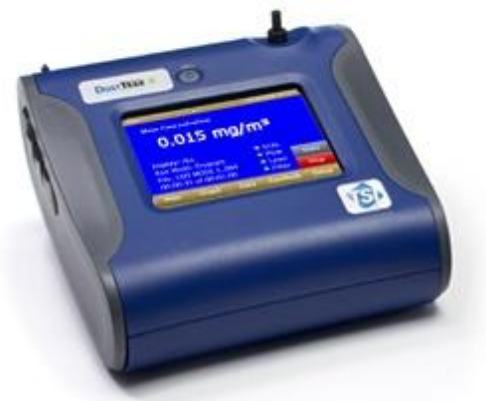

Figure 3.8 DustTrak ${ }^{\mathrm{TM}}$ II 8531 portable aerosol photometer (DustTrak ${ }^{\mathrm{TM}}$ monitor).

The PI-SWERL allows the user to select the testing scheme to be used with such variables as test duration and rotational speed of the annular ring. For all Fort Riley tests, a ramp-style test leading to a maximum of 4000 RPM was selected based on previous experiments 
conducted by researchers at the Desert Research Institute (Etyemezian et al., 2007). PI-SWERL measurements were taken at all locations where wind-tunnel tray samples were collected. A ramp-style test was used to simulate 3 different surface shear stress values that roughly correlate to three increasing wind speeds. After the initial 60-second cleanout period, the spinning ring was first increased from 0 to 2000 RPM over a 60-second interval. It was then held at this speed for 60 seconds before being increased to 3000 RPM over the next 60 seconds. This sequence was continued through 4000 RPM before the test end. After being held for 60 seconds at 4000 RPM, the rotation was quickly stopped but the test continues for several seconds as a cleanout period before ending the test.

At the Fort Benning and Yakima sites, this same testing scheme was not adequate for accurate measurement of the soil surface. Because of the very fine texture and minimal aggregation of the surface, significantly higher quantity of PM was generated at these two sites. At Fort Benning, the DustTrak ${ }^{\mathrm{TM}}$ monitor quickly reached its upper sampling limit of $400 \mathrm{mgm}^{-3}$ for particles $<10 \mu \mathrm{m}$. Because of this, the sampling scheme used on the PI-SWERL was set to a lower time and maximum angular velocity of the annular ring as necessary to prevent overloading the DustTrak ${ }^{\mathrm{TM}}$ monitor at Yakima Training Center. This change in testing parameters made it more difficult to directly compare the PI-SWERL data among the various sites as well as to the wind tunnel tray tests.

\subsection{Laboratory Wind-Tunnel Testing}

Soil tray samples, as described above, were collected from Fort Riley, Fort Benning and Yakima Training Center experimental plot sites. These trays were subjected to several tests in a laboratory wind tunnel to measure dust emission potential, total loose erodible material and saltation losses from the soil.

\subsubsection{Wind Tunnel Tray Collection}

The top $6 \mathrm{~cm}$ of the soil surface was carefully removed from a $122 \times 20 \mathrm{~cm}$ area for each sample location. Samples were removed with a flat-bottom shovel and placed into trays (Figure 3.9). Samples were collected and placed into trays with as little disturbance as possible to closely represent actual field surfaces. These trays allowed consistent samples to be collected and also aided in ease of transportation, storage and testing. The trays were retrieved from the field and stored on closely spaced shelving in a trailer for transport from the field site to the 
laboratory with minimum disturbance during transportation. The trays were then stored at the USDA-ARS Wind Erosion Laboratory, Manhattan, KS.

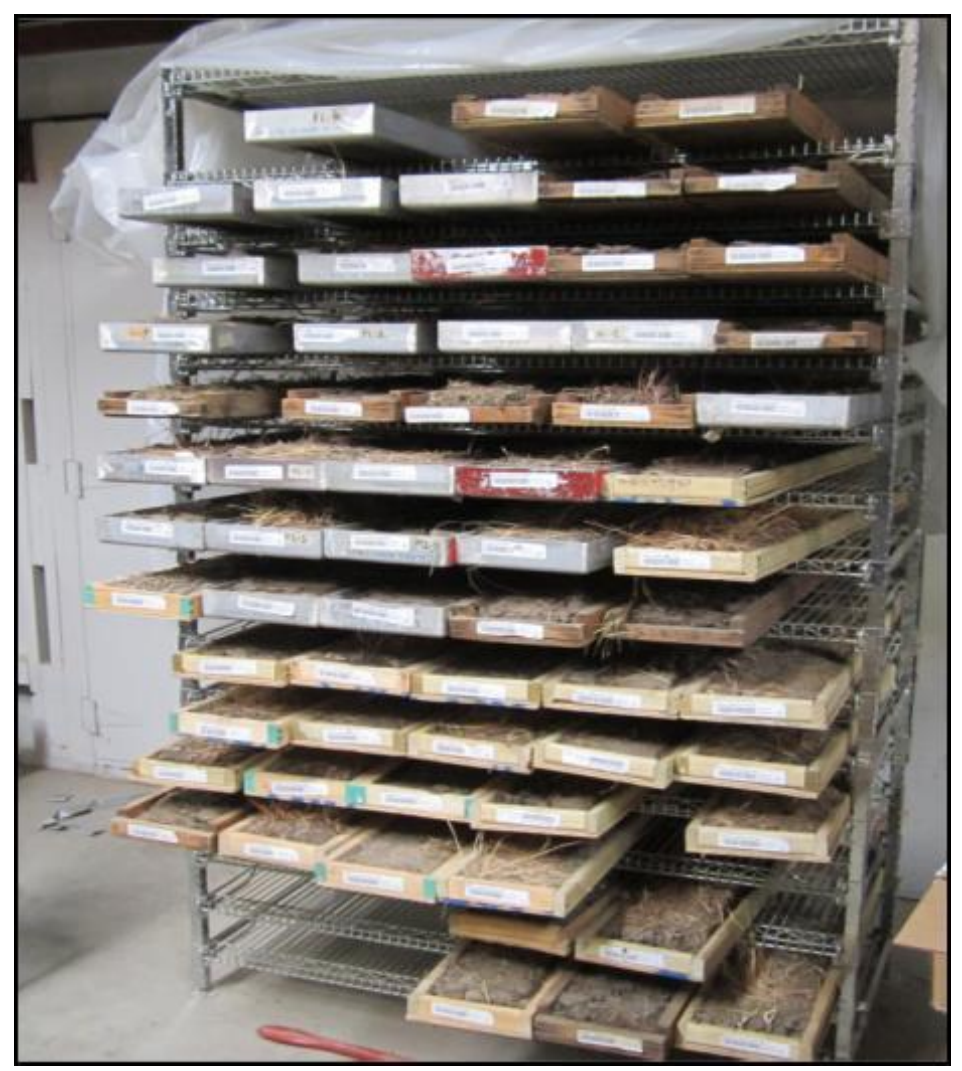

Figure 3.9 Wind tunnel tray storage.

\subsubsection{Wind Tunnel Testing Instrumentation}

A vertically integrated, slot-style sampler (Figure 3.10), developed by Mirzamostafa et al. (1998), was used for wind tunnel testing of soil erosion. The primary advantage of this sampler is that it can operate isokinetically at various wind speeds. The isokinetic conditions ensure the sampler does not interfere with the movement of the flowing air stream and allows accurate measurement of particulate emissions. The sampler has a 5-mm wide slot for particles to enter into the system. The system also contains a cyclonic design within the inside so larger sized particles are deposited into a catch pan located underneath the sampler. This sampler was an integral part of the wind tunnel tray experiments and allowed dust emissions of both suspension and saltation size ranges to be captured and measured. 


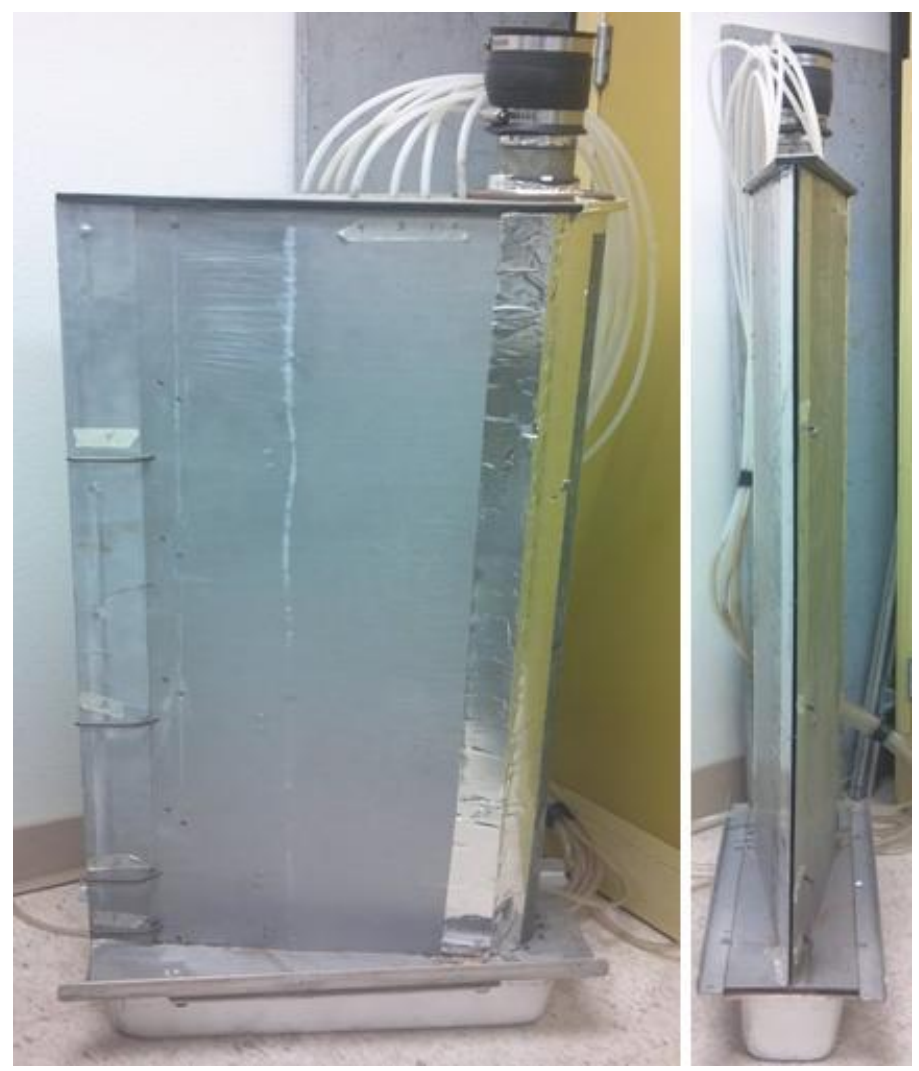

Figure 3.10 Slot-style sampler.

The concentrations of emitted particles from the trays were measured with a GRIMM aerosol spectrometer (Model 1.108, GRIMM Aerosol Technik GmbH \& Co) (Figure 3.11), herein referred to as GRIMM spectrometer. This spectrometer draws air at $1.2 \mathrm{~L} / \mathrm{min}$ past a lightscattering laser diode source. Using the principle of light scattering, particulate concentration for 15 distinct size distribution classes ranging from $>0.3 \mu \mathrm{m}$ to $>20 \mu \mathrm{m}$ were measured.

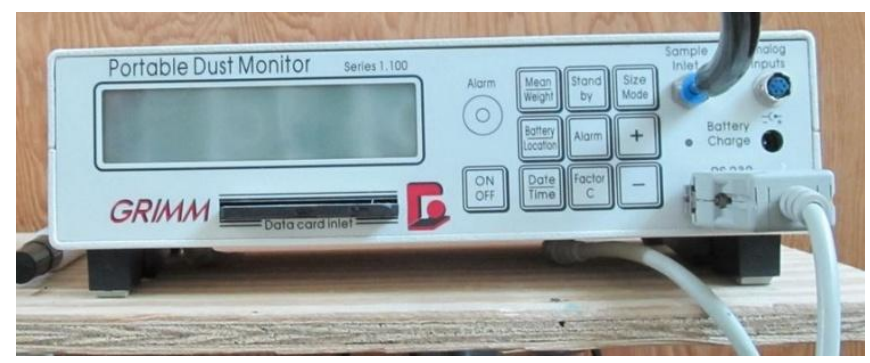

Figure 3.11 GRIMM model 1.108 aerosol spectrometer (GRIMM spectrometer). 
During wind-tunnel testing, humidity and temperature were measured in real time using temperature/humidity sensor (Model HMP 110, Vaisala) (Figure 3.12). This sensor utilizes a thin-film capacitive sensor. This instrument maintains accuracy in many environments including heavy dust loading, which made the instrument ideal for wind tunnel testing. The humidity and temperature were used in real-time to calculate the air density at the time of each test.

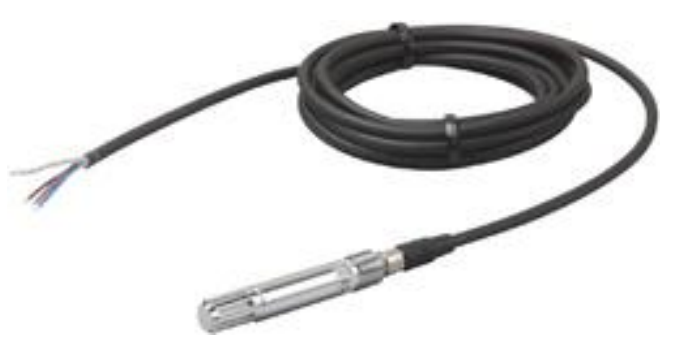

Figure 3.12 Vaisala HMP 110 temperature and humidity sensor.

Barometric pressure was measured with a barometric sensor (Model PTB-110, Vaisala) (Figure 3.13). This instrument uses a silicon capacitive sensor to directly measure ambient atmospheric pressure and converts the reading into a DC voltage signal. The barometric pressure was used in determining air density, which was subsequently used in calculating wind velocity within the tunnel.

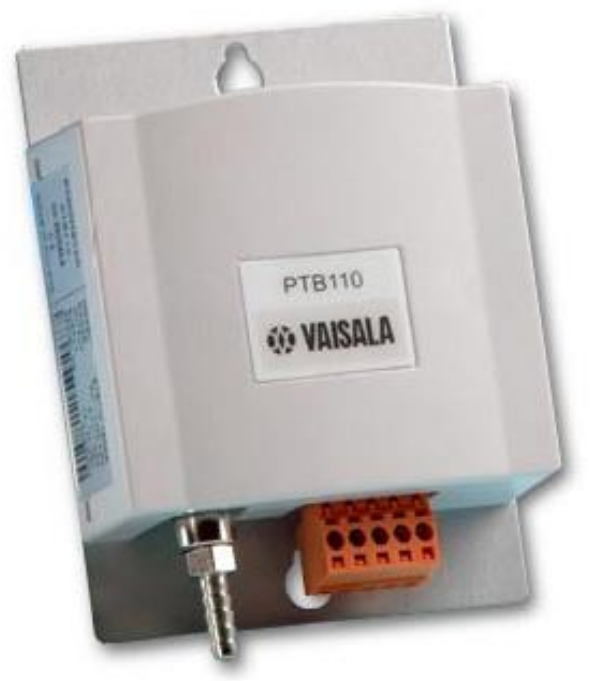

Figure 3.13 Vaisala PTB-110 electronic barometer. 
A low differential pressure transducer (Model 264, Setra Systems) (Figure 3.14) was used for pitot tube measurements as well as for a slot sampler (Figure 3.10). This instrument uses a capacitive element to convert pressure differential across the two ports into a DC voltage signal. It is temperature compensated. Additionally, the pressure within the slot style sampler was maintained at isokinetic conditions and was continuously monitored using the Setra transducers.

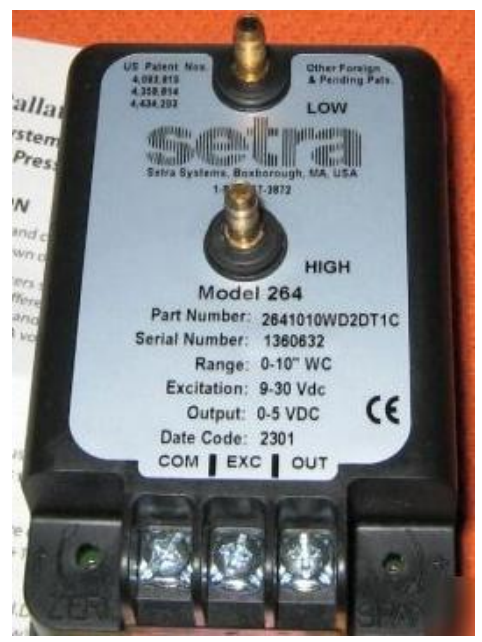

Figure 3.14 Setra model 264 differential pressure transducer.

A data acquisition system (DAS-3036, Measurement Computing Inc.) was used for analog-to-digital conversion of the temperature, humidity, barometer and pressure transducers. This device allowed readouts from the instrumentation to be directly input into a PC in real time. The measurements were directly input into a software program developed for the wind tunnel testing. This model has 16 single-ended independent analog-to-digital channels that can be read at $200 \mathrm{kS} / \mathrm{s}$.

Two high-volume sampling pumps were used during laboratory wind tunnel testing of the soil samples. These pumps were used to create a negative pressure within the slot-sampler system (Figure 3.10). The pumps were fitted with screen mesh apparatus to hold a filter (borosilicate glass fiber, 203 x $254 \mathrm{~mm}, 1 \mu \mathrm{m}$ pore size) for mass based emissions measurements from each test. The pumps were voltage adjusted to ensure flow within the sampling system was equivalent to the moving air stream within the wind tunnel during each test. The pressure was monitored in real time using a software program and pressure transducers (Figure 3.14). 


\subsubsection{Wind Tunnel Experimental Setup}

Figures 3.15 and 3.16 show a schematic of the wind tunnel. The tunnel is a $(12.2 \times 1.2 \mathrm{x}$ 1.5) $\mathrm{m}$, push-type laboratory wind tunnel. In the upwind portion of the tunnel, directly after the fan, is a screen followed by a honeycomb structure. This setup has been shown to decrease both lateral and longitudinal turbulence (Rae and Pope, 1984). Directly after the honeycomb structure are spires extending upward from the floor surface. The spires are used to generate turbulence near the floor which serves to slightly increase the initial boundary layer. Pea-sized gravel was sieved to a size range of 5 to $7 \mathrm{~mm}$ and applied to the entire length of the tunnel floor. The gravel was used to simulate roughness conditions more similar to the soil surface than the smooth plywood tunnel floor. The roughness provided boundary layer conditions within the air stream that better replicate those found in actual field conditions (Kohake et al., 2010; Hagen, 1999).

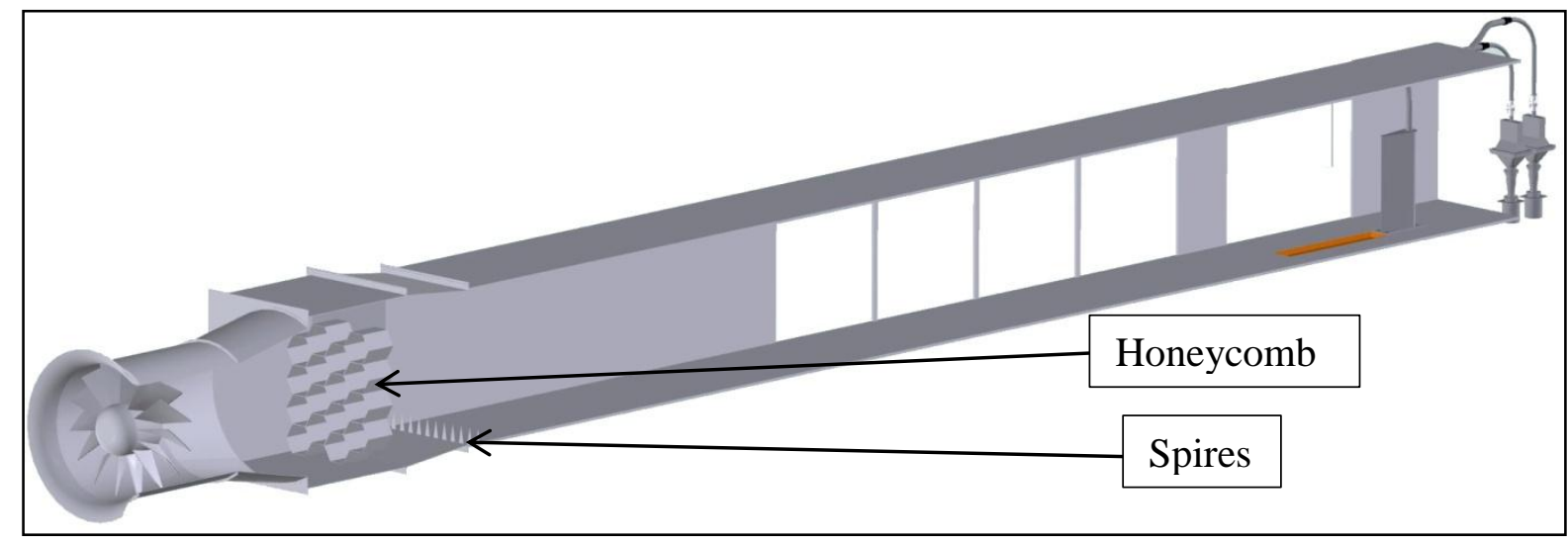

Figure 3.15 Schematic of the wind tunnel showing upstream flow conditioning elements.

Soil trays collected at the test sites were placed evenly with the wind tunnel floor directly upwind of the slot-style sampler. Two high-volume sampling pumps were attached to the slotstyle sampler using $63.5 \mathrm{~mm}$ galvanized metal tubing. The pumps generated negative pressure within the slot sampler to ensure isokinetic sampling conditions. The pressure within the sampler was adjusted until pressure equalized between the tunnel air flow and directly inside the slot sampler. Four pressure measurements were taken from static pressure tubes located at equal heights both inside and outside of the sampler during all tests. 
Total suspended PM was collected on 203 x $254 \mathrm{~mm}$ glass fiber filters located near the inlet of the sampling pumps. Filters were weighed before and after testing to determine the weight of collected PM emitted during testing. The filters were humidity conditioned in a chamber calibrated to $40 \%$ relative humidity that was maintained with a sulfuric acid solution. Filters were conditioned for a minimum of 24 hours before taking initial weights as well as for another 24-hour minimum period before taking final mass readings. The concept for this type of sampling system was adopted from a design described in a previous study by Stetler et al. (1997). Figure 3.16 shows a scaled model of the sampling system used within the wind tunnel.

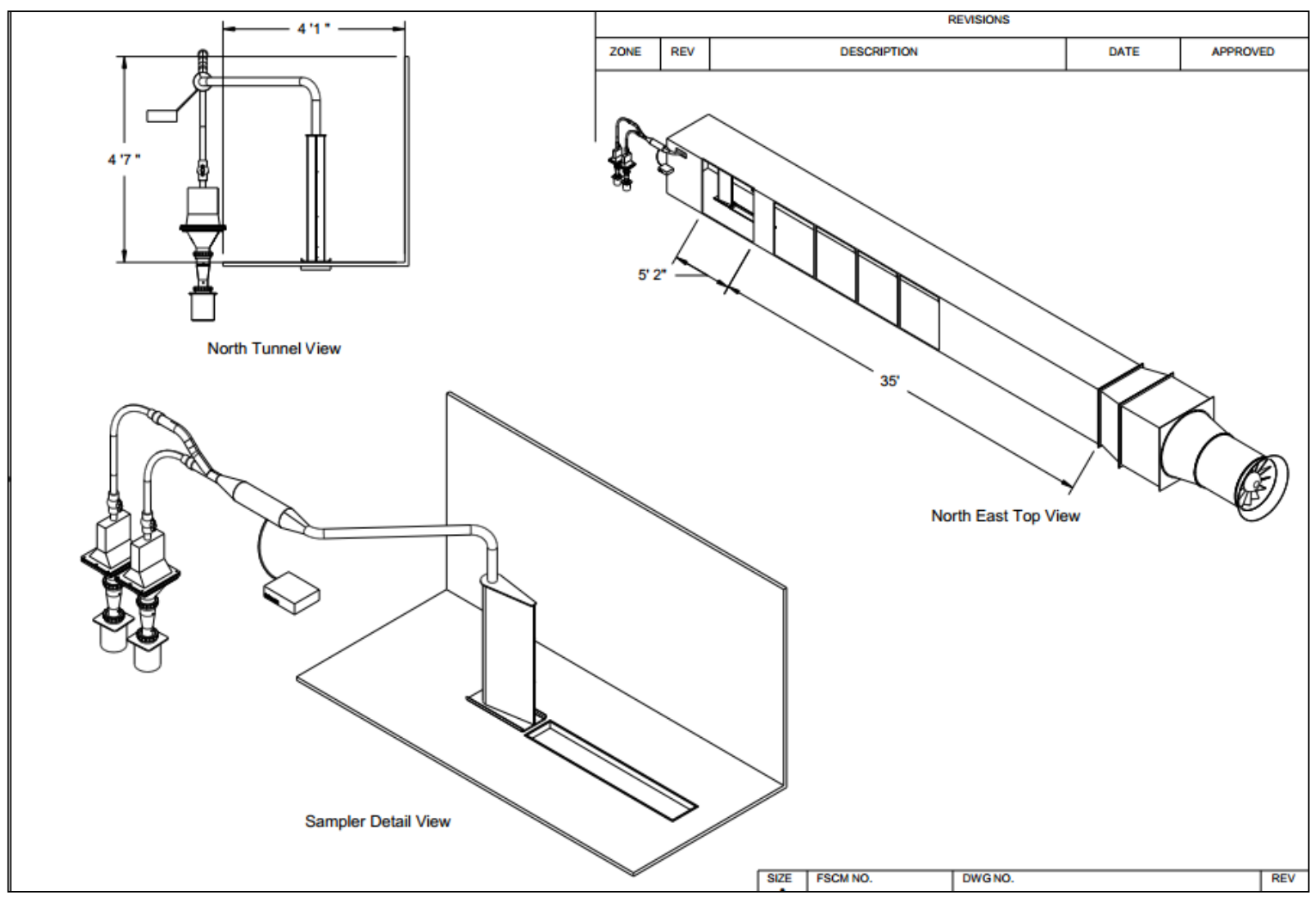

Figure 3.16 Schematic of wind tunnel setup.

A sub-sample of the sampler air stream was also obtained for analysis of PM emissions by the GRIMM spectrometer. The sub-sample allowed for a real-time view of the dust concentrations during testing. The subsample also allowed for determining the particle size distribution of the emissions from each tray.

During wind tunnel testing it was important to monitor the centerline wind velocity with the wind tunnel. In order to accomplish this, a pitot tube was used in conjunction with a pressure 
transducer (Model 264, Setra Systems, Inc.), which had a pressure measurement range of 0 to 1 in. $\mathrm{H}_{2} \mathrm{O}$ and corresponding voltage output of 1 to 5 VDC. The transducer was supplied with factory calibration curves. Figure 3.17 shows a calibration curve relating output voltage to pressure differential.

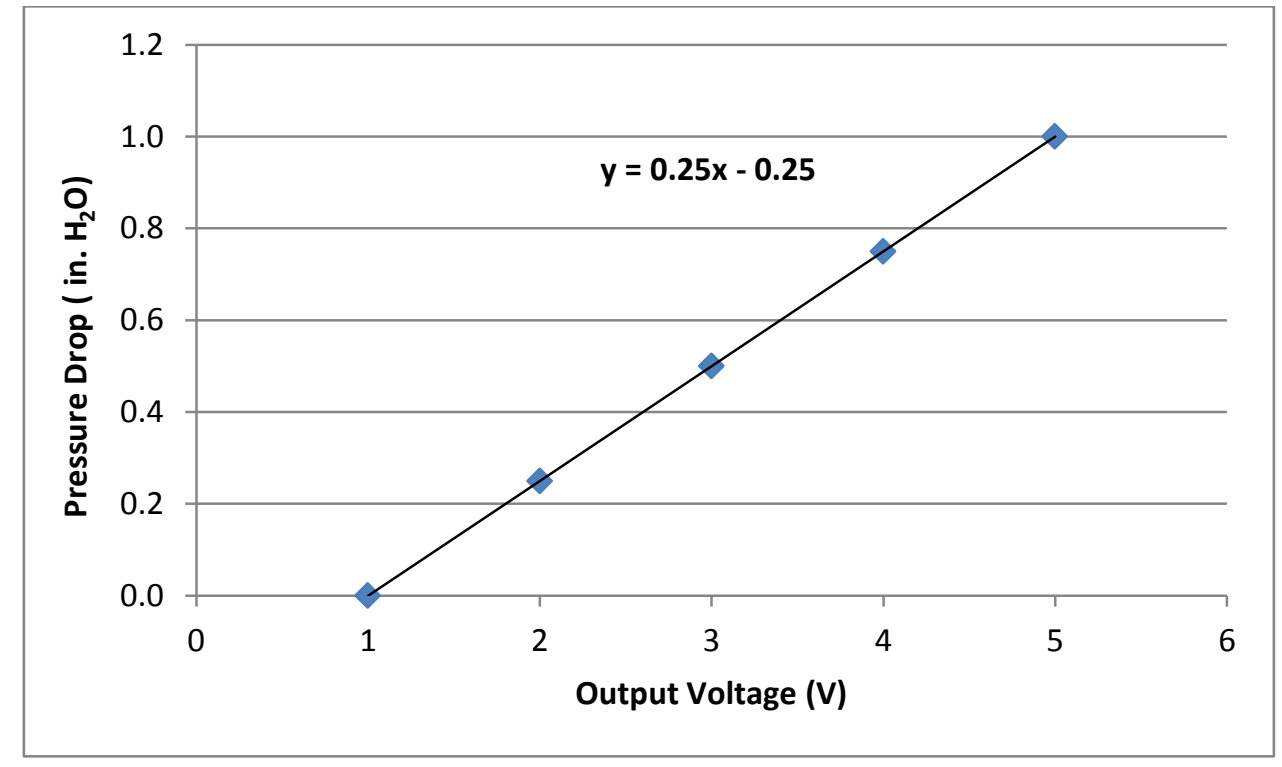

Figure 3.17 Pressure transducer calibration.

The pressure transducer was connected to a PC-based data acquisition card (DAS-6036, Measurement Computing Inc.). This card allowed the data from the pressure transducers to be read into a specially designed software program developed with National Instruments' LabVIEW 2011 software. Pitot tubes were also used during an initial calibration period to develop a velocity profile within the tunnel.

Temperature and relative humidity were recorded at 1-second interval using a capacitivetype electronic humidity sensor (HUMICAP HMP 110, Vaisala). Additionally, barometric pressure was measured and recorded using a micromechanical electronic pressure sensor (BAROCAP PTB110, Vaisala). Measurements were used for determining the air density at the time of testing. The air density was calculated in real-time and used in conjunction with the differential pressure measured across the pitot tubes to determine air velocity at various heights throughout the entire wind tunnel testing procedure. Equation 3.1 was used for calculating air velocity with the pitot tube pressure measurements (NASA, 2010). 


$$
V=\sqrt{\left[\frac{2\left(P_{2}-P_{1}\right)}{\rho}\right]}
$$

where:

$$
\begin{array}{ll}
\mathrm{V} & =\text { air velocity }\left(\mathrm{m} \mathrm{s}^{-1}\right) \\
P_{2}-P_{1} & =\text { differential pressure across pitot tube }(\mathrm{Pa}) \\
\rho & =\text { air density }\left(\mathrm{kg} \mathrm{m}^{-3}\right)
\end{array}
$$

The air density was calculated using (Picard et al., 2008):

$$
\rho=\left[\frac{P_{d}}{R_{d} * T}+\frac{P_{v}}{R_{v} * T}\right]=\left[\frac{\left(P_{t}-\phi * P_{s a t}\right)}{R_{d} * T}+\frac{\phi * P_{s a t}}{R_{v} * T}\right]
$$

where:

$$
\begin{array}{ll}
\mathrm{P}_{\text {sat }} & =\text { saturation vapor pressure of water }(\mathrm{Pa})=\left\{610.78 * 10\left(\frac{7.5 T-2048.625}{T-35.85}\right)\right\} \\
\mathrm{P}_{\mathrm{t}} & =\text { observed total pressure }(\mathrm{Pa}) \\
\rho & =\text { air density }\left(\mathrm{kg} \mathrm{m}^{-3}\right) \\
\mathrm{R}_{\mathrm{d}} & =\text { gas constant for dry air }=287 \mathrm{~J} \mathrm{~kg}^{-1} \mathrm{~K}^{-1} \\
\mathrm{R}_{\mathrm{v}} & =\text { gas constant for water vapor }=461.5 \mathrm{~J} \mathrm{~kg}^{-1} \mathrm{~K}^{-1} \\
\mathrm{~T} & =\text { temperature }(\mathrm{K}) \\
\mathrm{P}_{\mathrm{v}} & =\text { partial pressure of water vapor in air }(\mathrm{Pa}) \\
\mathrm{P}_{\mathrm{d}} & =\text { partial pressure of dry air }(\mathrm{Pa}) \\
\Phi & =\text { relative humidity }(\%)
\end{array}
$$

The environmental sensors used during experiments interfaced with a 100-pin analog-todigital terminal board that was connected to a PC through a PCI interface data acquisition card (PCI-DAS 6036, Measurement Computing). This board can acquire data from up to 16 separate analog input channels at approximately $10 \mathrm{kHz}$ per channel. The converted digital data values were input into the specially designed program developed in National Instruments' LabVIEW 2011 software. This software eliminated the need for data loggers that have traditionally been used in wind tunnel studies. The graphical interface allowed for sensor readings to be viewed in real-time to detect errors and make any required adjustments quickly. The LabVIEW interface allowed computations in real time. This enabled the ability for wind dynamics, static pressure drop across the slot-sampler and many other variables to be viewed in real time. Table 3.4 shows a summary of the instruments used during wind tunnel testing. 
Table 3.4 Wind tunnel testing instruments.

\begin{tabular}{|l|l|c|}
\hline \multicolumn{1}{|c|}{ Parameter } & \multicolumn{1}{|c|}{ Instrument } & Sampling Frequency \\
\hline Dust Concentration/Size Distribution & GRIMM Spectrometer & 6 seconds \\
\hline Relative Humidity & Vaisala HMP 110 & 1 second \\
\hline Air Temperature & Vaisala HMP 110 & 1 second \\
\hline Barometric Pressure & Vaisala PTB 110 & 1 second \\
\hline Wind Speed & Setra Model 264 & 1 second \\
\hline Dust Emissions & Isokinetic Slot Sampler & Continuous \\
\hline
\end{tabular}

\subsubsection{Wind Tunnel Tray Preparation}

The soil samples collected at the Fort Riley site had high clay content and were highly aggregated, and thus are generally not highly susceptible to wind erosion. This is in contrast to the soils collected from the other two sites, which had very little aggregation and higher fractions of erodible material. Because of the soil texture, the Fort Riley trays were subject to breakage of the surface as the samples were collected. Large cracks existed due to the length of the shovel used to sample the soil being shorter than the actual length of the tray, as well as the shrinkage of the clay from the natural air drying of the soils. A solution was devised to fill in the cracks to create a more uniform and natural surface that would not trap saltation particles, especially during future sand abrasion testing. A sample of soil, taken from the same location as the tray, was oven-dried and mechanically pulverized into a uniform consistency. Distilled water was then gradually added to the oven dried pulverized soil until a thick paste consistency was achieved. The paste was carefully inserted into the large cracks within the sample tray through a small orifice. This soil paste was allowed to solidify to create a more uniform surface comparable to actual field conditions. Figure 3.18 displays a tray after the filling procedure was completed. 


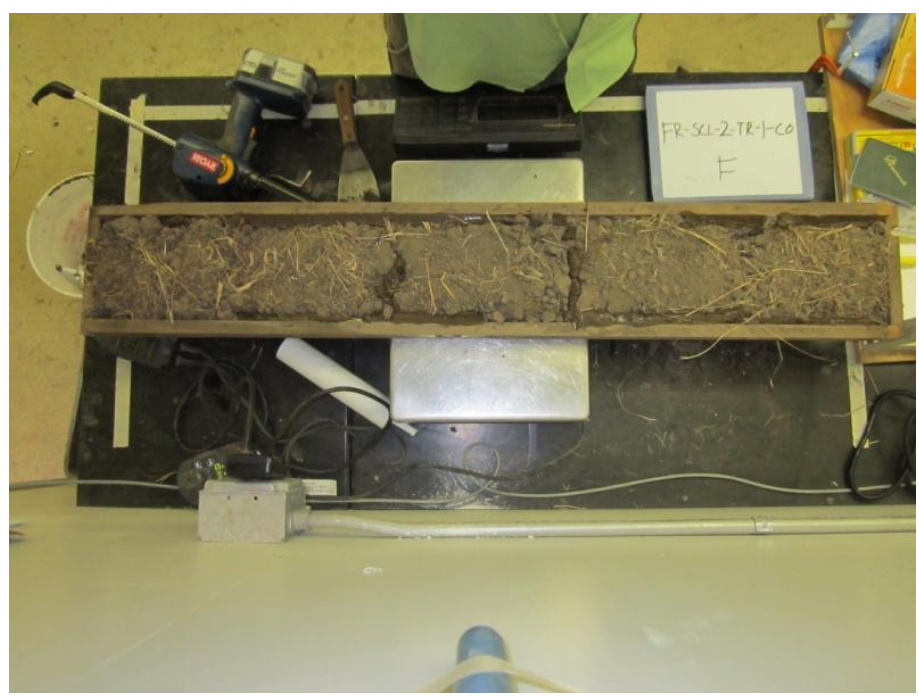

Figure 3.18 Fort Riley tray sample after filling procedure.

This hardened soil paste technique was non-erodible compared to the natural surface. The dried paste did not contribute significantly to any emissions during any tests. The surface area taken up by the soil paste was small compared with the tray, and was less than $10 \%$ as determined by image analysis.

\subsubsection{Wind Tunnel Tray Testing Procedure}

All wind tunnel trays were weighed immediately before and after wind tunnel testing. Additionally, trays were scanned with a laser scanning setup to determine surface roughness of each tray (Figure 3.19). After weighing and scanning, the trays were placed evenly with the wind tunnel floor directly upwind of the vertically integrated slot sampler. The wind tunnel has been outfitted with a cutout in the tunnel floor of the same dimension as the trays. Additionally, floor-mounted hydraulic jacks were located directly underneath to allow the trays to be inserted and lowered to a level even with the wind tunnel floor. 


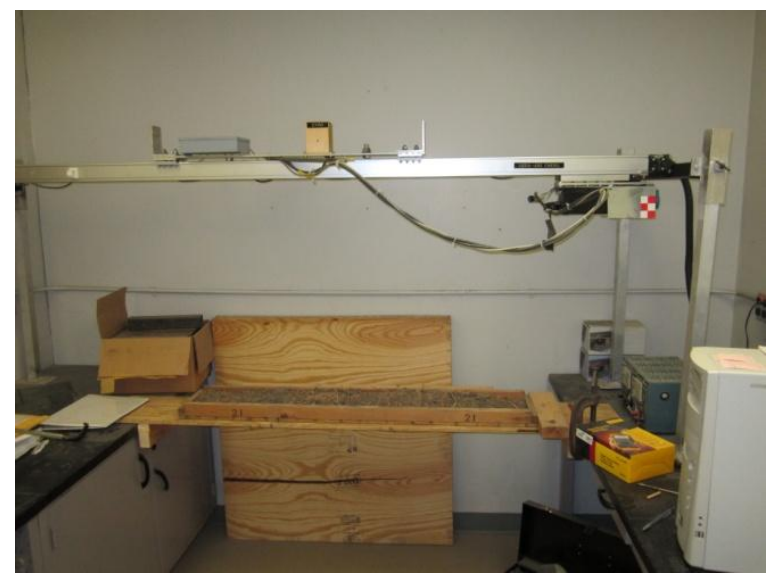

Figure 3.19 Surface roughness laser scanner.

Because surface roughness plays an important role in erodibility of soils, it was necessary to not only consider the wind velocity but also the friction velocity. This measurement gives a measurement of the physical interaction between the moving air mass and the soil surface. To measure this, air velocity profiles were developed at free stream velocities of 4 and $5 \mathrm{~m} / \mathrm{s} \mathrm{using}$ pitot tube measurements at heights of 1,2,3,5, 7.5 and $10 \mathrm{~cm}$ above the tray. The collected air speed data were used to determine friction velocity and aerodynamic roughness using a best fit to the Prandtl equation:

$$
\frac{U_{z}}{U_{*}}=\frac{1}{k} \ln \frac{z}{z_{0}}
$$

where:

$$
\begin{aligned}
& \mathrm{U}_{\mathrm{z}}=\text { Air speed }\left(\mathrm{m} \mathrm{s}^{-1}\right) \text { at height } \mathrm{z}(\mathrm{m}) \\
& \mathrm{k}=\text { von Karman constant }(0.4) \\
& \mathrm{z}_{0}=\text { Aerodynamic roughness height }(\mathrm{m})
\end{aligned}
$$

After the velocity profile testing was completed for a given tray, the air speed was increased to approximately $14 \mathrm{~m} / \mathrm{s}$. Kohake et al. (2010) determined that this speed will ensure all loose erodible material is fully removed. This speed is also near the maximum limit of the laboratory wind tunnel. This velocity was maintained for 5 minutes during emission testing. 
To determine the amount of loose erodible material removed from the surface of the trays, two high-volume sampling pumps were connected to a specially designed slot-style sampler. The slot sampler was outfitted with four static pressure tubes at equal heights both inside and outside the sampler in order to monitor pressure differential during testing and ensure isokinetic operations. Pressure differential between the wind tunnel and inside the sampler was maintained at or very near 0 during all testing. Figure 3.20 shows a schematic of the sampling train configuration.

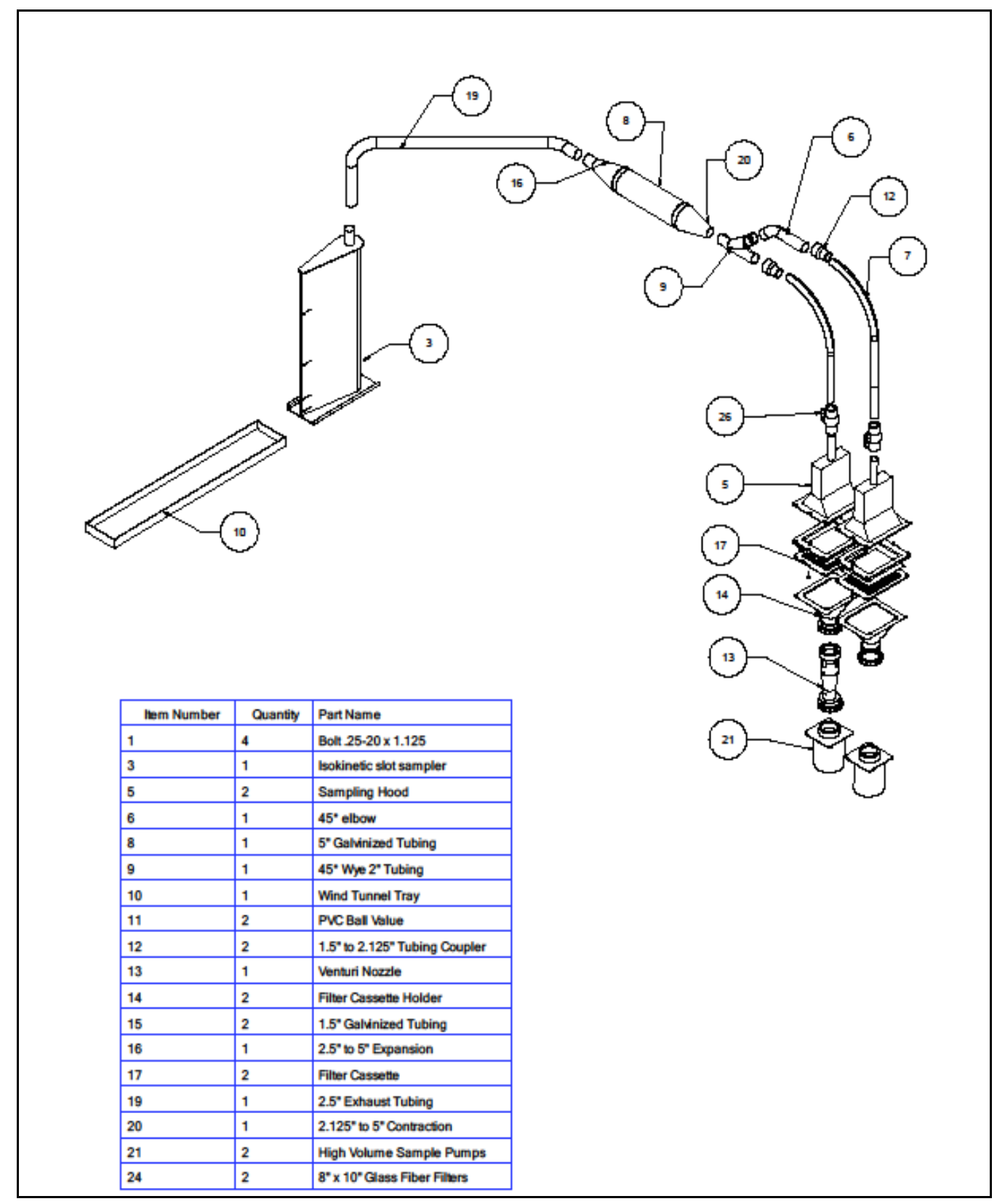

Figure 3.20 Sampling train configuration for wind tunnel testing. 
When sampling PM in a moving fluid it is important to maintain isokinetic conditions. The goal of an isokinetic system is to sample from the center line of a flow to minimize wall effects (Tyree and Allen, 2004). The system developed for the wind tunnel tray testing was designed to maintain nearly isokinetic conditions for sampling emissions in a moving air stream within a wind tunnel. Two high-volume sampling pumps were used to generate a negative pressure within the sampling system in order to equalize pressure with the moving air stream. The pressure was monitored at four locations along the sampler, both inside and out, to ensure isokinetic sampling conditions. The pumps were initiated for 60 seconds prior to engaging the wind tunnel to allow a settling period for the sub-sample system as well as to obtain background particulate levels. Dust particles emitted from each test tray were collected on two glass fiber filters (located directly above the sampling pumps) for each 5-minute testing procedure. The mass of the filters was measured before and after each experimental run. The filters were humidity conditioned for a minimum of 24 hours before and after testing to minimize inaccuracies caused by water weight fluctuations on the filters. Humidity was maintained constant at $40 \%$ in a sealed chamber by a sulfuric acid solution.

A subsample was obtained by the GRIMM spectrometer from within the center of the ducting of the isokinetic sampling train shown in Figure 3.20. This sample was obtained through a sample inlet with a diameter of $4 \mathrm{~mm}$. This allowed a sample of the suspended PM to be collected and analyzed from within the slot sampler system. The ducting connecting the highvolume sampling pumps was expanded to a diameter of $13 \mathrm{~cm}$ for a $50 \mathrm{~cm}$ length. This allowed for the velocity in the duct to better match the velocity of the GRIMM spectrometer sample inlet resulting in isokinetic sampling conditions. Figure 3.21 shows an image of the inside of the ducting as well as an external view. 


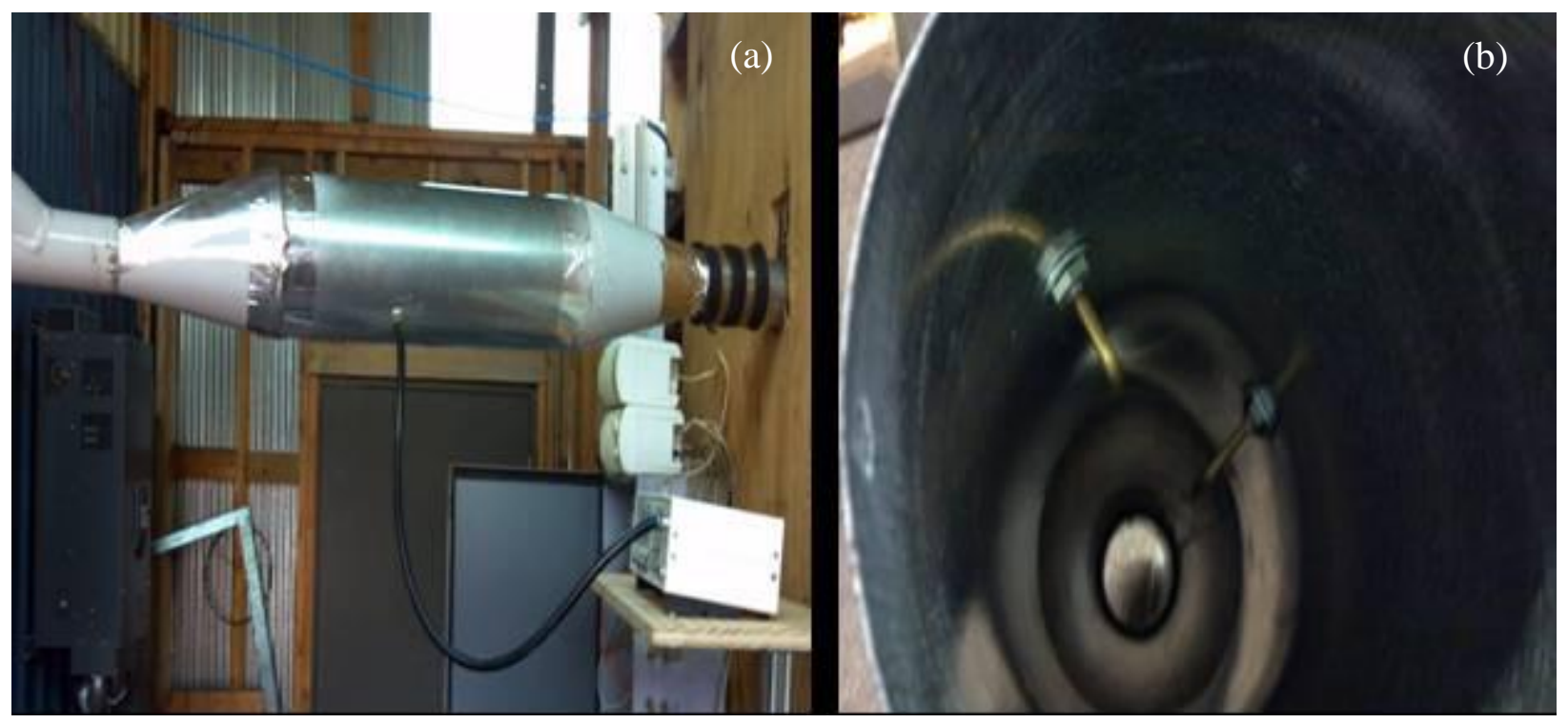

Figure 3.21 Subsample expansion outside (a) and inside (b) views.

The GRIMM spectrometer provided data for determination of 15 individual size fractions (i.e., $>0.3,>0.4,>0.5,>0.65,>0.8,>1.0,>1.6,>2.0,>3.0,>4.0,>5.0,>7.5,>10.0,>15.0$ and $>20.0 \mu \mathrm{m}$ ) of the suspended dust. This allowed for the determination of the fraction of particles in certain size ranges (i.e., $<10 \mu \mathrm{m},<2.5 \mu \mathrm{m}$ ).

\subsection{Data Analysis}

Collected data were summarized (Table 3.5) and analyzed based on a completely randomized design with split-plot and sub-sampling. Soil texture was considered the whole plot treatment factor while the number of passes was the split-plot treatment factor. Although a series of increasing passes was conducted on any given figure-8 plot, each plot/pass combination was considered separate for the data analysis. Tray samples, which were collected on the outside/inside curve (CO, CI) and straight sections (SS) within each figure-8, were considered subsamples for determining the average emissions from the entire figure- 8 plot. Each vehicle type was analyzed independently with soil texture and trafficking intensity considered as main effects. 
Table 3.5 Variables in statistical analysis.

\begin{tabular}{|l|l|c|}
\hline \multicolumn{1}{|c|}{ Parameter } & \multicolumn{1}{c|}{ Measurement Method } & Unit \\
\hline Total Dust & Gravimetric filter & $\mathrm{mg} \mathrm{m}^{-2}$ \\
\hline Total Dust & DustTrak ${ }^{\text {TM }}$ monitor & $\mathrm{mg} \mathrm{m}^{-2}$ \\
\hline Total Dust & GRIMM spectrometer & $\mathrm{mg} \mathrm{m}^{-2}$ \\
\hline Dust $<10 \mu \mathrm{m}$ & GRIMM spectrometer & $\mathrm{mg} \mathrm{m}^{-2}$ \\
\hline Dust $<2.5 \mu \mathrm{m}$ & GRIMM spectrometer & $\mathrm{mg} \mathrm{m}^{-2}$ \\
\hline Aggregates $<0.84 \mathrm{~mm}$ & $\begin{array}{l}\text { Rotary sieve separation and } \\
\text { gravimetric }\end{array}$ & $\mathrm{g} \mathrm{m}^{-2}$ \\
\hline Total Soil Loss & Gravimetric & $\mathrm{mg} \mathrm{m}^{-2}$ \\
\hline Saltation Loss & Gravimetric & \\
\hline
\end{tabular}

There were three vehicle types tested: tracked, light-wheeled and heavy-wheeled. For the wheeled vehicle testing at Fort Riley, only outside curve samples were obtained along each figure- 8 for each number of passes, with a straight section being obtained for the 50 pass at each replication. Additionally, only one initial condition sample was obtained from each replication at Fort Riley as opposed to three at the other sites. Table 3.6 shows a representation of the data points collected.

Preliminary statistical analysis on actual data values indicated non-normal distribution. As such, the analysis was performed by log-transformation of the data and a best fit to a gamma distribution. Results are presented in log-transformed estimates for the pairwise comparisons and in back-transformed values for the least squares means.

Table 3.6 Sampling matrix for all treatments.

\begin{tabular}{|l|cccc|c|ccccc|c|cccc|}
\hline \multicolumn{10}{|c|}{ TRACKED VEHICLE } & \multicolumn{5}{c|}{ HEAVY-WHEELED } \\
\hline \multicolumn{7}{|c|}{ Fort Benning } & \multicolumn{7}{c|}{ Fort Riley } & \multicolumn{5}{c|}{ Yakima Training Center } \\
\hline Loc. & 0 & 1 & 5 & 10 & Loc. & 0 & 1 & 5 & 10 & Loc. & 0 & 2 & 10 & 20 \\
\hline CO & $\mathbf{X}$ & $\mathbf{X}$ & $\mathbf{X}$ & $\mathbf{X}$ & CO & $\mathbf{X}^{\star}$ & $\mathbf{X}$ & $\mathbf{X}$ & $\mathbf{X}$ & CO & $\mathbf{X}$ & $\mathbf{X}$ & $\mathbf{X}$ & $\mathbf{X}$ \\
CI & $\mathbf{X}$ & $\mathbf{X}$ & $\mathbf{X}$ & $\mathbf{X}$ & CI & $\mathbf{X}^{\star}$ & $\mathbf{X}$ & $\mathbf{X}$ & $\mathbf{X}$ & CI & $\mathbf{X}$ & $\mathbf{X}$ & $\mathbf{X}$ & $\mathbf{X}$ \\
SS & $\mathbf{X}$ & $\mathbf{X}$ & $\mathbf{X}$ & $\mathbf{X}$ & SS & $\mathbf{X}^{\star}$ & $\mathbf{X}$ & $\mathbf{X}$ & $\mathbf{X}$ & SS & $\mathbf{X}$ & $\mathbf{X}$ & $\mathbf{X}$ & $\mathbf{X}$ \\
\hline
\end{tabular}
LIGHT-WHEELED VEHICLE

\begin{tabular}{|l|cccc|c|ccccc|c|cccc|}
\hline \multicolumn{9}{|c|}{ Fort Benning } & \multicolumn{5}{c|}{ Fort Riley } & \multicolumn{5}{c|}{ Yakima Training Center } \\
\hline Loc. & 0 & 10 & 25 & 50 & Loc. & 0 & 10 & 25 & 50 & Loc. & 0 & 10 & 25 & 50 \\
\hline CO & $\mathbf{X}$ & $\mathbf{X}$ & $\mathbf{X}$ & $\mathbf{X}$ & CO & $\mathbf{X}^{*}$ & $\mathbf{X}$ & $\mathbf{X}$ & $\mathbf{X}$ & CO & $\mathbf{X}$ & $\mathbf{X}$ & $\mathbf{X}$ & $\mathbf{X}$ \\
Cl & $\mathbf{X}$ & $\mathbf{X}$ & $\mathbf{X}$ & $\mathbf{X}$ & Cl & $\mathbf{X}^{*}$ & & & & Cl & $\mathbf{X}$ & $\mathbf{X}$ & $\mathbf{X}$ & $\mathbf{X}$ \\
SS & $\mathbf{X}$ & $\mathbf{X}$ & $\mathbf{X}$ & $\mathbf{X}$ & SS & $\mathbf{X}^{*}$ & & & $\mathbf{X}$ & SS & $\mathbf{X}$ & $\mathbf{X}$ & $\mathbf{X}$ & $\mathbf{X}$ \\
\hline
\end{tabular}

*One initial condition sample per figure-8 replication.

**Sampling locations: CO - Center Outside, CI - Curve Inside, SS - Straight Section. 


\section{Chapter 4 - Results and Discussion}

\subsection{Comparison of Measurement Techniques}

The following three measurement methods were compared in dust emission potential: (1) field measurement with the PI-SWERL that used a DustTrak ${ }^{\mathrm{TM}}$ monitor, (2) wind tunnel measurement of dust emissions using collection filters and (3) wind tunnel measurement of dust emissions using a GRIMM spectrometer.

\subsubsection{Comparison of PI-SWERL and Wind Tunnel (GRIMM Spectrometer) Tests}

In comparing the PI-SWERL (with DustTrak ${ }^{\mathrm{TM}}$ monitor) and GRIMM spectrometer, the data from each measurement method were correlated using the same unit of measure (mg dust per $\mathrm{m}^{2}$ land area). The two techniques were similar in that an optical spectrometer was used to give instantaneous dust concentration values throughout the testing procedure.

As described in Chapter 3, the PI-SWERL tests were conducted using a series of three distinct RPM levels. Published literature suggests that the RPM value can be directly correlated to a shear stress on the soil surface using Equation 4.1 (Sweeney et al., 2008). The value for $K_{R}$, a roughness correction factor, is largely based on observation of the site and can cause wide variations in the resulting friction velocity. Note that Equation 4.1 was developed using RPM values ranging from 600 to 1600, and therefore may not be applicable to all RPM values for this testing procedure, which reached as high as 5000 RPM.

$$
U_{*}=K_{R}\left(-4.7 \times 10^{-12} R P M^{3}-5.5 \times 10^{-8} R P M^{2}+5.3 \times 10^{-4} R P M+0.0165\right)
$$

where:

$\mathrm{RPM}=$ Revolutions per minute of rotating annular ring within PI-SWERL

$K_{R}=$ Correction factor for surface roughness

$\mathrm{U}_{*}=$ Peak friction velocity $\left(\mathrm{m} \mathrm{s}^{-1}\right)$

Based on the method originally described by Ling (1976), the shear stress for wind tunnel testing was determined by obtaining wind velocity profiles above the tray at various heights within the boundary layer as described in Section 3.3.3. Pitot tubes were used to obtain the air 
velocities above the trays during each test. These values were then used to determine the friction velocity $\left(\mathrm{U}_{*}\right)$, which is proportional to the shear stress, using Equation 3.3.

Using the shear stress values obtained from Equation 4.1, it was determined that the 4000 RPM testing value was most similar in shear stress to most wind tunnel tray testing procedures conducted at $14 \mathrm{~m} / \mathrm{s}$ free-stream wind speed. In addition to shear stress correlation, the two datasets were compared across the same testing duration as well. The wind tunnel was operated at a single wind speed throughout the entire testing procedure of 5 minutes. The PI-SWERL, on the other hand, was operated across three distinct RPM levels. Figure 4.1 compares the general patterns generated by each measurement method.

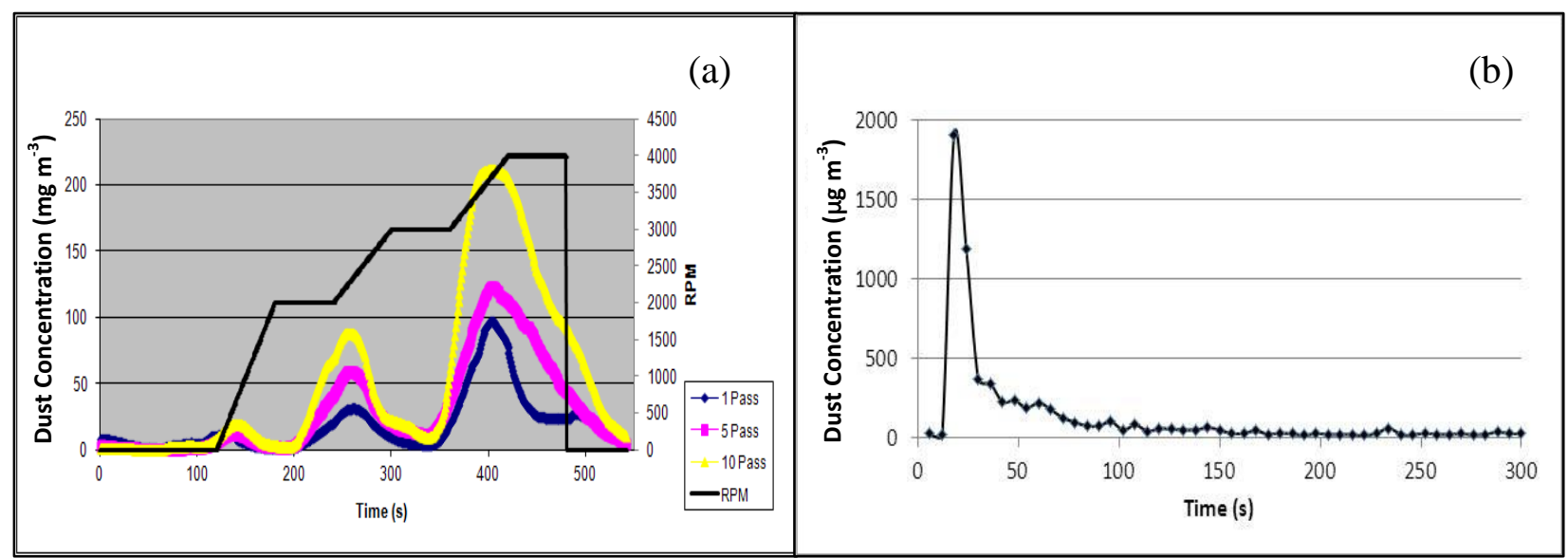

Figure 4.1 Comparison of sample dataset from (a) PI-SWERL and (b) wind tunnel (GRIMM spectrometer) tests.

As illustrated in Figure 4.1, there are three distinct peaks in dust emissions with each of the RPM levels during the PI-SWERL measurement. This is in contrast to the single peak followed by a rapid decline in emissions during wind tunnel testing. Because of the differences in testing techniques, it was decided to correlate the wind tunnel data using the same time period as the final 4000 RPM step in the PI-SWERL data. Only the first 60 seconds of GRIMM spectrometer data from the wind tunnel were utilized when comparing the two data sets. Additionally, the total mass from each of the three ramp sets was summed and divided over the 60 -second interval of the final step.

Note that the two techniques differed in active soil surface areas, defined as the soil surface area where the measured emissions originated. The PI-SWERL has an active surface 
area of $0.035 \mathrm{~m}^{2}$, which has been established through empirical evidence. The active area of the wind tunnel trays and slot-sampler setup has not been well documented. For this study, the active area was assumed to be $0.0061 \mathrm{~m}^{2}$, which was determined by multiplying the length of the trays $(1.22 \mathrm{~m})$ by the width of the slot sampler opening $(0.005 \mathrm{~m})$. The final emissions values were compared using total dust emission potential value $\left(\mathrm{mg} \mathrm{m}^{-2}\right)$.

The PI-SWERL has been shown to correlate well with emissions data obtained by outdoor wind tunnel measurements (Sweeney et al., 2008). However, during this study the two techniques showed little or no correlation (Figure 4.2). Several possible explanations may exist for the lack of correlation. One is the high degree of variability associated with measuring emissions from soil surfaces in a dynamic environment. Another possible explanation is the water content of the soils in the field differed from those of the trays, as the trays were allowed to air dry for an extended period of time in a laboratory before testing. Finally, and perhaps most important, the two techniques utilize different mechanisms to initiate dust emissions from the soil surface. Specifically, the PI-SWERL uses an annular ring to simulate shear stress within the chamber of the instrument. The spinning ring can cause saltation-sized material ricocheting off of surfaces within the chamber and/or accumulating on the outer edge of the instrument creating much different conditions than a wind tunnel (Sweeney et al., 2008). 


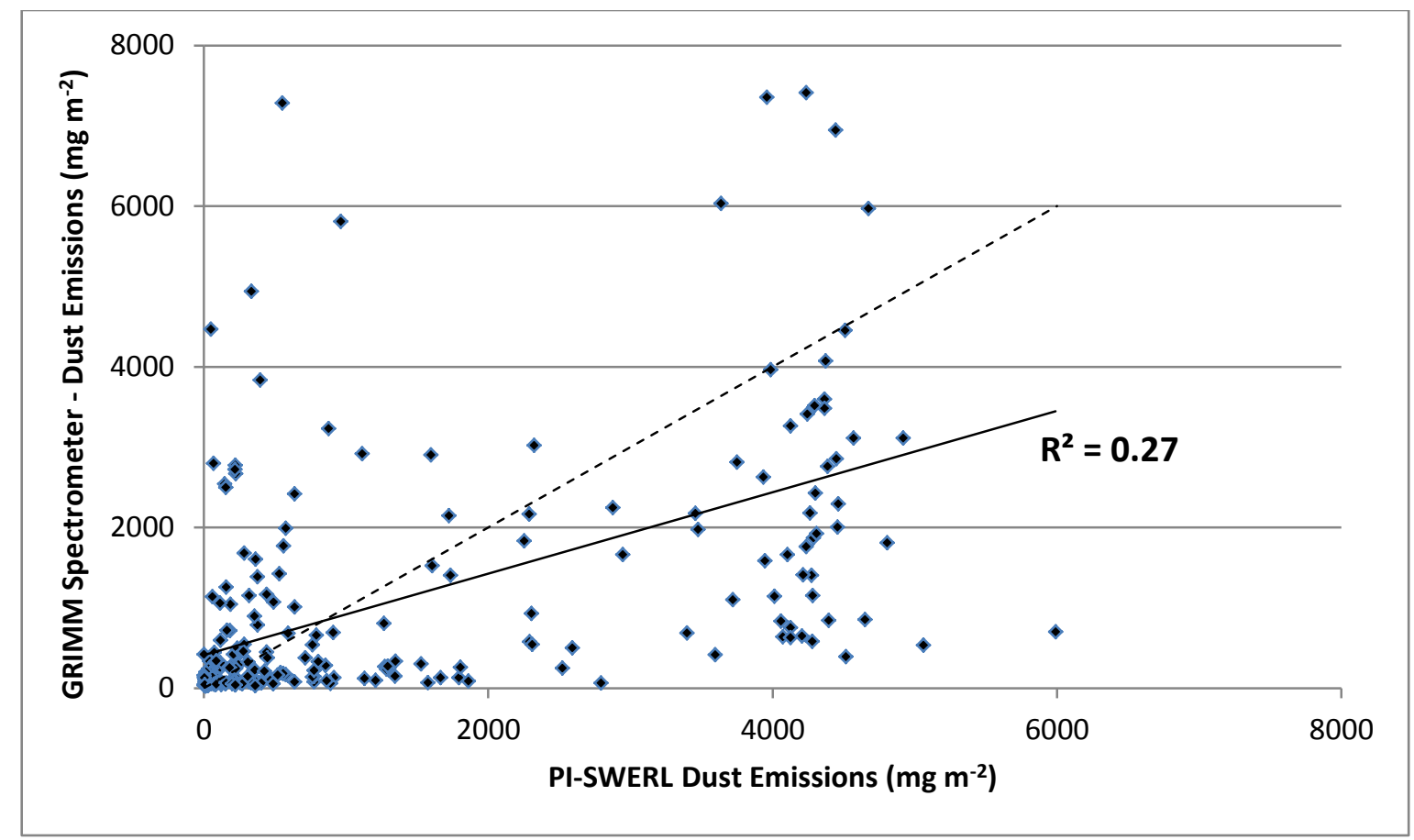

Figure 4.2 Correlation of wind tunnel (with GRIMM spectrometer) and PI-SWERL (with DustTrak $^{\mathrm{TM}}$ monitor) tests - all sites. The solid line represents the least-squares regression line, while dashed line represents 1:1 correspondence.

Figure 4.3 shows the correlation between the PI-SWERL (with DustTrak ${ }^{\mathrm{TM}}$ monitor) and GRIMM spectrometer measurements for the Fort Riley site. This site exhibited very low correlation between the two measurement techniques $\left(\mathrm{R}^{2}=0.15\right)$. Note, however, that this site also had the lowest dust emission potential of the three sites. Another important consideration is that the tray samples were stored over a period of time before testing, whereas the PI-SWERL measurements were performed on-site at the time of testing. The Fort Riley soils were also high in clay content compared with the other soil types. 


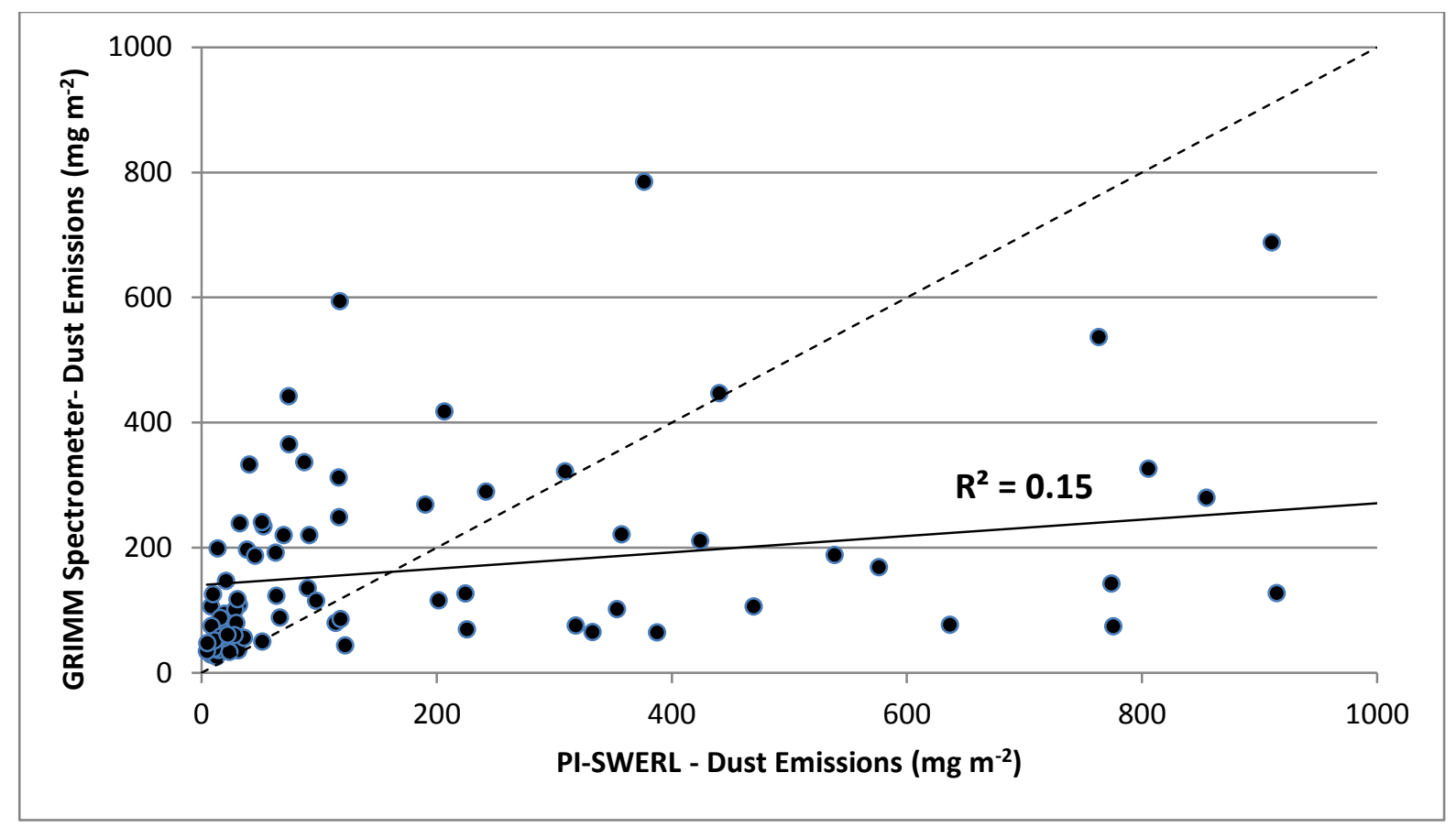

Figure 4.3 Correlation of wind tunnel (with GRIMM spectrometer) and PI-SWERL (with Dust Trak $^{\mathrm{TM}}$ monitor) tests - Fort Riley. The solid line represents the least-squares regression line, while dashed line represents 1:1 correspondence.

Another possible limitation of comparing these two methods can be explained using Figure 4.4. During Fort Riley emissions testing, the RPM profile chosen for the PI-SWERL was determined to be adequate for testing emissions. However, this RPM profile was not applicable for all sites. From Figure 4.4, a large number of the PI-SWERL data points from Fort Benning were clustered around $4000 \mathrm{mg} \mathrm{m}^{-2}$. This was due to the higher erodibility of the soil at this location in conjunction with limitations of the DustTrak ${ }^{\mathrm{TM}}$ monitor on the PI-SWERL. For majority of each test, the spectrometer was operating at or close to its upper limit. Figure 4.5 shows a sample dataset showing the experimental error experienced at Fort Benning. Surprisingly, the correlation was higher at Fort Benning than at Fort Riley. 


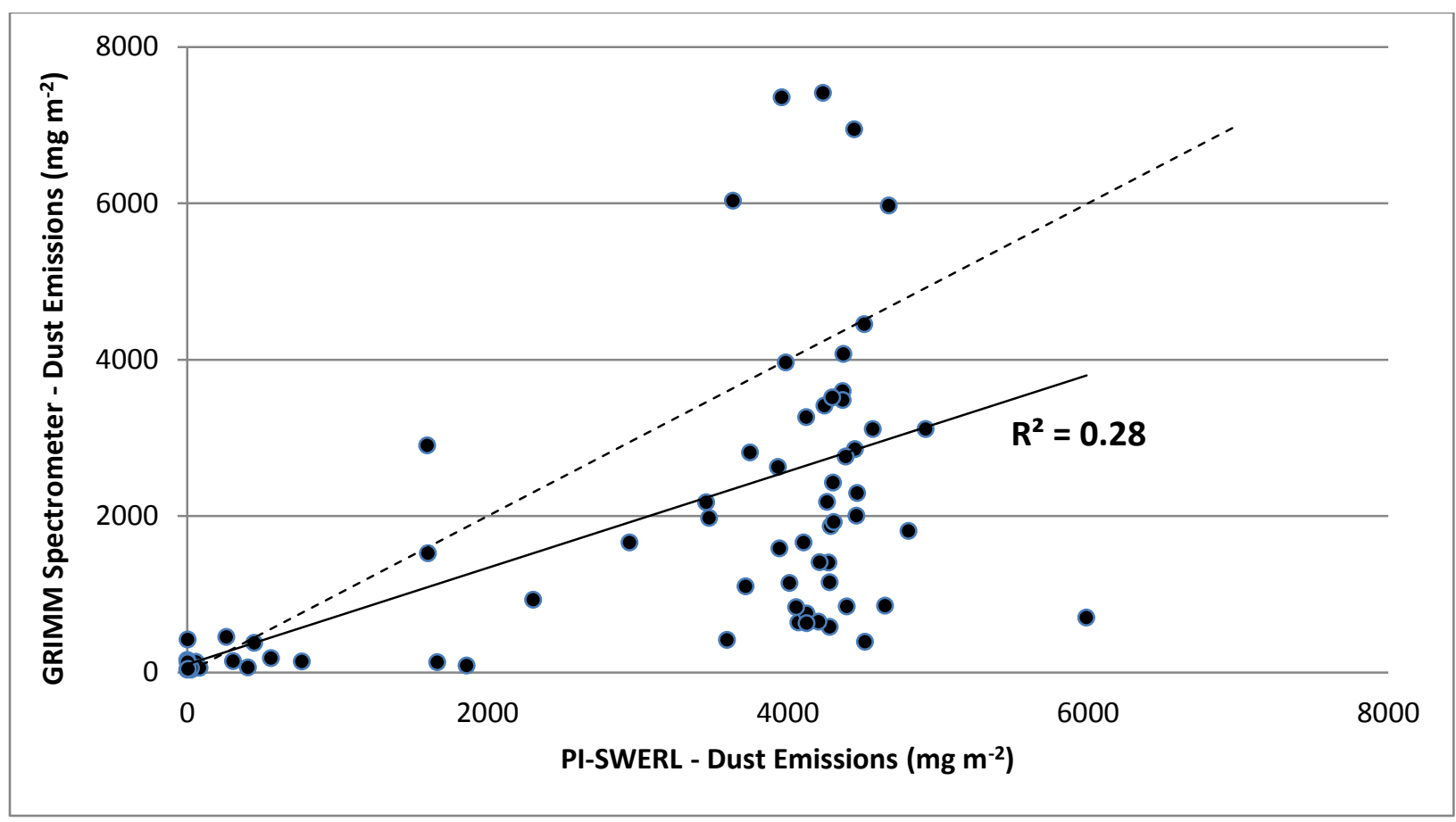

Figure 4.4 Correlation of wind tunnel (with GRIMM spectrometer) and PI-SWERL (with

DustTrak ${ }^{\mathrm{TM}}$ monitor) tests - Fort Benning. The solid line represents the least-squares regression line, while dashed line represents $1: 1$ correspondence.

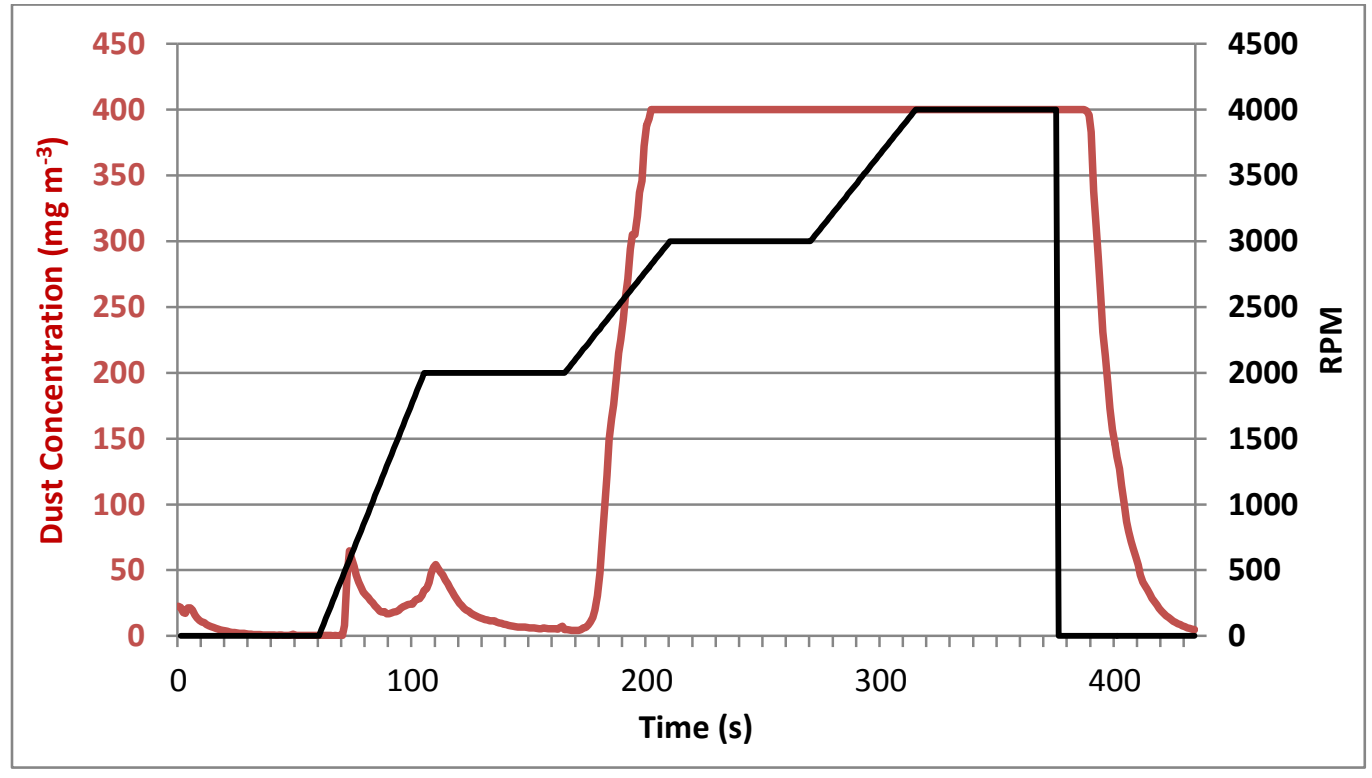

Figure 4.5 Sample PI-SWERL dataset - Fort Benning. 


\subsubsection{Comparison of Wind Tunnel Emissions Measurements}

In addition to comparing the PI-SWERL results to the wind tunnel (GRIMM spectrometer) tests, the wind tunnel testing used two methods of determining dust emissions that were also compared. The first method was gravimetric analysis of total dust captured on glass fiber filters. Total dust weight was divided by the active surface area of the soil tray sample $\left(0.0061 \mathrm{~m}^{2}\right)$. The second method involved the GRIMM spectrometer that measured a subsample of the air stream being collected on the filters. Figure 4.6 shows relatively good correlation between the two methods. Additionally, the filter data showed much higher emission values than the spectrometer. One possible explanation for this is due to particles larger than suspension sized dust being captured on the filters. Observation at the time of testing confirmed that significantly large sand-sized particles were being captured, but further analysis should be conducted. Another possible explanation for the differences is the sub-sample inlet not capturing a true representation of the suspended PM within the entire duct system. It was assumed that the PM was evenly distributed within the ducting, but this was not verified through any type of testing. Due to the differences between the two techniques, emissions data were primarily analyzed using the GRIMM spectrometer datasets as it more closely represented what was actually observed during testing.

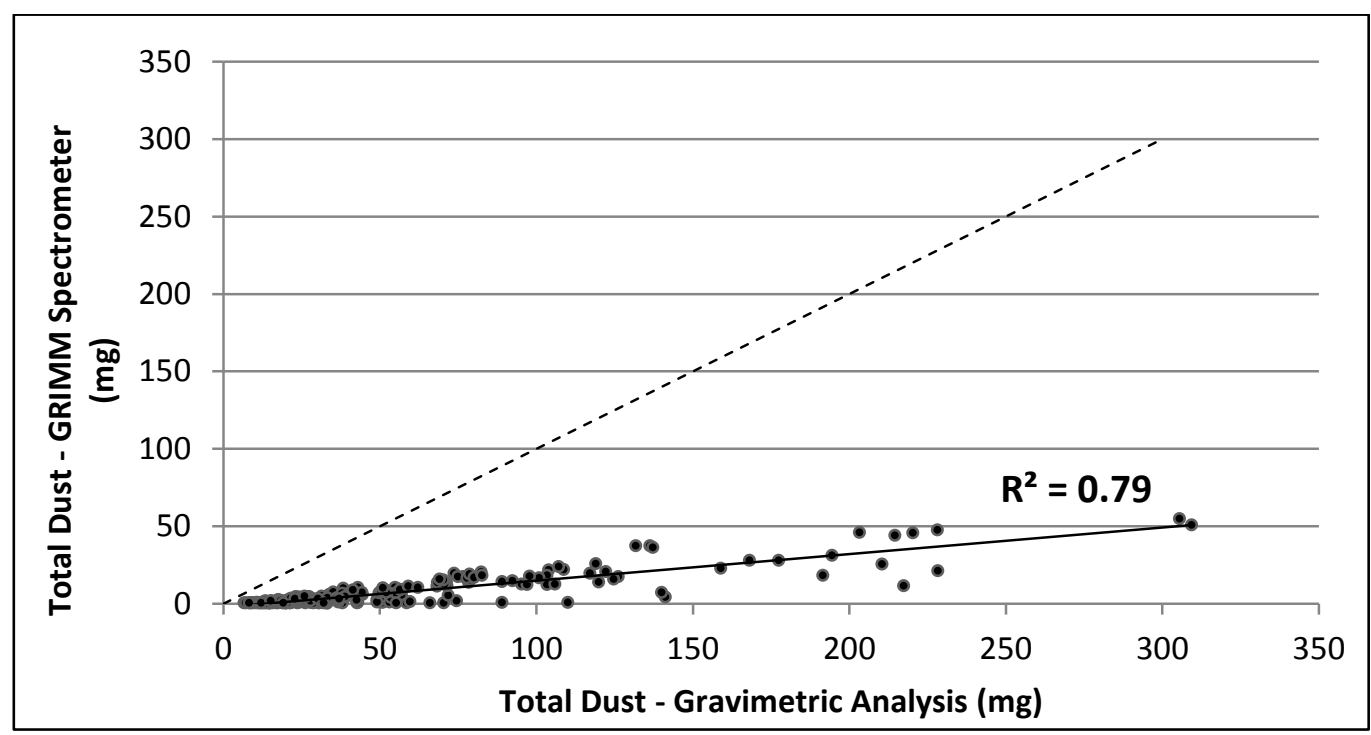

Figure 4.6 Correlation of wind tunnel measurements - all sites. The solid line represents the least-squares regression line, while dashed line represents 1:1 correspondence. 
There was generally good correlation $\left(\mathrm{R}^{2}=0.79\right)$ between the methods; however, there is one possible limitation to this correlation. During wind tunnel testing the laboratory wind tunnel had to be dismantled and relocated after Fort Riley testing was completed, but before Fort Benning and Yakima Training Center samples were measured. While the wind tunnel was being reconstructed, the ducting connecting the high-volume samplers to the slot-sampler was modified due to slight differences in wind tunnel configuration between locations. At the new location, the inlet ducting within the slot sampler was raised approximately $30 \mathrm{~cm}$ above the previous height. This change may have resulted in errors primarily caused during the Fort Riley tests which were later corrected with the change in height.

Figures 4.7 and 4.8 show the difference in correlation between two sites that were measured before (4.7) and after (4.8) the wind tunnel relocation. A significant difference can be observed between the two sites. While one possible explanation may be the relocation, it is also possibly due to the inherent differences between soil properties from the different sites. Fort Riley had relatively high clay content with low emission potential, whereas Yakima Training Center had high sand content and high emission potential.

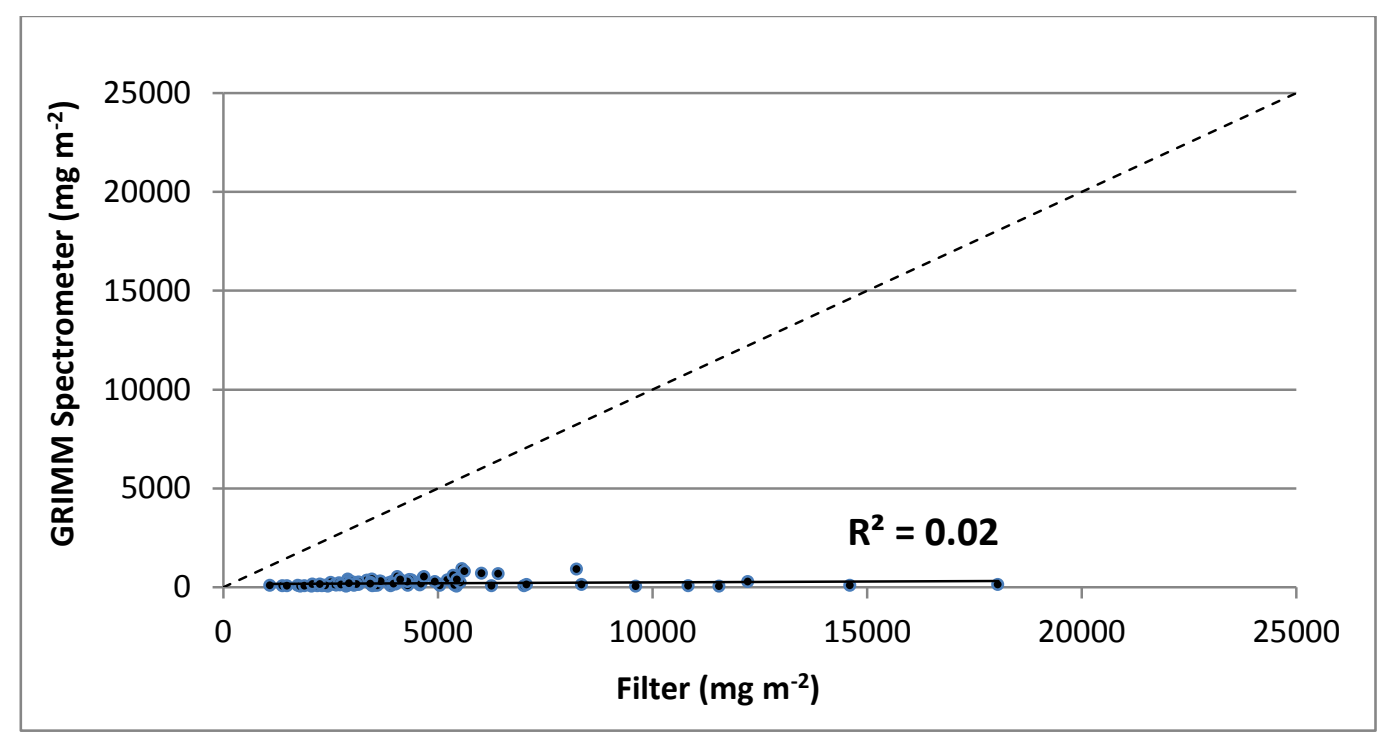

Figure 4.7 Correlation of wind tunnel measurements - Fort Riley. The solid line represents the least-squares regression line, while dashed line represents 1:1 correspondence. 


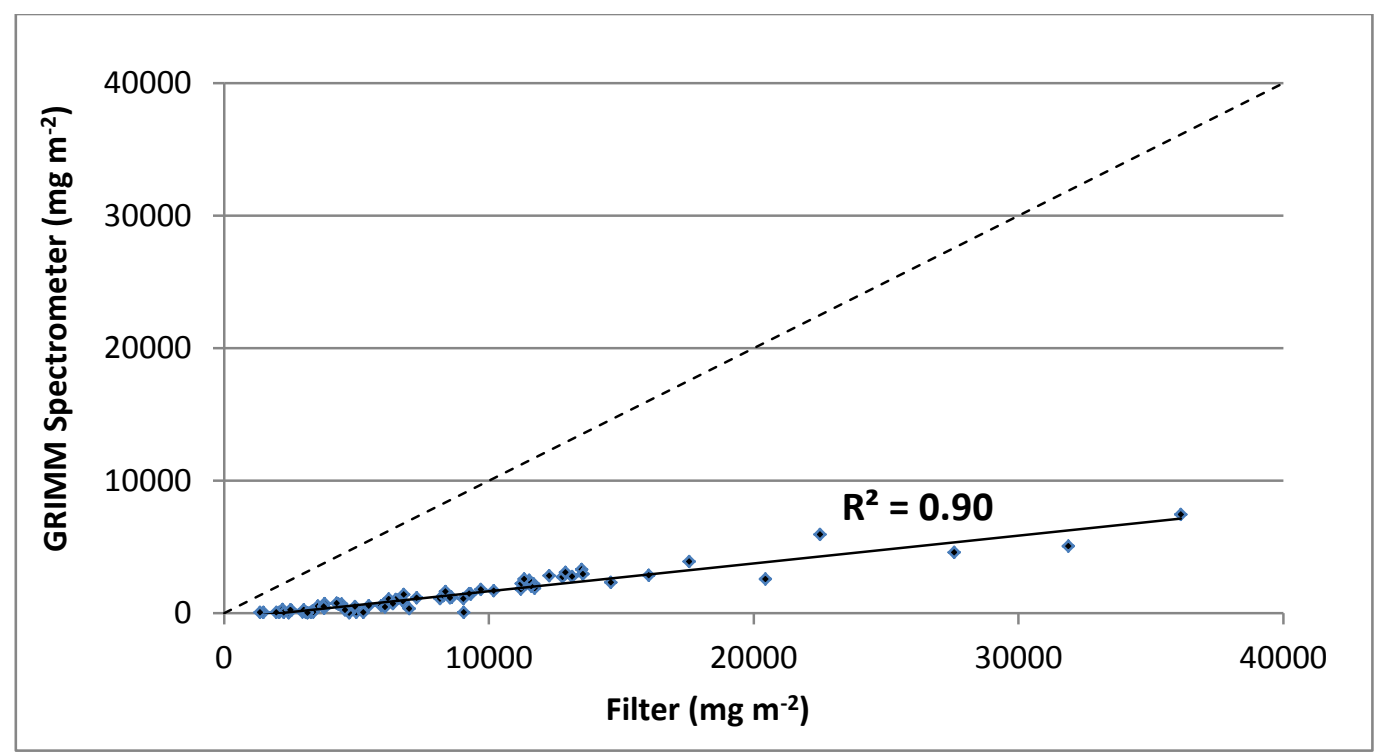

Figure 4.8 Correlation of wind tunnel measurements - Yakima Training Center. The solid line represents the least-squares regression line, while dashed line represents 1:1 correspondence.

\subsection{Wind Tunnel Emissions Testing}

The effects of number of vehicle passes and soil texture were examined for each of the three vehicle types. Total suspended dust, as well as the fraction less than 10 and $2.5 \mu \mathrm{m}$ in diameter, was determined from the GRIMM spectrometer measurements.

\subsubsection{Light-wheeled Vehicle}

Data were collected for the light-wheeled vehicle (HMMWV) on four soil types across three sampling sites. Due to resource constraints, a balanced experiment was not conducted at the Fort Riley site, which had two soil types (silt loam and silty clay loam). Table 4.1 shows the sample points that were collected for the light-wheeled vehicle.

Table 4.1 Light-wheeled vehicle sampling matrix

\begin{tabular}{|l|cccc|c|ccccc|c|ccc|}
\hline \multicolumn{5}{|c|}{ Fort Benning } & \multicolumn{5}{c|}{ Fort Riley } & \multicolumn{4}{c|}{ Yakima Training Center } \\
\hline Loc. $^{* *}$ & 0 & 10 & 25 & 50 & Loc. & 0 & 10 & 25 & 50 & Loc. & 0 & 10 & 25 & 50 \\
\hline CO & $\mathbf{X}$ & $\mathbf{X}$ & $\mathbf{X}$ & $\mathbf{X}$ & CO & $\mathbf{X}^{*}$ & $\mathbf{X}$ & $\mathbf{X}$ & $\mathbf{X}$ & CO & $\mathbf{X}$ & $\mathbf{X}$ & $\mathbf{X}$ & $\mathbf{X}$ \\
CI & $\mathbf{X}$ & $\mathbf{X}$ & $\mathbf{X}$ & $\mathbf{X}$ & CI & $\mathbf{X}^{*}$ & & & & Cl & $\mathbf{X}$ & $\mathbf{X}$ & $\mathbf{X}$ & $\mathbf{X}$ \\
SS & $\mathbf{X}$ & $\mathbf{X}$ & $\mathbf{X}$ & $\mathbf{X}$ & SS & $\mathbf{X}^{*}$ & & & $\mathbf{X}$ & SS & $\mathbf{X}$ & $\mathbf{X}$ & $\mathbf{X}$ & $\mathbf{X}$ \\
\hline
\end{tabular}

*One initial condition sample per figure-8 replication

**Sampling locations: CO - Center Outside, CI - Curve Inside, SS - Straight Section 
The difference in mean emission potential for each testing parameter (i.e., pass and soil) was significant $(\mathrm{P}<0.05)$ for all emissions tests. Table 4.2 shows that there was significant $(\mathrm{P}<0.05)$ soil, pass and interaction effects for the light-wheeled vehicle. This indicates that soil texture as well as vehicle maneuvers influence dust emissions.

Table 4.2 Type III tests of fixed effects - light-wheeled vehicle.

\begin{tabular}{|l|r|r|r|r|}
\hline Effect & $\begin{array}{r}\text { Degrees of Freedom } \\
\text { (DF) - Numerator }\end{array}$ & $\begin{array}{r}\text { Degrees of Freedom } \\
\text { (DF) - Denominator }\end{array}$ & F-value & Pr > F \\
\hline Soil & 3 & 8 & 54.5 & $<.0001$ \\
\hline Pass & 3 & 24 & 63.6 & $<.0001$ \\
\hline Soil*Pass & 9 & 24 & 6.9 & $<.0001$ \\
\hline
\end{tabular}

Table 4.3 shows the pairwise comparisons for soil type and number of passes for all tests collectively. All but two comparisons showed significant differences at the 5\% level. The two soil types at Fort Riley (silt loam and silty clay loam) did not show any significant $(\mathrm{P}=0.13)$ difference in emissions. This result is not surprising as the two soil types are very close in texture and geographical proximity. Additionally, there was no significant increase in emissions by doubling the number of passes from 25 to $50(\mathrm{P}=0.66)$. This indicates that all emission increases generally occurred between undisturbed conditions and 25 passes. Table 4.3 also shows that, from undisturbed conditions to 10 passes, emissions increased by $357 \%$ on average for all light-wheeled vehicle tests. From 10 passes to 25 passes, an additional $72 \%$ increase was observed. 
Table 4.3 Pairwise comparisons of total dust emissions from wind tunnel tests (GRIMM spectrometer) - light-wheeled vehicle.

\begin{tabular}{|l|l|r|r|r|r|r|r|r|}
\hline Soil* & _Soil & Estimate & Estimate $\mathbf{( \% )}$ & $\begin{array}{r}\text { Standard } \\
\text { Error }\end{array}$ & DF & t Value & Pr $>|\mathbf{t}|$ & Adj P \\
\hline SiCL & SiL & -0.60 & $\mathbf{8 2}$ & 0.24 & 8 & -2.53 & 0.035 & 0.13 \\
\hline SiCL & L & -1.94 & $\mathbf{5 9 8}$ & 0.24 & 8 & -8.22 & $<.0001$ & 0.0002 \\
\hline SiCL & LS & -2.71 & $\mathbf{1 3 9 6}$ & 0.24 & 8 & -11.44 & $<.0001$ & $<.0001$ \\
\hline SiL & L & -1.35 & $\mathbf{2 8 4}$ & 0.24 & 8 & -5.69 & 0.0005 & 0.0021 \\
\hline SiL & LS & -2.11 & $\mathbf{7 2 2}$ & 0.24 & 8 & -8.91 & $<.0001$ & $<.0001$ \\
\hline L & LS & -0.76 & $\mathbf{1 1 4}$ & 0.24 & 8 & -3.22 & 0.012 & 0.049 \\
\hline Pass & Pass & & & & & & & \\
\hline 0 & 10 & -1.52 & $\mathbf{3 5 7}$ & 0.18 & 24 & -8.36 & $<.0001$ & $<.0001$ \\
\hline 0 & 25 & -2.06 & $\mathbf{6 8 6}$ & 0.18 & 24 & -11.34 & $<.0001$ & $<.0001$ \\
\hline 0 & 50 & -2.27 & $\mathbf{8 6 8}$ & 0.18 & 24 & -12.48 & $<.0001$ & $<.0001$ \\
\hline 10 & 25 & -0.54 & $\mathbf{7 2}$ & 0.18 & 24 & -2.98 & 0.0065 & 0.031 \\
\hline 10 & 50 & -0.75 & $\mathbf{1 1 2}$ & 0.18 & 24 & -4.13 & 0.0004 & 0.002 \\
\hline 25 & 50 & -0.21 & $\mathbf{2 3}$ & 0.18 & 24 & -1.15 & 0.26 & 0.66 \\
\hline
\end{tabular}

*SiCL - silty clay loam (Fort Riley), SiL - silt loam (Fort Riley), L - loam (Yakima Training Center), LS - loamy sand (Fort Benning)

In general, trafficking beyond 25 passes did not result in significant increase in emissions; however, this may vary from site to site. While the emissions on the loam soil type at Yakima Training Center did not increase from 25 to 50 passes, the emissions on the loamy sand at Fort Benning increased from 25 to 50 passes (Figure 4.9).

In addition to the effect of number of passes, Table 4.3 shows the effect of soil texture. On average, the loamy sand soil had the highest emission potential, whereas the silty clay loam soil had the lowest. The loamy sand soil had increased emission potential of $1,396 \%$ over the silty clay loam soil. The effect of soil texture was evident with all comparisons being significant $(\mathrm{P}<0.05)$ except between the two Fort Riley soils.

Dust emission potential was shown to be significantly influenced by both trafficking passes and soil texture. In general, the soil textures with more sand content were more susceptible to emissions for all testing parameters. The two soils at the Fort Riley site had sand contents of $5.8 \%$ (silty clay loam) and $11.8 \%$ (silt loam). The other two sites had higher sand contents, $47.2 \%$ (loam) and $91.3 \%$ (loamy sand). While the effect of soil type was more distinct than the vehicle passes, Table 4.3 shows evidence that the trafficking intensity can influence increased emissions nearly as much as soil texture alone. 
Figure 4.9 shows the total dust emission potential for treatment interaction effects of soil type and number of passes. The silty clay loam and silt loam soil types at the Fort Riley site had relatively low emission potential compared to the other sites. Additionally, while there was no significant $(\mathrm{P}>0.05)$ increase in emissions between 25 and 50 passes, the loamy sand soil continued to increase between these two treatment levels. Statistical analysis indicated significant $(\mathrm{P}<0.05)$ effects of both trafficking passes and soil texture classification, as well as their interaction.

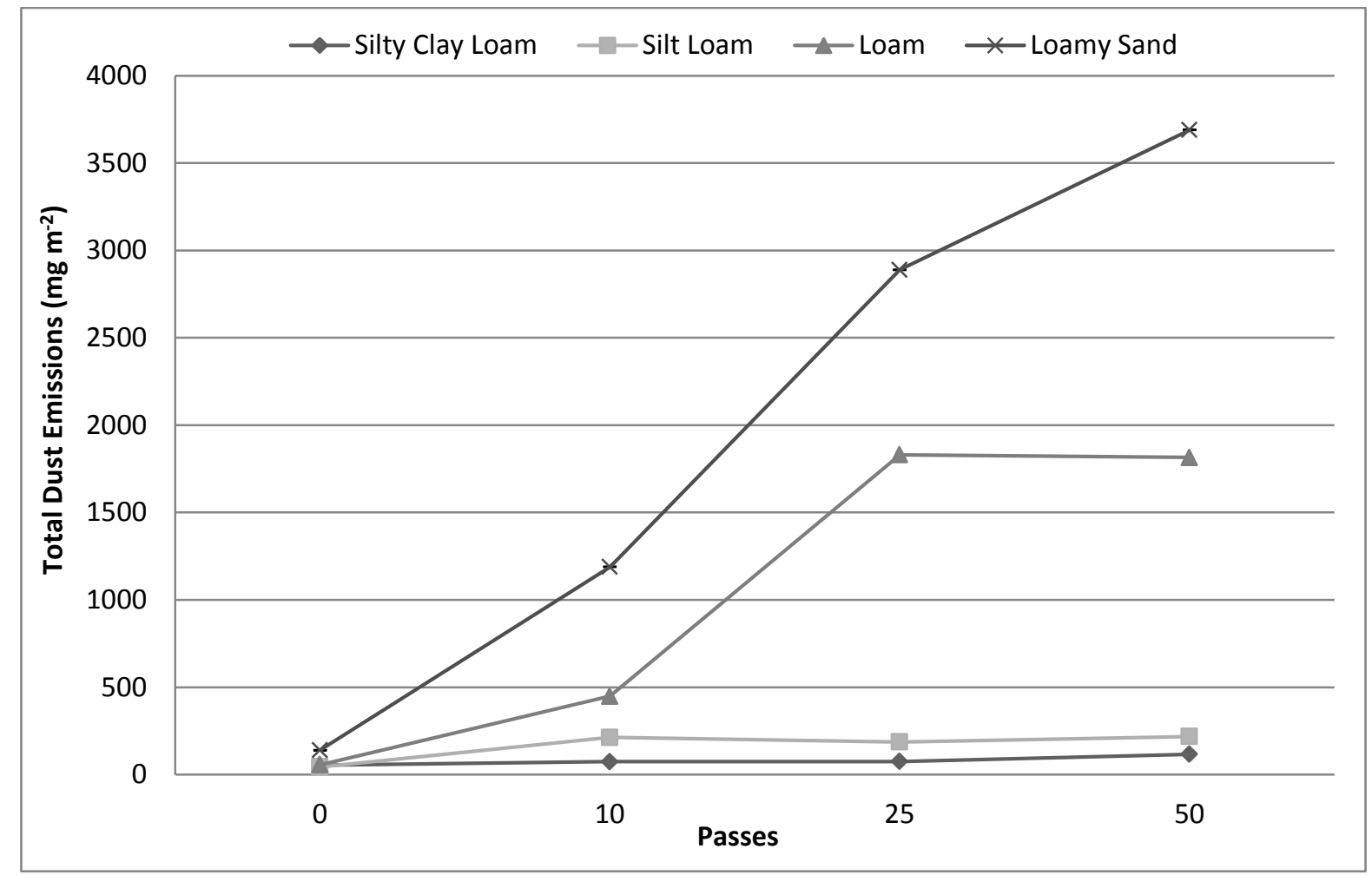

Figure 4.9 Soil-pass interaction plot for total dust emissions from wind tunnel tests (GRIMM spectrometer) - light-wheeled vehicle.

Table 4.3 shows overall pairwise comparisons for all sites; however, it can also be instructive to observe the results on a site-by-site basis as seen in Figure 4.9. Of particular interest is that Fort Riley soils did not show increases in emissions nearly as high as the other two locations. This could possibly be due to higher moisture content of the Fort Riley soils at the time of field sampling. Although there was wide variability in the data, the loamy sand samples showed much higher emission potential than the other soils types. 
Table 4.4 shows the least squares means for the various treatment effects. The two Fort Riley soils experienced increases of $38 \%$ and $375 \%$ in total dust emissions from undisturbed conditions to 10 passes for the silty clay loam and silt loam soil types, respectively. From 10 to 25 passes, the silt loam soil type experienced $12 \%$ decrease. One possible explanation for this is the high degree of shearing caused by the tracked vehicle at the time of testing. The shearing action caused a significant crust layer and exposed underlying moisture which could aid in resisting dust emission. Because the data included two curved and one straight location, the majority of the data represented the curved sections where the shearing occurred.

Table 4.4 Least squares means of dust emissions from wind tunnel tests (GRIMM spectrometer) - light-wheeled vehicle.

\begin{tabular}{|c|c|c|c|c|c|}
\hline Soil* & Pass & $\operatorname{Pr}>|\mathbf{t}|$ & Total Dust & Dust $<\mathbf{1 0} \mu \mathrm{m}$ & Dust $<2.5 \mu \mathrm{m}$ \\
\hline & & & \multicolumn{3}{|c|}{$\left(\mathrm{mg} \mathrm{m}^{-2}\right)$} \\
\hline $\mathrm{SiCL}$ & & $<.0001$ & 77 & 71 & 14 \\
\hline SiL & & $<.0001$ & 141 & 125 & 22 \\
\hline $\mathrm{L}$ & & $<.0001$ & 540 & 524 & 130 \\
\hline LS & & $<.0001$ & 1156 & 1129 & 260 \\
\hline \multicolumn{6}{|c|}{ Pass Least Squares Means } \\
\hline & 0 & $<.0001$ & 66 & 61 & 15 \\
\hline & 10 & $<.0001$ & 304 & 288 & 56 \\
\hline & 25 & $<.0001$ & 522 & 492 & 96 \\
\hline & 50 & $<.0001$ & 643 & 606 & 130 \\
\hline \multicolumn{6}{|c|}{ Soil*Pass Least Squares Means } \\
\hline SiCL & 0 & $<.0001$ & 54 & 52 & 11 \\
\hline $\mathrm{SiCL}$ & 10 & $<.0001$ & 75 & 66 & 13 \\
\hline SiCL & 25 & $<.0001$ & 75 & 72 & 14 \\
\hline $\mathrm{SiCL}$ & 50 & $<.0001$ & 117 & 106 & 22 \\
\hline $\mathrm{SiL}$ & 0 & $<.0001$ & 45 & 37 & 9 \\
\hline $\mathrm{SiL}$ & 10 & $<.0001$ & 213 & 205 & 31 \\
\hline SiL & 25 & $<.0001$ & 187 & 162 & 25 \\
\hline $\mathrm{SiL}$ & 50 & $<.0001$ & 218 & 198 & 34 \\
\hline $\mathrm{L}$ & 0 & $<.0001$ & 57 & 54 & 17 \\
\hline $\mathrm{L}$ & 10 & $<.0001$ & 449 & 438 & 97 \\
\hline $\mathrm{L}$ & 25 & $<.0001$ & 1831 & 1795 & 385 \\
\hline $\mathrm{L}$ & 50 & $<.0001$ & 1815 & 1786 & 437 \\
\hline LS & 0 & $<.0001$ & 141 & 137 & 32 \\
\hline $\mathrm{LS}$ & 10 & $<.0001$ & 1189 & 1165 & 254 \\
\hline LS & 25 & $<.0001$ & 2889 & 2812 & 638 \\
\hline LS & 50 & $<.0001$ & 3689 & 3632 & 876 \\
\hline
\end{tabular}

*SiCL - silty clay loam (Fort Riley), SiL - silt loam (Fort Riley), L - loam (Yakima Training Center), LS - loamy sand (Fort Benning) 
Fort Benning and Yakima Training Center experienced much higher total dust emissions than the Fort Riley soils. From undisturbed conditions to 10 passes, percentage increases of 745\% and 689\% were observed for Fort Benning and Yakima Training Center, respectively. Increasing the number of passes from 10 to 25 at Fort Benning caused an additional 143\% increase (1,953\% above undisturbed) and Yakima soils increased by an additional 308\% (3,119\% above undisturbed).

At Yakima Training Center, the undisturbed soil emissions were near the same value observed for the silty clay loam soil at Fort Riley. From undisturbed condition to 10 passes the silty clay loam soil increased by $38 \%$ from 54 to $75 \mathrm{mg} \mathrm{m}^{-2}$. However, the Yakima Training Center soil (loam) increased by $689 \%$ from 57 to $449 \mathrm{mg} \mathrm{m}^{-2}$.

The emission of dust less than 10 and $2.5 \mu \mathrm{m}$ in diameter (as determined by the GRIMM spectrometer) generally followed the same trend as total dust emissions. Fort Benning showed a $1,870 \%$ increase in emissions of dust $<2.5 \mu \mathrm{m}$ between undisturbed conditions and 25 passes, and Yakima Training Center had a 2,143\% increase for the same treatment. The emissions of these size classifications can be seen in Figures 4.10 and 4.11 with the 95\% confidence limits.

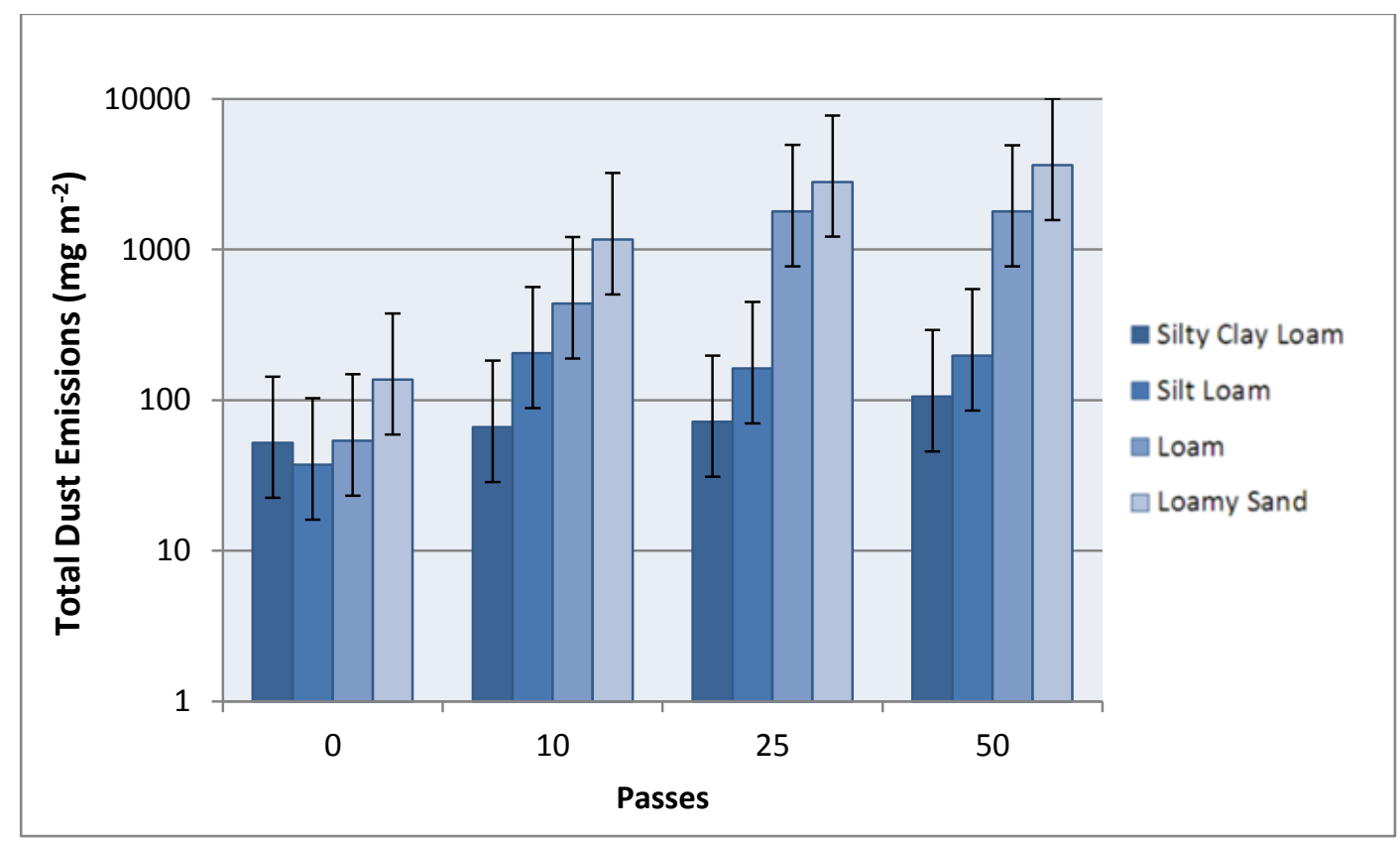

Figure 4.10 Emissions of dust $<10 \mu \mathrm{m}$ from wind tunnel tests (GRIMM spectrometer) light-wheeled vehicle. Error bars represent $95 \%$ confidence limits. 


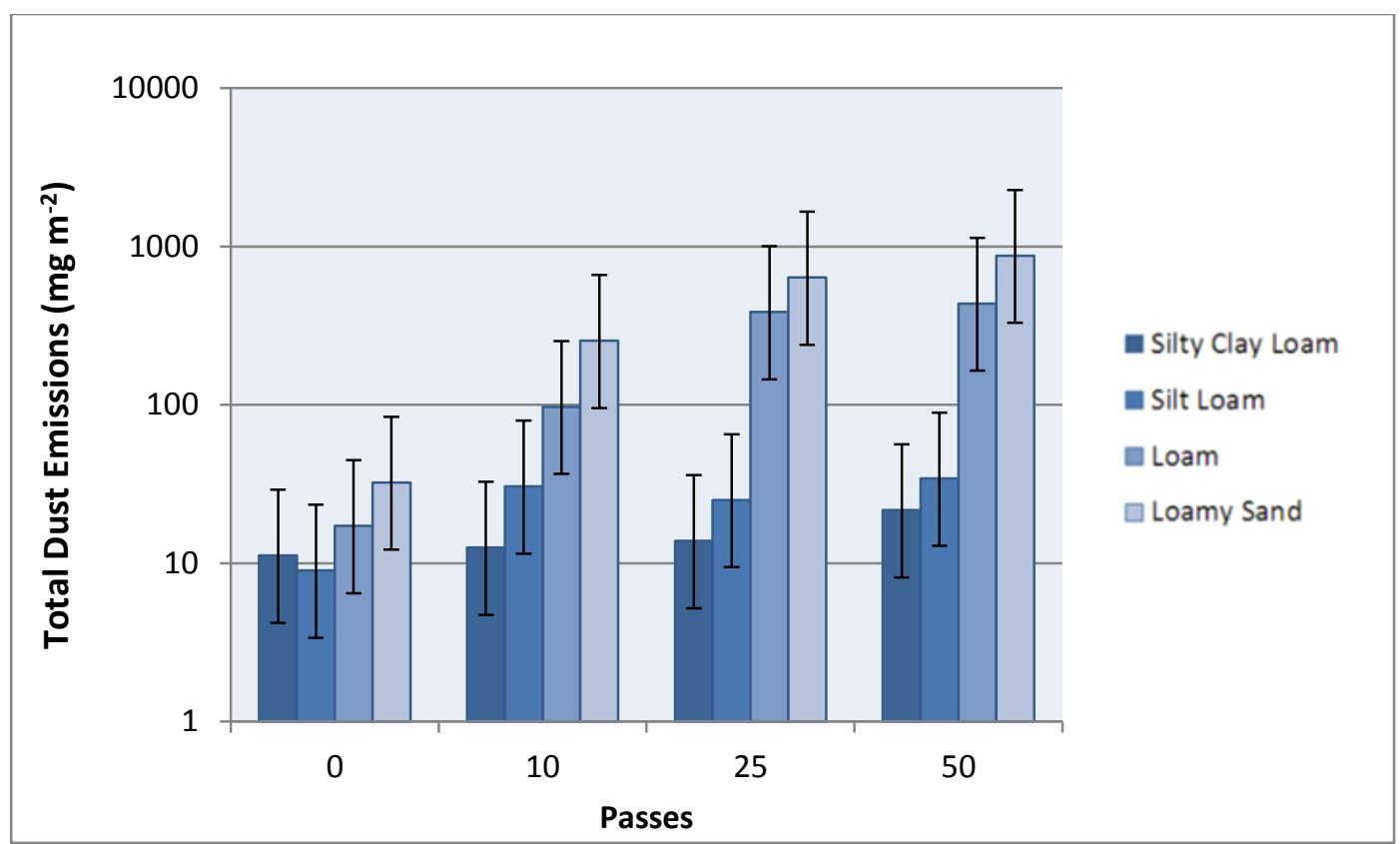

Figure 4.11 Emissions of dust $<2.5 \mu \mathrm{m}$ from wind tunnel tests (GRIMM spectrometer) light-wheeled vehicle. Error bars represent $95 \%$ confidence limits.

\subsubsection{Tracked Vehicle}

A tracked vehicle was used for testing at two sampling sites (Fort Benning and Fort Riley). At the Yakima Training Center site, a heavy-wheeled vehicle was used instead because a tracked vehicle was not available at the time of testing. Table 4.5 shows a matrix of the sample points collected for the tracked vehicle.

Table 4.5 Tracked vehicle sampling matrix

\begin{tabular}{|l|llll|l|llll|}
\hline \multicolumn{5}{|c|}{ Fort Benning } & \multicolumn{5}{c|}{ Fort Riley } \\
\hline Loc. $^{* *}$ & 0 & 1 & 5 & 10 & Loc. & 0 & 1 & 5 & 10 \\
\hline CO & $\mathbf{X}$ & $\mathbf{X}$ & $\mathbf{X}$ & $\mathbf{X}$ & CO & $\mathbf{X}^{*}$ & $\mathbf{X}$ & $\mathbf{X}$ & $\mathbf{X}$ \\
CI & $\mathbf{X}$ & $\mathbf{X}$ & $\mathbf{X}$ & $\mathbf{X}$ & CI & $\mathbf{X}^{*}$ & $\mathbf{X}$ & $\mathbf{X}$ & $\mathbf{X}$ \\
SS & $\mathbf{X}$ & $\mathbf{X}$ & $\mathbf{X}$ & $\mathbf{X}$ & SS & $\mathbf{X}^{*}$ & $\mathbf{X}$ & $\mathbf{X}$ & $\mathbf{X}$ \\
\hline
\end{tabular}

*One initial condition sample per figure-8 replication.

**Sampling locations: CO - Center Outside, CI - Curve Inside, SS - Straight Section.

For all one-way tests, the main effects of soil and trafficking passes were significant $(\mathrm{P}<0.05)$. The interaction effect between soil and pass was not significant $(\mathrm{P}>0.05)$ for all tests with the exception of emission potential of dust $<2.5 \mu \mathrm{m}$ (Table 4.6). In general, the tracked- 
vehicle testing was less conclusive than the light-wheeled vehicle testing, especially for the interaction effects. This may be due to the small number of data points.

Table 4.6 Type III tests of fixed effects for dust emissions $<2.5 \mu \mathrm{m}$ - tracked vehicle.

\begin{tabular}{|l|r|r|r|r|}
\hline Effect & Numerator DF & Denominator DF & F Value & Pr $>$ F \\
\hline Soil & 2 & 6 & 19.8 & 0.0023 \\
\hline Pass & 3 & 18 & 30.7 & $<.0001$ \\
\hline Soil*Pass & 6 & 18 & 4.98 & 0.0036 \\
\hline
\end{tabular}

Table 4.7 shows the pairwise comparison of the effects of soil and trafficking passes. As seen with the light-wheeled vehicle testing, the two Fort Riley soils showed no significant $(\mathrm{P}>0.05)$ difference across all trafficking tests. While there was significant $(\mathrm{P}<0.05)$ increase in emissions from undisturbed condition to any number of passes, there was no significant $(\mathrm{P}>0.05)$ difference between 1,5 or 10 passes. One possible explanation of this result is that tracked vehicle testing was only completed on three soil types and two out of the three soils (silt loam and silty clay loam) were high in clay content, relatively low in sand content and much less susceptible to emissions. Additionally, the moisture content at the time of field sampling was likely very different from that at the time of wind tunnel testing, causing fluctuations in emissions results.

Table 4.7 Pairwise comparisons of total dust emissions from wind tunnel tests (GRIMM spectrometer) - tracked vehicle.

\begin{tabular}{|l|l|r|r|r|r|r|r|r|}
\hline Soil* & _Soil* & Estimate & Estimate (\%) & $\begin{array}{r}\text { Standard } \\
\text { Error }\end{array}$ & DF & t Value & Pr > $|\mathbf{t}|$ & Adj P \\
\hline SiCL & SiL & -0.15 & $\mathbf{1 6}$ & 0.33 & 6 & -0.45 & 0.67 & 0.90 \\
\hline SiCL & LS & -1.91 & $\mathbf{5 7 5}$ & 0.33 & 6 & -5.79 & 0.0012 & 0.0028 \\
\hline SiL & LS & -1.76 & $\mathbf{4 8 1}$ & 0.33 & 6 & -5.34 & 0.0018 & 0.0042 \\
\hline Pass & \multicolumn{1}{|c}{ Pass } & & & & & & & \\
\hline 0 & 1 & -1.90 & $\mathbf{5 6 9}$ & 0.24 & 18 & -7.86 & $<.0001$ & $<.0001$ \\
\hline 0 & 5 & -1.71 & $\mathbf{4 5 3}$ & 0.24 & 18 & -7.07 & $<.0001$ & $<.0001$ \\
\hline 0 & 10 & -2.30 & $\mathbf{8 9 6}$ & 0.24 & 18 & -9.51 & $<.0001$ & $<.0001$ \\
\hline 1 & 5 & 0.19 & $\mathbf{- 1 7}$ & 0.24 & 18 & 0.79 & 0.44 & 0.86 \\
\hline 1 & 10 & -0.40 & $\mathbf{4 9}$ & 0.24 & 18 & -1.65 & 0.12 & 0.38 \\
\hline 5 & 10 & -0.59 & $\mathbf{8 0}$ & 0.24 & 18 & -2.43 & 0.026 & 0.11 \\
\hline
\end{tabular}

*SiCL - silty clay loam (Fort Riley), SiL - silt loam (Fort Riley), L - loam (Yakima Training Center), LS - loamy sand (Fort Benning) 
Figure 4.12 illustrates the soil-pass interaction plot for emission of dust $<2.5 \mu \mathrm{m}$. While most of the interaction effects were not significant $(\mathrm{P}>0.05)$ for the tracked vehicle testing, the interaction of the dust $<2.5 \mu \mathrm{m}$ was significant $(\mathrm{P}<0.05)$. A decrease in emissions can be seen between 1 and 5 passes for all three soil types although it was not significant $(\mathrm{P}>0.05)$. Figure 4.13 shows the same interaction; however, it is on a log-scale with error bars shown for the $95 \%$ confidence level.

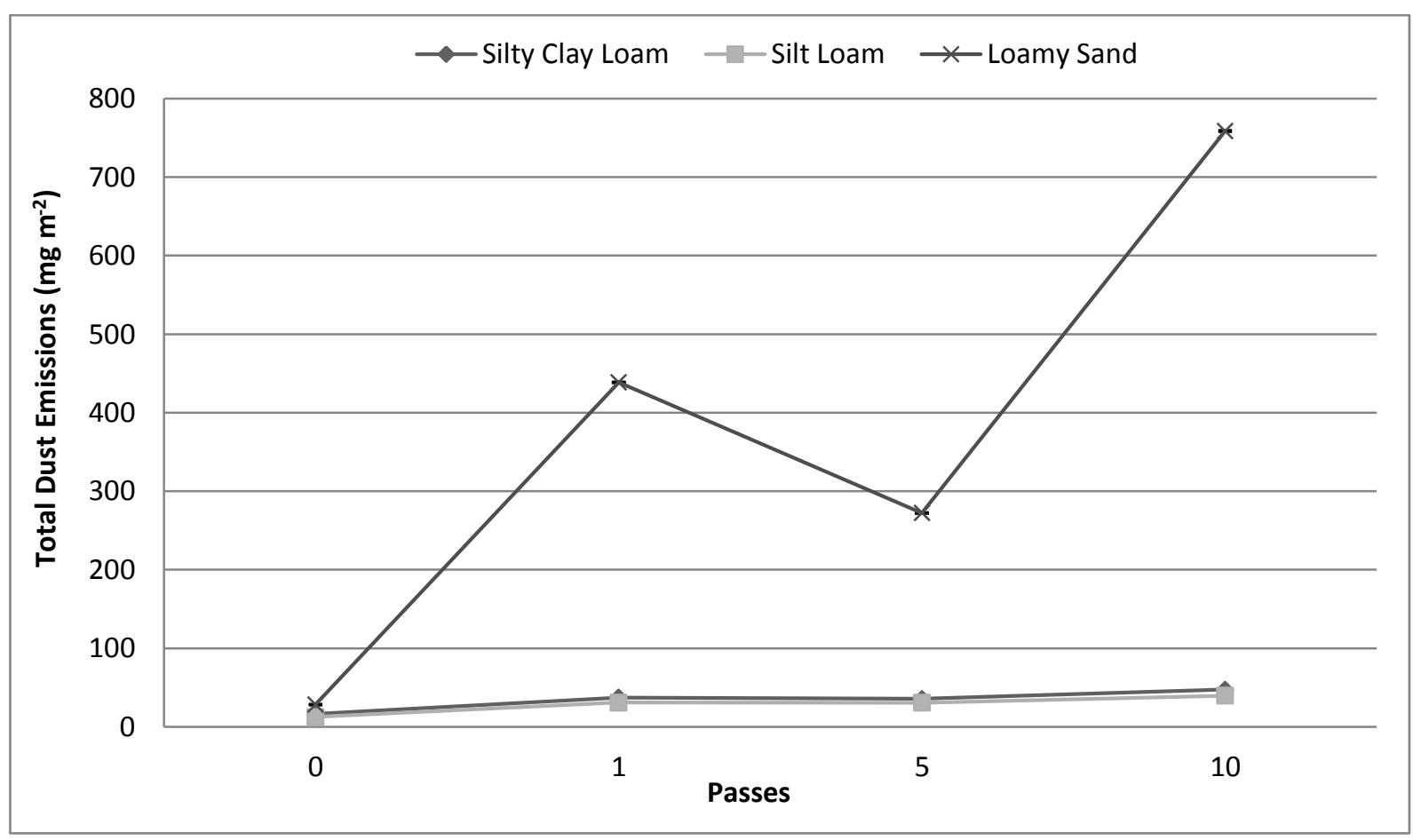

Figure 4.12 Soil-pass interaction plot of dust $<2.5 \mu \mathrm{m}$ from wind tunnel tests (GRIMM spectrometer) - tracked vehicle. 


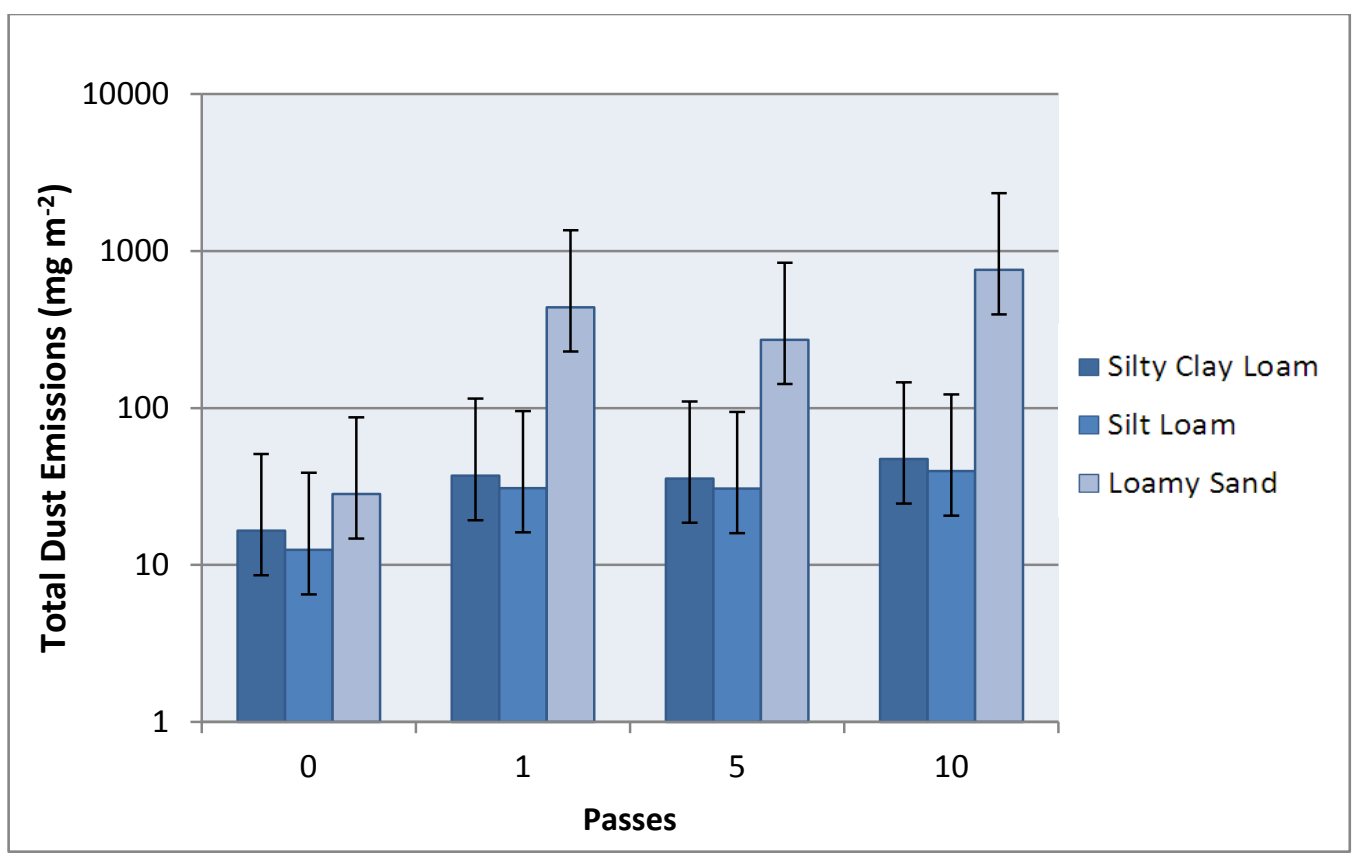

Figure 4.13 Emissions of dust $<2.5 \mu \mathrm{m}$ from wind tunnel tests (GRIMM spectrometer) tracked vehicle. Error bars represent $95 \%$ confidence limits.

Table 4.8 shows the least squares means for the tracked vehicles. The Fort Riley soils experienced relatively low increases in emissions when compared to the Fort Benning soils. This is likely due to a combination of soil texture differences as well as initial moisture content differences between the locations. The Fort Riley soils had an increase of $313 \%$ and $340 \%$ between undisturbed conditions and one pass for the silty clay loam and silt loam soils, respectively. On the other hand, the Fort Benning soil increased from $132 \mathrm{mg} \mathrm{m}^{-2}$ to 2,180 $\mathrm{mg}$ $\mathrm{m}^{-2}$ for a $1,547 \%$ increase between undisturbed condition and one pass of the tracked vehicle. 
Table 4.8 Least squares means of dust emissions from wind tunnel tests (GRIMM spectrometer) - tracked vehicle.

\begin{tabular}{|c|c|c|c|c|c|}
\hline \multicolumn{6}{|c|}{ Soil Least Squares Means - Tracked } \\
\hline Soil* & Pass & $\operatorname{Pr}>|t|$ & Total Dust & Dust $<10 \mu \mathrm{m}$ & Dust $<2.5 \mu \mathrm{m}$ \\
\hline \multicolumn{6}{|c|}{$\left(\mathrm{mg} \mathrm{m}^{-2}\right)$} \\
\hline SiCL & & $<.0001$ & 164 & 146 & 32 \\
\hline $\mathrm{SiL}$ & & $<.0001$ & 190 & 166 & 26 \\
\hline LS & & $<.0001$ & 1105 & 1072 & 225 \\
\hline \multicolumn{6}{|c|}{ Pass Least Squares Means } \\
\hline & 0 & $<.0001$ & 74 & 68 & 18 \\
\hline & 1 & $<.0001$ & 497 & 444 & 80 \\
\hline & 5 & $<.0001$ & 410 & 374 & 67 \\
\hline & 10 & $<.0001$ & 739 & 679 & 112 \\
\hline \multicolumn{6}{|c|}{ Soil*Pass Least Squares Means } \\
\hline SiCL & 0 & $<.0001$ & 52 & 47 & 17 \\
\hline SiCL & 1 & $<.0001$ & 213 & 184 & 37 \\
\hline $\begin{array}{l}\text { SiCL } \\
\end{array}$ & 5 & $<.0001$ & 204 & 183 & 36 \\
\hline SiCL & 10 & $<.0001$ & 320 & 290 & 47 \\
\hline SiL & 0 & $<.0001$ & 60 & 53 & 12 \\
\hline SiL & 1 & $<.0001$ & 263 & 227 & 31 \\
\hline$\overline{\mathrm{SiL}}$ & 5 & $<.0001$ & 250 & 218 & 31 \\
\hline SiL & 10 & $<.0001$ & 331 & 291 & 40 \\
\hline LS & 0 & $\begin{array}{c}<.0001 \\
\end{array}$ & 132 & 128 & 28 \\
\hline LS & 1 & $\begin{array}{c}<.0001 \\
\end{array}$ & 2180 & \begin{tabular}{|l|l|}
2108 \\
\end{tabular} & 439 \\
\hline LS & 5 & $\begin{array}{c}<.0001 \\
\end{array}$ & 1355 & 1315 & 272 \\
\hline LS & 10 & $<.0001$ & 3814 & 3704 & 759 \\
\hline
\end{tabular}

*SiCL - silty clay loam (Fort Riley), SiL - silt loam (Fort Riley), L - loam (Yakima Training Center), LS - loamy sand (Fort Benning)

There was a 569\% increase in total dust emissions between undisturbed conditions and one pass of the tracked vehicle for all soil types. This increase corresponded to an increase from $74 \mathrm{mg} \mathrm{m}^{-2}$ for undisturbed soils to an average of $497 \mathrm{mg} \mathrm{m}^{-2}$ for one pass.

\subsubsection{Heavy-wheeled Vehicle}

Table 4.9 shows that there were significant $(\mathrm{P}<0.05)$ treatment effects for all tests. After 20 passes of the heavy-wheeled vehicle, the soil surface showed 5,276\% increase in dust emission potential over undisturbed conditions. In contrast to the light-wheeled and tracked vehicles, the emission increase between each pass level was significant $(\mathrm{P}<0.05)$. 
Table 4.9 Pairwise comparisons of total dust emissions from wind tunnel tests (GRIMM spectrometer) - heavy-wheeled vehicle.

\begin{tabular}{|r|r|r|r|r|r|r|r|r|}
\hline \multicolumn{1}{|c|}{ Pass } & \multicolumn{1}{c|}{ Pass } & Estimate & Estimate (\%) & $\begin{array}{r}\text { Standard } \\
\text { Error }\end{array}$ & DF & t Value & Pr > |t| & Adj P \\
\hline 0 & 2 & -2.35 & $\mathbf{9 4 7}$ & 0.22 & 8 & -10.5 & $<.0001$ & $<.0001$ \\
\hline 0 & 10 & -3.09 & $\mathbf{2 1 0 8}$ & 0.22 & 8 & -13.8 & $<.0001$ & $<.0001$ \\
\hline 0 & 20 & -3.98 & $\mathbf{5 2 7 6}$ & 0.22 & 8 & -17.8 & $<.0001$ & $<.0001$ \\
\hline 2 & 10 & -0.75 & $\mathbf{1 1 1}$ & 0.22 & 8 & -3.34 & 0.010 & 0.042 \\
\hline 2 & 20 & -1.63 & $\mathbf{4 1 3}$ & 0.22 & 8 & -7.32 & $<.0001$ & 0.0004 \\
\hline 10 & 20 & -0.89 & $\mathbf{1 4 4}$ & 0.22 & 8 & -3.98 & 0.0041 & 0.0171 \\
\hline
\end{tabular}

Figure 4.14 illustrates an increase in dust emission potential with each subsequent increase in vehicle passes for each treatment level up to 20 passes. While the light-wheeled vehicle showed less increase in emission at higher number of passes, the heavy-wheeled vehicle did not show that trend for the same soil type. Note, however, that the number of passes only went up to 20, whereas the light-wheeled vehicle used 50 passes as the upper level.

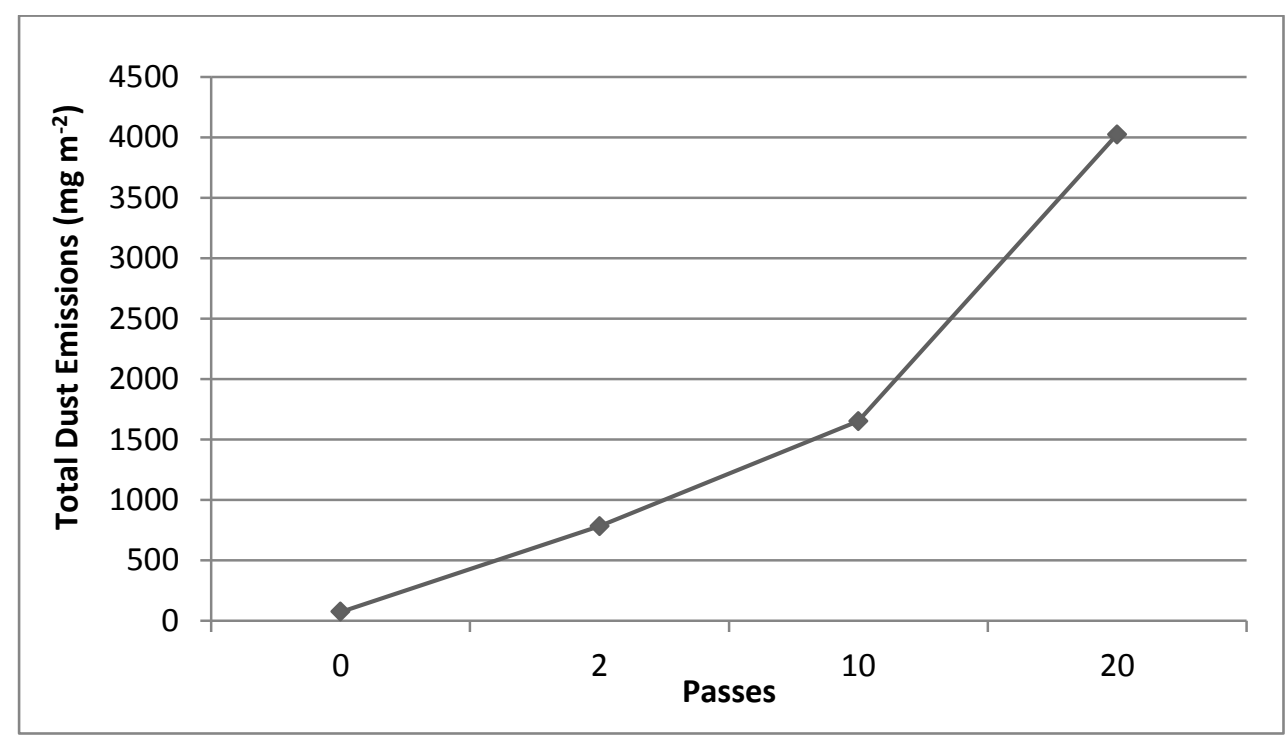

Figure 4.14 Total dust emissions by pass from wind tunnel tests (GRIMM spectrometer) heavy-wheeled vehicle

Table 4.10 shows the least squares means of dust emission potential for the heavywheeled vehicle testing. The undisturbed soil condition had total dust emission potential of 75 $\mathrm{mg} \mathrm{m}^{-2}$ while a surface that had been traversed 20 times had emission potential of $4,023 \mathrm{mg} \mathrm{m}^{-2}$, 
equivalent to a $5,276 \%$ increase. The emission potential of the dust $<2.5 \mu \mathrm{m}$ increased from 19 to $843 \mathrm{mg} \mathrm{m}^{-2}(4,350 \%)$ between undisturbed conditions and 20 passes.

Table 4.10 Least squares means of dust emissions from wind tunnel tests (GRIMM spectrometer) - heavy-wheeled vehicle.

\begin{tabular}{|l|r|r|r|r|}
\hline \multicolumn{5}{|c|}{ Pass Least Squares Means } \\
\hline Pass & $\mathbf{P r}>|\mathbf{t}|$ & Total Dust & Dust $<\mathbf{1 0} \boldsymbol{\mu m}$ & Dust $<\mathbf{2 . 5} \boldsymbol{\mu m}$ \\
\hline & & \multicolumn{3}{|c|}{$\left(\mathbf{m g ~ m}^{-2}\right)$} \\
\hline 0 & 0.0038 & $\mathbf{7 5}$ & $\mathbf{7 2}$ & $\mathbf{1 6 4}$ \\
\hline 2 & $<.0001$ & $\mathbf{7 8 4}$ & $\mathbf{7 5 9}$ & $\mathbf{3 4 5}$ \\
\hline 10 & $<.0001$ & $\mathbf{1 6 5 2}$ & $\mathbf{1 6 1 2}$ & $\mathbf{8 4 3}$ \\
\hline 20 & $<.0001$ & $\mathbf{4 0 2 3}$ & $\mathbf{3 9 3 9}$ & \\
\hline
\end{tabular}

\subsection{Aggregate Size Distribution and Soil Losses}

\subsubsection{Aggregate Size Distribution}

An important parameter for wind erosion is aggregate size distribution, which has been established to be correlated to wind erodibility. Soil samples were collected in the field and sieved using a rotary sieve to determine the erodible fraction of soil (aggregates $<0.84 \mathrm{~mm}$ ). Table 4.11 shows the test of fixed effects for the aggregate size distribution testing. The type of soil and number of passes had significant $(\mathrm{P}<0.05)$ one-way effects. The interaction was not significant $(\mathrm{P}>0.05)$ for all vehicle types. While it is expected that soil aggregation will vary with soil texture, Table 4.11 demonstrates that it is also affected by vehicle trafficking.

Table 4.11 Type III tests of fixed effects for aggregate size distribution - light-wheeled vehicle.

\begin{tabular}{|l|r|r|r|r|}
\hline Effect & Numerator DF & Denominator DF & F Value & Pr $>$ F \\
\hline Soil & 3 & 15.4 & 49.8 & $<.0001$ \\
\hline Pass & 3 & 26.2 & 11.0 & $<.0001$ \\
\hline Soil*Pass & 9 & 26.2 & 0.54 & 0.83 \\
\hline
\end{tabular}


Table 4.12 shows the pairwise comparison of the fraction of soil contained in aggregates $<0.84 \mathrm{~mm}$. Again, the Fort Riley soils (silt loam and silty clay loam) showed no significant ( $P>0.05)$ difference when compared to the other two sites. The loam soil showed the highest fraction of erodible $(<0.84 \mathrm{~mm})$ aggregates for all sites. As shown in Section 4.2 , the effect of vehicle passes on emission potential was nearly the same as the effect of soil texture alone. The erodible size fraction $(<0.84 \mathrm{~mm})$ was much less pronounced with vehicle passes. While the fraction of aggregates falling in the erodible category $(<0.84 \mathrm{~mm})$ changed significantly $(\mathrm{P}<0.05)$ between undisturbed and trafficked soil, increasing the number of passes did not alter the size fraction significantly $(\mathrm{P}>0.05)$.

Table 4.12 Pairwise comparisons of soil fraction $<0.84 \mathbf{~ m m}$ - light-wheeled vehicle.

\begin{tabular}{|l|l|r|r|r|r|r|r|r|}
\hline Soil* & _Soil* & Estimate & Estimate (\%) & $\begin{array}{r}\text { Standard } \\
\text { Error }\end{array}$ & DF & t Value & Pr > |t| & Adj P \\
\hline SiCL & SiL & -0.60 & $\mathbf{8 2}$ & 0.40 & 11.8 & -1.49 & 0.16 & 0.47 \\
\hline SiCL & L & -4.44 & $\mathbf{8 3 5 7}$ & 0.50 & 21.5 & -8.96 & $<.0001$ & $<.0001$ \\
\hline SiCL & LS & -4.07 & $\mathbf{5 7 7 9}$ & 0.46 & 17.7 & -8.90 & $<.0001$ & $<.0001$ \\
\hline SiL & L & -3.84 & $\mathbf{4 5 5 5}$ & 0.46 & 17.9 & -8.36 & $<.0001$ & $<.0001$ \\
\hline SiL & LS & -3.48 & $\mathbf{3 1 3 6}$ & 0.41 & 13.6 & -8.30 & $<.0001$ & $<.0001$ \\
\hline L & LS & 0.36 & $\mathbf{3 0}$ & 0.51 & 22.8 & 0.71 & 0.48 & 0.89 \\
\hline Pass & Pass & & & & & & & \\
\hline 0 & 10 & -1.75 & $\mathbf{4 7 7}$ & 0.38 & 26.2 & -4.64 & $<.0001$ & 0.0005 \\
\hline 0 & 25 & -1.92 & $\mathbf{5 8 0}$ & 0.40 & 26.2 & -4.83 & $<.0001$ & 0.0003 \\
\hline 0 & 50 & -1.86 & $\mathbf{5 4 2}$ & 0.41 & 26.2 & -4.55 & 0.0001 & 0.0006 \\
\hline 10 & 25 & -0.16 & $\mathbf{1 8}$ & 0.38 & 26.2 & -0.43 & 0.67 & 0.97 \\
\hline 10 & 50 & -0.11 & $\mathbf{1 1}$ & 0.39 & 26.2 & -0.27 & 0.79 & 0.99 \\
\hline 25 & 50 & 0.058 & $\mathbf{- 5 . 6 6}$ & 0.41 & 26.2 & 0.14 & 0.89 & 1.00 \\
\hline
\end{tabular}

*SiCL - silty clay loam (Fort Riley), SiL - silt loam (Fort Riley), L - loam (Yakima Training Center), LS - loamy sand (Fort Benning)

Table 4.13 shows the same pairwise comparison for the tracked vehicle. While the same general trend was observed, the difference was lower for the heavier tracked vehicle. Again, there was no significant $(\mathrm{P}>0.05)$ difference in erodible aggregates between 1,5 and 10 passes; however, there was significant $(\mathrm{P}<0.05)$ difference between undisturbed and trafficked soil. 
Table 4.13 Pairwise comparisons of soil aggregates $<0.84 \mathrm{~mm}$ - tracked vehicle.

\begin{tabular}{|l|l|r|r|r|r|r|r|r|}
\hline Soil* & _Soil* & Estimate & Estimate $(\%)$ & $\begin{array}{r}\text { Standard } \\
\text { Error }\end{array}$ & DF & t Value & Pr > |t| & Adj P \\
\hline SiCL & SiL & -0.57 & $\mathbf{7 7}$ & 0.22 & 6.51 & -2.64 & 0.036 & 0.072 \\
\hline SiCL & LS & -3.68 & $\mathbf{3 8 5 6}$ & 0.24 & 9.23 & -15.48 & $<.0001$ & $<.0001$ \\
\hline SiL & LS & -3.11 & $\mathbf{2 1 3 6}$ & 0.23 & 7.9 & -13.65 & $<.0001$ & $<.0001$ \\
\hline Pass & \multicolumn{1}{|l}{ Pass } & & & & & & & \\
\hline 0 & 1 & -1.57 & $\mathbf{3 8 2}$ & 0.20 & 18.3 & -7.81 & $<.0001$ & $<.0001$ \\
\hline 0 & 5 & -1.56 & $\mathbf{3 7 6}$ & 0.20 & 18.3 & -7.68 & $<.0001$ & $<.0001$ \\
\hline 0 & 10 & -1.43 & $\mathbf{3 1 8}$ & 0.20 & 18.3 & -7.23 & $<.0001$ & $<.0001$ \\
\hline 1 & 5 & 0.013 & $\mathbf{- 1 . 3}$ & 0.18 & 18.3 & 0.07 & 0.94 & 1.00 \\
\hline 1 & 10 & 0.14 & $\mathbf{- 1 3}$ & 0.17 & 18.3 & 0.82 & 0.42 & 0.84 \\
\hline 5 & 10 & 0.13 & $\mathbf{- 1 2}$ & 0.17 & 18.3 & 0.74 & 0.47 & 0.88 \\
\hline
\end{tabular}

*SiCL - silty clay loam (Fort Riley), SiL - silt loam (Fort Riley), L - loam (Yakima Training Center), LS - loamy sand (Fort Benning)

Table 4.14 shows the least squares mean values for the percentage of soil aggregates $<0.84 \mathrm{~mm}$. The Fort Riley soil textures contained considerably lower fractions of erodible aggregates at $15 \%$ and $24 \%$ for all treatments on the silty clay loam and silt loam soil types, respectively. The additional two soil types both contained $>90 \%$ aggregates $<0.84 \mathrm{~mm}$ across all treatments. It is clear that vehicle trafficking affected the erodible fraction of soil; however, it was a less pronounced effect than soil texture. Between undisturbed conditions and 10 passes of the light-wheeled vehicle, the erodible fraction increased from $30 \%$ to $71 \%$; however, after 10 passes, the change was not significant $(\mathrm{P}>0.05)$ and was near $70 \%$ for all pass replications. 
Table 4.14 Least squares means for soil aggregates $<0.84 \mathbf{m m}$ - light-wheeled vehicle.

\begin{tabular}{|c|c|c|c|}
\hline Soil* & Pass & $\operatorname{Pr}>|t|$ & \% Aggregates $<0.84 \mathrm{~mm}$ \\
\hline \multicolumn{4}{|c|}{ Soil Least Squares Means - Light-wheeled } \\
\hline $\mathrm{SiCL}$ & & $<.0001$ & $15 \%$ \\
\hline SiL & & 0.0020 & $24 \%$ \\
\hline $\mathrm{L}$ & & $<.0001$ & $94 \%$ \\
\hline LS & & $<.0001$ & $91 \%$ \\
\hline \multicolumn{4}{|c|}{ Pass Least Squares Means } \\
\hline & 0 & 0.0055 & $30 \%$ \\
\hline & 10 & 0.0023 & $71 \%$ \\
\hline & 25 & 0.0011 & $74 \%$ \\
\hline & 50 & 0.0031 & $73 \%$ \\
\hline \multicolumn{4}{|c|}{ Soil*Pass Least Squares Means } \\
\hline $\mathrm{SiCL}$ & 0 & 0.0005 & $3 \%$ \\
\hline $\mathrm{SiCL}$ & 10 & 0.0193 & $28 \%$ \\
\hline $\mathrm{SiCL}$ & 25 & 0.0182 & $28 \%$ \\
\hline $\mathrm{SiCL}$ & 50 & 0.0006 & $15 \%$ \\
\hline SiL & 0 & 0.0002 & $10 \%$ \\
\hline SiL & 10 & 0.0139 & $27 \%$ \\
\hline SiL & 25 & 0.0255 & $29 \%$ \\
\hline SiL & 50 & 0.1627 & $38 \%$ \\
\hline $\mathrm{L}$ & 0 & 0.0044 & $78 \%$ \\
\hline $\mathrm{L}$ & 10 & 0.0002 & $95 \%$ \\
\hline $\mathrm{L}$ & 25 & 0.0004 & $96 \%$ \\
\hline $\mathrm{L}$ & 50 & 0.0005 & $97 \%$ \\
\hline LS & 0 & 0.0181 & $72 \%$ \\
\hline LS & 10 & 0.0002 & $93 \%$ \\
\hline LS & 25 & 0.0002 & $94 \%$ \\
\hline LS & 50 & 0.0002 & $95 \%$ \\
\hline
\end{tabular}

*SiCL - silty clay loam (Fort Riley), SiL - silt loam (Fort Riley), L - loam

(Yakima Training Center), LS - loamy sand (Fort Benning)

Table 4.15 shows the results of the erodible fraction of soil for the tracked vehicle. Again, a similar trend is observed in which the contrast between undisturbed and trafficked conditions was very pronounced; however, between numbers of passes there was little change. Note that the trafficked soil with the tracked vehicle had an erodible fraction of approximately $60 \%$, whereas the wheeled vehicle had near $70 \%$. This was likely due to the tracked vehicle testing being conducted on only three out of the four soil textures. 
Table 4.15 Least squares means for soil aggregates $<0.84 \mathbf{~ m m}$ - tracked vehicle.

\begin{tabular}{|c|c|c|c|}
\hline Soil* & Pass & $\operatorname{Pr}>|t|$ & Aggregates $<0.84 \mathrm{~mm}$ \\
\hline \multicolumn{4}{|c|}{ Soil Least Squares Means -Tracked } \\
\hline $\mathrm{SiCL}$ & & $<.0001$ & $19 \%$ \\
\hline SiL & & 0.0016 & $30 \%$ \\
\hline LS & & $<.0001$ & $90 \%$ \\
\hline \multicolumn{4}{|c|}{ Pass Least Squares Means } \\
\hline & 0 & $<.0001$ & $24 \%$ \\
\hline & 1 & 0.0071 & $60 \%$ \\
\hline & 5 & 0.0098 & $60 \%$ \\
\hline & 10 & 0.0551 & $57 \%$ \\
\hline \multicolumn{4}{|c|}{ Soil*Pass Least Squares Means } \\
\hline $\mathrm{SiCL}$ & 0 & $<.0001$ & $5 \%$ \\
\hline $\mathrm{SiCL}$ & 1 & 0.0001 & $27 \%$ \\
\hline $\mathrm{SiCL}$ & 5 & 0.0007 & $30 \%$ \\
\hline $\mathrm{SiCL}$ & 10 & 0.0003 & $28 \%$ \\
\hline $\mathrm{SiL}$ & 0 & $<.0001$ & $11 \%$ \\
\hline SiL & 1 & 0.2373 & $44 \%$ \\
\hline $\mathrm{SiL}$ & 5 & 0.0136 & $37 \%$ \\
\hline SiL & 10 & 0.0124 & $36 \%$ \\
\hline LS & 0 & $<.0001$ & $83 \%$ \\
\hline LS & 1 & $<.0001$ & $92 \%$ \\
\hline LS & 5 & $<.0001$ & $93 \%$ \\
\hline LS & 10 & $<.0001$ & $91 \%$ \\
\hline
\end{tabular}

*SiCL - silty clay loam (Fort Riley), SiL - silt loam (Fort Riley), L - loam

(Yakima Training Center), LS - loamy sand (Fort Benning)

\subsubsection{Saltation and Total Soil Losses}

Saltation and total soil losses were measured during wind tunnel testing. Total soil loss was determined as the difference in mass of the tray before and after the test divided by the soil tray area. The slot-sampler system (Figure 3.10) was designed to capture saltation-sized material in a lower catch-pan. The material in this pan was weighed after each tray sample test to determine saltation material. Tables 4.16 and 4.17 show the pairwise comparison for the saltation and total losses observed for each treatment effect across all tests. As in previous tests, there was no significant $(\mathrm{P}>0.05)$ difference in saltation loss between the Fort Riley soil textures across all pass treatments. Additionally, the same trend as that observed in the erodible fraction testing was observed. The effect between undisturbed and trafficked soil was significant 
$(\mathrm{P}<0.05)$; however, increasing the number of passes beyond the initial test level was not significant $(\mathrm{P}>0.05)$ for all tests of both saltation and total soil losses.

Table 4.16 Pairwise comparisons of saltation and total soil losses - light-wheeled vehicle.

\begin{tabular}{|c|c|c|c|c|c|c|c|}
\hline \multirow[b]{2}{*}{ Soil* } & \multirow[b]{2}{*}{ _Soil* } & \multicolumn{3}{|c|}{ Saltation Loss } & \multicolumn{3}{|c|}{ Total Soil Loss } \\
\hline & & Estimate & Estimate (\%) & Adj P & Estimate & Estimate (\%) & Adj P \\
\hline $\mathrm{SiCL}$ & $\mathrm{SiL}$ & 0.47 & -37 & 0.69 & -0.56 & 75 & 0.50 \\
\hline $\mathrm{SiCL}$ & $\mathrm{L}$ & -1.66 & 426 & 0.016 & -2.09 & 709 & 0.0026 \\
\hline $\mathrm{SiCL}$ & LS & -4.71 & 11042 & $<.0001$ & -4.35 & 7670 & $<.0001$ \\
\hline $\mathrm{SiL}$ & $\mathrm{L}$ & -2.13 & 739 & 0.004 & -1.53 & 361 & 0.015 \\
\hline $\mathrm{SiL}$ & $\mathrm{LS}$ & -5.18 & 17652 & $<.0001$ & -3.79 & 4334 & $<.0001$ \\
\hline $\mathrm{L}$ & $\mathrm{LS}$ & -3.05 & 2017 & 0.0003 & -2.26 & 861 & 0.0014 \\
\hline Pass & _Pass & & & & & & \\
\hline 0 & 10 & -2.21 & 812 & $<.0001$ & -1.27 & 255 & 0.0002 \\
\hline 0 & 25 & -2.58 & 1221 & $<.0001$ & -1.72 & 458 & $<.0001$ \\
\hline 0 & 50 & -2.43 & 1030 & $<.0001$ & -1.47 & 334 & $<.0001$ \\
\hline 10 & 25 & -0.37 & 45 & 0.47 & -0.45 & 58 & 0.26 \\
\hline 10 & 50 & -0.21 & 24 & 0.81 & -0.20 & 23 & 0.84 \\
\hline 25 & 50 & 0.16 & -14 & 0.92 & 0.25 & -22 & 0.73 \\
\hline
\end{tabular}

*SiCL - silty clay loam (Fort Riley), SiL - silt loam (Fort Riley), L - loam (Yakima Training Center), LS - loamy sand (Fort Benning)

Table 4.17 Pairwise comparisons of saltation and total soil losses - tracked vehicle.

\begin{tabular}{|c|c|c|c|c|c|c|c|}
\hline \multirow[b]{2}{*}{ Soil* } & \multirow[b]{2}{*}{ _Soil* } & \multicolumn{3}{|c|}{ Saltation Loss } & \multicolumn{3}{|c|}{ Total Soil Loss } \\
\hline & & Estimate & Estimate (\%) & Adj P & Estimate & Estimate (\%) & Adj P \\
\hline $\mathrm{SiCL}$ & $\mathrm{SiL}$ & -0.38 & 46 & 0.44 & -0.55 & 74 & 0.29 \\
\hline $\mathrm{SiCL}$ & $\mathrm{LS}$ & -5.74 & 30960 & $<.0001$ & -3.85 & 4598 & $<.0001$ \\
\hline $\mathrm{SiL}$ & $\mathrm{LS}$ & -5.36 & 21228 & $<.0001$ & -3.30 & 2605 & 0.0001 \\
\hline Pass & _Pass & & & & & & \\
\hline 0 & 1 & -2.53 & 1149 & $<.0001$ & -1.64 & 414 & $<.0001$ \\
\hline 0 & 5 & -2.46 & 1069 & $<.0001$ & -1.51 & 352 & 0.0002 \\
\hline 0 & 10 & -3.13 & 2187 & $<.0001$ & -1.89 & 560 & $<.0001$ \\
\hline 1 & 5 & 0.067 & -7 & 1.00 & 0.13 & -12 & 0.96 \\
\hline 1 & 10 & -0.60 & 83 & 0.20 & -0.25 & 29 & 0.78 \\
\hline 5 & 10 & -0.67 & 96 & 0.13 & -0.38 & 46 & 0.50 \\
\hline
\end{tabular}

*SiCL - silty clay loam (Fort Riley), SiL - silt loam (Fort Riley), L - loam (Yakima Training Center), LS - loamy sand (Fort Benning)

Table 4.18 shows the least square means for the saltation and total soil losses for the light-wheeled vehicle. While the trends associated with trafficking effects for the pairwise 
comparison were similar to the erodible soil fraction testing, several differences can be observed. While the erodible fraction was nearly the same for the loamy sand and the loam soil types, the loss associated with these two soil types was different. The loamy sand soil from Fort Benning had considerably higher saltation and total soil losses. For all trafficking passes, the loamy sand experienced an average of $1,549 \mathrm{~g} \mathrm{~m}^{-2}$ total soil loss, whereas the loam soil had $162 \mathrm{~g} \mathrm{~m}^{-2}$ total soil loss. The pairwise comparison in Table 4.16 shows the difference between these two soil types with the loamy sand having around $2,000 \%$ greater saltation loss but only $1,000 \%$ greater total loss.

Table 4.18 Least squares means for saltation and total soil losses - light-wheeled vehicle.

\begin{tabular}{|c|c|c|c|c|c|}
\hline Soil* & Pass & $\operatorname{Pr}>|\mathbf{t}|$ & Saltation Loss $\left(\mathrm{g} \mathrm{m}^{-2}\right)$ & $\operatorname{Pr}>|t|$ & Total Soil Loss $\left(\mathrm{g} \mathrm{m}^{-2}\right)$ \\
\hline \multicolumn{6}{|c|}{ Soil Least Squares Means - Light-wheeled } \\
\hline $\mathrm{SiCL}$ & & 0.008 & 2.8 & $<.0001$ & 19.9 \\
\hline SiL & & 0.095 & 1.8 & $<.0001$ & 34.9 \\
\hline $\mathrm{L}$ & & $<.0001$ & 14.7 & $<.0001$ & 161 \\
\hline LS & & $<.0001$ & 311 & $<.0001$ & 1549 \\
\hline \multicolumn{6}{|c|}{ Pass Least Squares Means } \\
\hline & 0 & 0.0026 & 2.0 & $<.0001$ & 37.7 \\
\hline & 10 & $<.0001$ & 18.4 & $<.0001$ & 133.7 \\
\hline & 25 & $<.0001$ & 26.6 & $<.0001$ & 210.6 \\
\hline & 50 & $<.0001$ & 22.8 & $<.0001$ & 163.7 \\
\hline \multicolumn{6}{|c|}{ Soil*Pass Least Squares Means } \\
\hline $\mathrm{SiCL}$ & 0 & 0.8643 & 1.1 & $<.0001$ & 15.9 \\
\hline $\mathrm{SiCL}$ & 10 & $<.0001$ & 10.6 & $<.0001$ & 24.5 \\
\hline $\mathrm{SiCL}$ & 25 & 0.14 & 1.9 & $<.0001$ & 19.4 \\
\hline $\mathrm{SiCL}$ & 50 & 0.0199 & 2.8 & $<.0001$ & 21.0 \\
\hline $\mathrm{SiL}$ & 0 & 0.0359 & 0.4 & $<.0001$ & 12.6 \\
\hline $\mathrm{SiL}$ & 10 & 0.2247 & 1.7 & $<.0001$ & 46.3 \\
\hline $\mathrm{SiL}$ & 25 & 0.001 & 6.1 & $<.0001$ & 76.4 \\
\hline $\mathrm{SiL}$ & 50 & 0.054 & 2.3 & $<.0001$ & 33.5 \\
\hline $\mathrm{L}$ & 0 & 0.4135 & 0.7 & $<.0001$ & 21.1 \\
\hline $\mathrm{L}$ & 10 & $<.0001$ & 14.6 & $<.0001$ & 160 \\
\hline $\mathrm{L}$ & 25 & $<.0001$ & 74.5 & $<.0001$ & 543 \\
\hline $\mathrm{L}$ & 50 & $<.0001$ & $\begin{array}{l}60.9 \\
\end{array}$ & $<.0001$ & 368 \\
\hline LS & 0 & $<.0001$ & $\begin{array}{l}54.8 \\
\end{array}$ & $<.0001$ & 481 \\
\hline LS & 10 & $<.0001$ & 438 & $<.0001$ & 1760 \\
\hline LS & 25 & $<.0001$ & 583 & $<.0001$ & 2444 \\
\hline LS & 50 & $<.0001$ & 671 & $<.0001$ & 2779 \\
\hline
\end{tabular}

*SiCL - silty clay loam (Fort Riley), SiL - silt loam (Fort Riley), L - loam (Yakima Training Center), LS - loamy sand (Fort Benning) 
Figure 4.15 shows the soil-pass interaction plot for the saltation loss testing. Trends for saltation loss were similar to the emissions testing with the GRIMM spectrometer. The loam soil type experienced relatively flat, or insignificant, change between 25 and 50 passes, whereas the loamy sand soil type continued to increase for all pass levels. While the trend was similar, the loam soil type was much closer to the Fort Riley soils than was observed for the dust emissions testing.

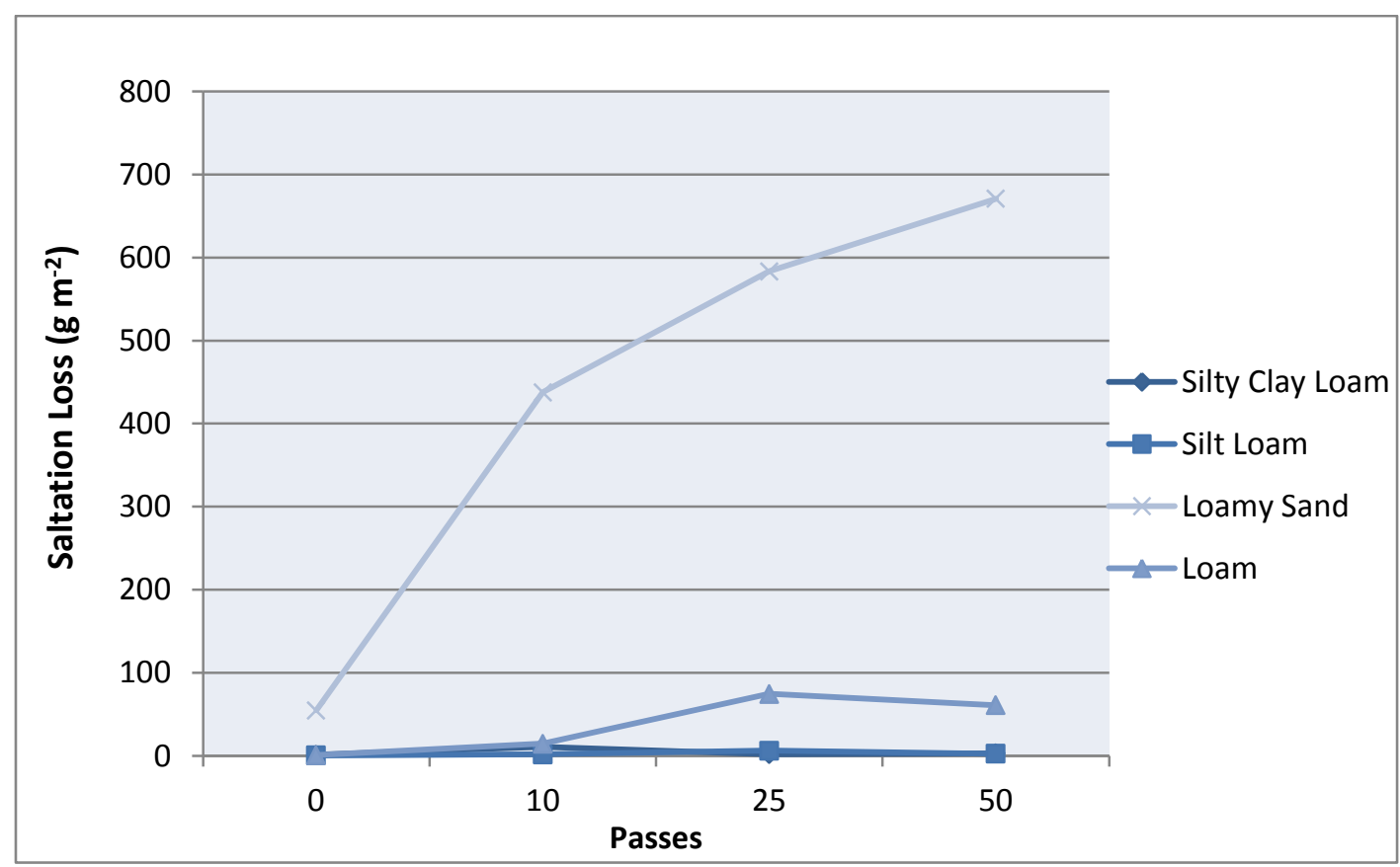

Figure 4.15 Saltation loss by soil type for light-wheeled vehicle.

Table 4.19 shows the least squares means for saltation and total soil losses for tracked vehicle testing. The Fort Riley soils experienced very little saltation and total losses compared with the Fort Benning soil. The Fort Benning soil had greater soil loss for initial, undisturbed conditions than the Fort Riley soils did for any trafficked soils. As indicated in Table 4.17, the contrast in both saltation and total losses between undisturbed and trafficked conditions was significantly $(\mathrm{P}<0.05)$ different; however, there was no significant $(\mathrm{P}>0.05)$ variation between 1 , 5 or 10 passes. 
Table 4.19 Least squares means for saltation and total soil losses - tracked vehicle.

\begin{tabular}{|c|c|c|c|c|c|}
\hline Soil* & Pass & $\operatorname{Pr}>|\mathbf{t}|$ & Saltation Loss $\left(\mathrm{g} \mathrm{m}^{-2}\right)$ & $\operatorname{Pr}>|t|$ & Total Soil Loss $\left(\mathrm{g} \mathrm{m}^{-2}\right)$ \\
\hline \multicolumn{6}{|c|}{ Soil Least Squares Means -Tracked } \\
\hline $\mathrm{SiCL}$ & & 0.16 & 1.4 & $<.0001$ & 32 \\
\hline$\overline{\mathrm{SiL}}$ & & 0.014 & 2.0 & $<.0001$ & 55 \\
\hline LS & & $<.0001$ & 429 & $<.0001$ & 1497 \\
\hline \multicolumn{6}{|c|}{ Pass Least Squares Means } \\
\hline & 0 & 0.13 & 1.4 & $<.0001$ & 39 \\
\hline & 1 & $<.0001$ & 17 & $<.0001$ & 202 \\
\hline & 5 & $<.0001$ & 16 & $<.0001$ & 178 \\
\hline & 10 & $<.0001$ & 32 & $<.0001$ & 259 \\
\hline \multicolumn{6}{|c|}{ Soil*Pass Least Squares Means } \\
\hline$\overline{\mathrm{SiCL}}$ & 0 & $<.0001$ & 0.2 & $<.0001$ & 12 \\
\hline $\mathrm{SiCL}$ & 1 & 0.12 & 1.8 & $<.0001$ & 42 \\
\hline $\mathrm{SiCL}$ & 5 & 0.039 & 2.2 & $<.0001$ & 41 \\
\hline $\mathrm{SiCL}$ & 10 & 0.0001 & 5.3 & $<.0001$ & 50 \\
\hline SiL & 0 & 0.0006 & 0.2 & $<.0001$ & 24 \\
\hline SiL & 1 & 0.0027 & 3.4 & $<.0001$ & 61 \\
\hline$\overline{\mathrm{SiL}}$ & 5 & 0.0019 & 3.6 & $<.0001$ & 67 \\
\hline SiL & 10 & $<.0001$ & 5.7 & $<.0001$ & 93 \\
\hline LS & 0 & $<.0001$ & 69 & $<.0001$ & 209 \\
\hline LS & 1 & $<.0001$ & 853 & $<.0001$ & 3175 \\
\hline LS & 5 & $<.0001$ & 534 & $<.0001$ & 2026 \\
\hline LS & 10 & $<.0001$ & 1073 & $<.0001$ & 3733 \\
\hline
\end{tabular}

*SiCL - silty clay loam (Fort Riley), SiL - silt loam (Fort Riley), L - loam (Yakima Training Center), LS - loamy sand (Fort Benning) 


\section{Chapter 5 - Conclusions and Recommendations}

\subsection{Conclusions}

Multi-pass military vehicle trafficking experiments were conducted at three military training installations. Dust emission potential was measured on site (with the PI-SWERL equipped with a DustTrak ${ }^{\mathrm{TM}}$ dust monitor) and in a laboratory wind tunnel (with a GRIMM spectrometer and gravimetric filters). The filter method did not prove to be as useful as the GRIMM spectrometer in determining dust emission potential in the laboratory; as such, the GRIMM spectrometer data were selected as the primary response variable for most of the analysis. The following conclusions were drawn from this research:

- Wind tunnel testing showed strong correlation between off-road trafficking passes and dust emissions for most tests, especially for the light-wheeled vehicle. For the light-wheeled vehicle there seemed to be a threshold of maximum increase in emission potential. From undisturbed conditions to 10 and 25 vehicle passes, there was a significant $(\mathrm{P}<0.05)$ increase in emissions; however, when doubling the number of passes from 25 to 50 , the increase was not significant $(\mathrm{P}>0.05)$.

- In general, soil texture played an important role in dust emissions, but vehicle passes can produce an effect nearly as pronounced. Because of the lack of significant increase between 25 and 50 passes, intensive vehicle training should likely be conducted on lands that have already been previously disturbed.

- For the tracked vehicle, in general, there was an increase in emission potential in soils with higher sand content. Additionally, there was significant dust emission increase from undisturbed conditions to any number of passes with the tracked vehicle. Differences among various levels of passes did not produce statistically significant increases in dust emissions. This may likely be due to limited amount of data due to the lack of vehicle availability at Yakima Training Center.

- Comparison of the PI-SWERL (with DustTrak ${ }^{\mathrm{TM}}$ dust monitor) and wind tunnel (with GRIMM aerosol spectrometer) results showed significant differences and relatively low correlation. The filter and GRIMM spectrometer data from the wind tunnel tests also were significantly different, although they were highly correlated. 
- Wind tunnel tests showed that saltation and total soil losses increased after vehicle trafficking. However, the only significant $(\mathrm{P}<0.05)$ increases were observed between undisturbed and disturbed conditions. Significant increases in saltation or total soil loss were not observed when increasing the number of passes beyond the initial testing condition.

\subsection{Recommendations for Future Research}

Based on findings and limitations of this research, the following are recommendations for further study:

- Evaluate the performance of the PI-SWERL under controlled conditions. The PI-SWERL instrument could be adjusted based on the site conditions to ensure the instrument does not reach concentration limits.

- Measure the dust emission potential of soil samples in the wind tunnel in terms of PM $_{10}$ and $\mathrm{PM}_{2.5}$. This study used an aerosol spectrometer that measured the size distribution and concentration of emitted dust. While $\mathrm{PM}_{10}$ and $\mathrm{PM}_{2.5}$ emissions may be inferred from the spectrometer measurements, there is a need to directly measure $\mathrm{PM}_{10}$ and $\mathrm{PM}_{2.5}$ concentrations and emissions using standard methods.

- Establish the effective surface area of emission of the soil tray sample. For this study, the active surface area was estimated to be $0.0061 \mathrm{~m}^{2}$; however, experiments should be conducted to establish the true active surface area.

- Investigate more sites and/or soil types, particularly for the tracked vehicle. Data for the tracked vehicle in this study were limited to only two locations. Of these two sites, only one provided significant differences in data among treatment effects (Fort Benning) as the other site (Fort Riley) was much less susceptible to fugitive dust emissions.

- Consider the effect of abrasion on dust emission potential. Results of this study presented emission potential of loose erodible material due to wind alone. Literature suggests that a significant portion of suspended dust may result from the mechanical abrasion of the soil surface from the saltation component of wind erosion.

- Investigate the impact of surface roughness and/or vegetative cover on the effect of vehicle type and passes on dust emission potential. 


\section{References}

Alfaro, S. C., Rajot, J. L. and Nickling, W. (2004). Estimation of $\mathrm{PM}_{20}$ emissions by wind erosion: main sources of uncertainties. Geomorphology, 59(1-4), 63-74.

doi:10.1016/j.geomorph.2003.09.006

Althoff, P. S., Thien, S. J. and Todd, T. C. (2010). Primary and residual effects of Abrams tank traffic on prairie soil properties. Soil Science Society of America Journal, 74(6), 2151-2161. doi:10.2136/sssaj2009.0091

Ashbaugh, L. L., Carvacho, O. F., Brown, M. S., Chow, J. C., Watson, J. G. and Magliano, K. C. (2003). Soil sample collection and analysis for the Fugitive Dust Characterization Study. Atmospheric Environment, 37(9-10), 1163-1173. doi:10.1016/S1352-2310(02)01022-1

Charola, A. (1987). Acid rain effects on stone monuments. Journal of Chemical Education, 64(5), 436-437. Retrieved from: http://pubs.acs.org/doi/abs/10.1021/ed064p436

Chepil, W.S. (1958). Soil conditions that influence wind erosion. USDA Technical Bulletin 1185. U.S. Government Printing Office, Washington, D.C.

Chepil, W. and Woodruff, N. (1963). The physics of wind erosion and its control. Advances in Agronomy, 15, 211-302 Retrieved from:

http://www.sciencedirect.com/science/article/pii/S0065211308604009

Du, K., Yuen, W., Wang, W., Rood, M. J., Varma, R. M., Hashmonay, R. A., Kim, B. J. and Kemme M. R. (2011). Optical remote sensing to quantify fugitive particulate mass emissions from stationary short-term and mobile continuous sources: Part II. Field applications. Environmental Science and Technology, 45(2), 666-672. doi:10.1021/es101906v

Environmental Protection Agency. (2010). Fort Riley, Kansas. Retrieved from: http://www.epa.gov/region07/cleanup/npl_files/ks6214020756.pdf.

Environmental Protection Agency. (2011). National Ambient Air Quality Standards (NAAQS). Retrieved from: http://www.epa.gov/air/criteria.html.

Environmental Protection Agency. (2012). PM 2.5 NAAQS Implementation. Retrieved from: http://www.epa.gov/ttnnaaqs/pm/pm25_index.html.

Etyemezian, V., Nikolich, G., Ahonen, S., Pitchford, M., Sweeney, M., Purcell, R., Gillies, J. and Kuhns, H. (2007). The Portable In Situ Wind Erosion Laboratory (PI-SWERL): A new method to measure $\mathrm{PM}_{10}$ windblown dust properties and potential for emissions. Atmospheric Environment, 41(18), 3789-3796. doi:10.1016/j.atmosenv.2007.01.018 
Gillies, J. A., Etyemezian, V., Kuhns, H., Nikolic, D. and Gillette, D. A. (2005). Effect of vehicle characteristics on unpaved road dust emissions. Atmospheric Environment, 39(13), 23412347. doi:10.1016/j.atmosenv.2004.05.064

Gomes, L., Arrúe, J. L., López, M. V., Sterk, G., Richard, D., Gracia, R., Sabre, M., Gaudichet, A. and Frangi, J. P. (2003a). Wind erosion in a semiarid agricultural area of Spain: the WELSONS project. Catena, 52(3-4), 235-256. doi:10.1016/S0341-8162(03)00016-X

Gomes, L., Rajot, J., Alfaro, S. and Gaudichet, A. (2003b). Validation of a dust production model from measurements performed in semi-arid agricultural areas of Spain and Niger. Catena, 52(3-4), 257-271. doi:10.1016/S0341-8162(03)00017-1

González, C. M. and Aristizábal, B. H. (2012). Acid rain and particulate matter dynamics in a mid-sized Andean city: The effect of rain intensity on ion scavenging. Atmospheric Environment, 60, 164-171. doi:10.1016/j.atmosenv.2012.05.054

Goossens, D. and Offer, Z. (2000). Wind tunnel and field calibration of six aeolian dust samplers. Atmospheric Environment, 34, 1043-1057. Retrieved from: http://www.sciencedirect.com/science/article/pii/S1352231099003763

Guoliang, L., Xuan, J. and Park, S. (2003). A new method to calculate wind profile parameters of the wind tunnel boundary layer. Journal of Wind Engineering, 91, 1155-1162.

Hagen, L. (1999). Assessment of wind erosion parameters using wind tunnels. Sustaining the Global Farm. (pp. 742-746). D. E. Stott, R. H. Mohtar and G. C. Steinhardt (Eds.). West Lafayette, IN: International Soil Conservation Organization. Retrieved from: http://www.tucson.ars.ag.gov/isco/isco10/SustainingTheGlobalFarm/P003-Hagen.pdf

Hagen, L., Mirzamostafa, N. and Hawkins, A. (1996). PM-10 generation by wind erosion. International Conference on Air Pollution from Agricultural Operations Proceedings. Midwest Plan Service, Ames, IA.

Kavouras, I. G., Etyemezian, V., Nikolich, G., Gillies, J., Sweeney, M., Young, M. and Shafer, D. (2009). A new technique for characterizing the efficacy of fugitive dust suppressants. Journal of the Air and Waste Management Association, 59(5), 603-612. doi:10.3155/10473289.59.5.603

Kohake, D. J., Hagen, L. J. and Skidmore, E. L. (2010). Wind erodibility of organic soils. Soil Science Society of America Journal, 74(1), 250-257. doi:10.2136/sssaj2009.0163

Li, J., Okin, G. S., Herrick, J. E., Belnap, J., Munson, S. M. and Miller, M. E. (2010). A simple method to estimate threshold friction velocity of wind erosion in the field. Geophysical Research Letters, 37(10), 1-5. doi:10.1029/2010GL043245 
Li, P., Xin, J., Wang, Y., Wang, S., Li, G., Pan, X., Liu, Z. and Wang, L. (2013). The acute effects of fine particles on respiratory mortality and morbidity in Beijing, 2004-2009. Environmental Science and Pollution Research International, doi:10.1007/s11356-013$1688-8$

Ling, C. (1976). On the calculation of surface shear stress using the profile method. Journal of Geophysical Research, 81(15), 2581-2582. Retrieved from: http://europa.agu.org/?uri=/journals/jc/JC081i015p02581.xmlandview=article

Lyles, L., Dickerson, J. and Disrud, L. (1970). Modified rotary sieve for improved accuracy. Soil Science, 109(3). 207-210. Retrieved from: http://journals.lww.com/soilsci/Abstract/1970/03000/Modified_Rotary_Sieve_for_Improve d_Accuracy.11.aspx

Marticorena, B. and Bergametti, G. (1997). Factors controlling threshold friction velocity in semiarid and arid areas of the United States. Journal of Geophysical Research, 102(D19), 23277-23287. Retrieved from:

http://citeseerx.ist.psu.edu/viewdoc/download?doi=10.1.1.13.1671 andrep=rep1 andtype=pdf

Mirzamostafa, N., Stone, L., Hagen, L. J. and Skidmore, E. L. (1998). Soil aggregate and texture effects on suspension components from wind erosion. Soil Science Society of America Journal, 62(5), 1351-1361. Retrieved from: https://www.crops.org/publications/sssaj/abstracts/62/5/SS0620051351

National Aeronautics and Space Administration. (2010). Pitot-static tube. Retrieved from: http://www.grc.nasa.gov/WWW/k-12/airplane/pitot.html

National Oceanic and Atmospheric Administration. (2011). Most Popular Data. Retrieved from: http://www.ncdc.noaa.gov/most-popular-data\#loc-clim

Picard, A., Davis, R. S., Gläser, M. and Fujii, K. (2008). Revised formula for the density of moist air (CIPM-2007). Metrologia, 45(2), 149-155. doi:10.1088/0026-1394/45/2/004

Presley, D. and Tatarko, J. (2009). Principles of wind erosion and its control. MF-2860. Kansas State University Research and Extension, Manhattan, KS. Retrieved from: http://scholar.google.com/scholar?hl=enandbtnG=Searchandq=intitle:Principles+of+Wind+ Erosion+and+its+Control\#0

Rae, W.H. Jr. and Pope. A. (1984). Low-speed wind tunnel testing. John Wiley and Sons, New York.

Rabl, A., Thach, T. Q., Chau, P. Y. K. and Wong, C. M. (2011). How to determine life expectancy change of air pollution mortality: a time series study. Environmental Health: A Global Access Science Source, 2011, 10-25. doi:10.1186/1476-069X-10-25 
Rajot, J., Alfaro, S., Gomes, L. and Gaudichet, A. (2003). Soil crusting on sandy soils and its influence on wind erosion. Catena, 53(1), 1-16. doi:10.1016/S0341-8162(02)00201-1

Retta, A., Wagner, L. E., Tatarko, J. and Todd, T. C. (2013). Evaluation of bulk density and vegetation as affected by military vehicle traffic at Fort Riley, Kansas. Transactions of the $A S A B E, 56$.

Ricketts, M. (2011). The respiratory system: particulates in the airways [powerpoint slides]. Retrieved from: Online lecture notes, GENAG 711, Spring 2012.

Sawyer, K., Mundandhara, S., Ghio, A. J. and Madden, M. C. (2010). The effects of ambient particulate matter on human alveolar macrophage oxidative and inflammatory responses. Journal of Toxicology and Environmental Health. Part A, 73(1), 41-57. doi: $10.1080 / 15287390903248901$

Stetler, L. D. (1997). An isokinetic sampler for wind tunnel Use. ASAE Meeting Paper No. 972031. American Society of Agricultural Engineers, St. Joseph, MI.

Sweeney, M., Etyemezian, V., Macpherson, T., Nickling, W., Gillies, J., Nikolich, G. and McDonald, E. (2008). Comparison of PI-SWERL with dust emission measurements from a straight-line field wind tunnel. Journal of Geophysical Research, 113(F1), 1-12. doi:10.1029/2007JF000830

Tegen, I. (1995). Contribution to the atmospheric mineral aerosol load from land surface modification. Journal of Geophysical Research, 100(9), 18707-18726. doi: 10.1029/95JD02051

Tsoar, H. and Pye, K. (1987). Dust transport and the question of desert loess formation. Sedimentology, 34, 139-153. Retrieved from: http://onlinelibrary.wiley.com/doi/10.1111/j.1365-3091.1987.tb00566.x/abstract

Tyree, C. and Allen, J. (2004). Diffusional particle loss upstream of isokinetic sampling inlets. Aerosol Science and Technology, 38(10), 1019-1026. doi:10.1080/027868290519201

United States Army. (2012). U.S. Army Fact Files. Retrieved from: http://www.army.mil/factfiles/.

van Donk, S. J., Huang, X., Skidmore, E. L., Anderson, A. B., Gebhart, D. L., Prehoda, V. E. and Kellogg, E. M. (2003). Wind erosion from military training lands in the Mojave Desert, California, U.S.A. Journal of Arid Environments, 54(4), 687-703. doi:10.1006/jare.2002.1085

van Donk, S. J. and Skidmore, E. L. (2003). Measurement and simulation of wind erosion, roughness degradation and residue decomposition on an agricultural field. Earth Surface Processes and Landforms, 28(11), 1243-1258. doi:10.1002/esp.1037 
Vrins, E. (1996). Sampling requirements for estimating fugitive dust emissions. Journal of Aerosol Science, 27(1), S71-S72.

Wanjura, J. D., Parnell, Jr., C. B., Shaw, B. W., Capareda, S. C. and Lacey, R. E. (2009). Source sampling of particulate matter emissions from cotton harvesting: System design and evaluation. Applied Engineering in Agriculture, 25(1), 85-96.

Zobeck, T. M., Sterk, G., Funk, R., Rajot, J. L., Stout, J. E. and van Pelt, R. S. (2003). Measurement and data analysis methods for field-scale wind erosion studies and model validation. Earth Surface Processes and Landforms, 28, 1163-1188. doi:10.1002/esp.1033 